\title{
Numerical study of alternate bars in alluvial channels with non-uniform sediment
}

\author{
F. Cordier ${ }^{1,2}$, P. Tassi ${ }^{1,2}$, N. Claude ${ }^{2}$, A. Crosato $^{3}$, S. Rodrigues ${ }^{4}$, and D. Pham Van Bang ${ }^{5}$ \\ ${ }^{1}$ Laboratoire d'Hydraulique Saint-Venant, École des Ponts ParisTech, EDF R\&D, Cerema (Chatou, France) \\ ${ }^{2}$ EDF R\&D LNHE - Laboratoire National d'Hydraulique et Environnement (Chatou, France) \\ ${ }^{3}$ IHE Delft (Delft, The Netherlands) \\ ${ }^{4}$ Ecole Polytechnique Universitaire de Tours (Tours, France) \& UMR CNRS 7324 CITERES \\ ${ }^{5}$ INRS-ETE, LHE and Lab. CT-Scan (Québec, Canada)
}

\section{Key Points:}

- Free bars and hybrid bars show distinct topography, bed shear stress, sediment transport and sediment sorting patterns

- Increased sediment size heterogeneity induces longer free and hybrid bars, free bars of higher amplitudes but no general trend for the hybrid bar amplitude

- Sediment sorting does not impact the averaged free bar characteristics, while hybrid bars become longer and damped: a clear distinction between these two types of bars has to be considered for the further works

This article has been accepted for publication and undergone full peer review but has not been through the copyediting, typesetting, pagination and proofreading process which may lead to

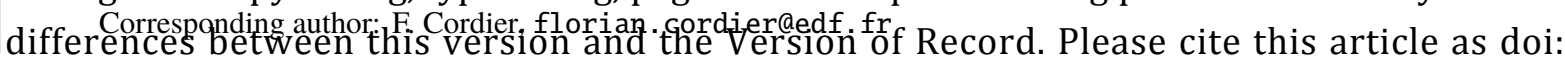
10.1029/2017WR022420

$-1-$ 


\section{Introduction}

Rivers often present a wavy bed due to the presence of periodic bars [Bridge and Demicco, 2008], which are large sediment deposits alternating with deeper areas (pools) that arise from an instability phenomenon of the alluvial bed [Engelund, 1970]. The number of bars in river cross-sections can be used to characterize the river type. For instance, the sequence of sediment deposits on one bank and pool at the opposite bank, i.e. alternate bars, is typical of single thread rivers and meanders, while the presence of multiple bars in the cross-section characterize braided rivers [Engelund and Skovgaard, 1973]. A deep knowledge of bar processes is important for river engineers and river managers, because bars strongly alter the river bed topography and influence bank erosion, with consequences for navigation, water intakes and infrastructure [Bridge, 2003; Claude et al., 2012, 2014; Jaballah et al., 2015]. Bars also affect the hydraulic and sedimentary conditions of river systems, and therefore the quality of their habitats [Tonina and Buffington, 2007; Wintenberger et al., 2015].

Numerous studies [e.g. Engelund, 1970; Colombini et al., 1987; Lanzoni and Tubino, 1999; Crosato and Mosselman, 2009] have shown that the formation and the geometry of bars are primarily governed by the width-to-depth ratio of the flow (or aspect ratio). At unstable conditions, starting from a flat bed, incipient bars tend to increase in size, eventually reaching a steady value of amplitude and wavelength [Fujita and Muramoto, 1985] which scales with the water depth and the channel width, respectively. Over time, multiple bars may tend to merge to form much larger bars [e.g. Enggrob and Tjerry, 1999]. Two distinct linear theories and subsequent terminologies are commonly used to interpret bar dynamics Van der Meer et al. [2011]. Parker and Johannesson [1989] distinguish a "Genova School" (Blondeaux, Seminara and co-workers) and a "Delft School" (Struiksma and co-workers). Following the Genova School, free bars arise spontaneously from an intrinsic instability of the cohesionless bottom of a channel and invariably migrate downstream (convective instability). Forced bars are the response of the river to a given forcing (e.g., channel curvature, variations of channel width) and do not migrate (stationary bars). The authors kindly acknowledge the efforts devoted by the Genova School in the 1980s. 
This definition caused problematic ambiguity and vagueness, because it did not distinguish between forcing over the full length of a bar, as in the case of point bars that cannot be described by linear stability analysis, and forcing in a single cross-section, leading to a dynamic response of non-migrating bars that can be described using linear stability analysis. Eekhout et al. [2013] and Rodrigues et al. [2015] discussed this ambiguity of using the term "forced bars" for two types of bars, albeit without proposing a new terminology. To resolve the old ambiguity, the Delft School introduced the term "hybrid bars", which was then gratefully adopted by Duró et al. [2016], Le et al. [2018a,b] and Scorpio et al. [2018]. This second and more recent classification distinguishes two types of periodic bars: free and hybrid bars. Hybrid bars form on morphodynamically unstable river beds, like free bars, but their migration is inhibited by an external factor (forcing), e.g. a change in channel geometry, which permanently deform the flow field, fixing their location. For this reason, hybrid bars do not migrate. Their wavelength is not influenced by the forcing itself, but corresponds to the one of free bars having zero celerity, which is generally 2 to 3 times longer than the wavelength of free migrating bars [Crosato et al., 2011; Rodrigues et al., 2015; Duró et al., 2016]. A common earlier term for hybrid bars is "forced bars" [e.g. Blondeaux and Seminara, 1985; Seminara and Tubino, 1989; Federici and Seminara, 2003] or stationary bars [Lanzoni et al., 2006]. Differences between the two terminologies presented above are inherited from the differences in the theoretical framework, which are summed-up by Van der Meer et al. [2011].

Sediment mobility, represented by the Shields number, is crucial for bar morphodynamics and it depends on particle size and grain size distribution (GSD) of the mixture forming the river bed. Analytical studies [e.g. Lanzoni and Tubino, 1999], field and laboratory observations [e.g. Lisle and Madej, 1992; Powell, 1998; Lanzoni, 2000b; Lisle et al., 2000], as well as numerical simulations [e.g. Hoey and Ferguson, 1994; Mosselman et al., 1999; Wu, 2004; Tritthart et al., 2011a,b; Mosselman, 2012; Nelson et al., 2015a,b; Juez et al., 2016; Qian et al., 2016; Siviglia and Crosato, 2016; Singh et al., 2017] have shown that bars are affected by both size and heterogeneity of bed sediment. Lanzoni and Tubino [1999] as well as Takebayashi and Egashira [2001] state that sediment heterogeneity leads to the diminishing of free migrating bar amplitude and wavelength. Opposite results were obtained by Lanzoni [2000a,b] and Lisle et al. [1991] who find that, while free migrating bar amplitude is decreased, the trend exhibited by the wavelength is less clear. The effects of sediment heterogeneity on resonant free bars and hybrid bars, however, seem different. Using a numerical model, Nelson et al. [2015b] found a decrease of the resonant free bars and hybrid bars amplitude, confirming the findings on free migrating bars, but at the same time found an increase instead of a decrease of bar wavelength. Knowing that free migrating bars display a different topography with respect to resonant free and hybrid bars, the observation of Nelson et al. [2015b] highlights that sediment heterogeneity can affect steady periodic bars and free migrating bars in a different way.

Hoey and Ferguson [1994], Seal et al. [1997] and Toro-Escobar et al. [2000] observed that heterogeneous sediment tends to form a pattern of downstream fining during aggradational scenarios in sediment feeding flumes, whether alluvial bars formed or not. They linked this process to the mechanism of selective sediment transport, because fine sediment moves faster than coarse sediment, resulting in the pattern of coarser sediment upstream and finer sediment downstream. The authors also observed that surface sediment is always coarser than subsurface sediment. The pattern of sediment sorting over bars can either display coarse sediment over bar crests and finer sediment in pools [Lisle et al., 1991; Lisle and Madej, 1992; Diplas, 1994; Lanzoni, 2000b; Nelson et al., 2015a] or the opposite, i.e. fine sediment over bar crests and coarser sediment in pools [Takebayashi and Egashira, 2001]. Nelson et al. [2015a,b] attribute the occurrence of coarser bar tops to the decrease of local flow velocity and increase of lateral flow, explaining that longer bars grow faster than shorter bars when the roughness is variable over space, with respect to a spatially constant roughness. In their numerical model, the authors used a single sediment 


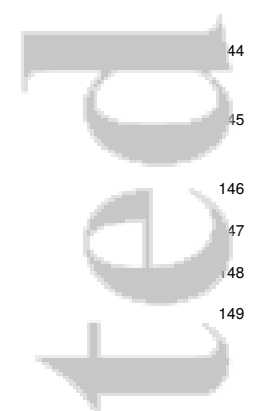

150

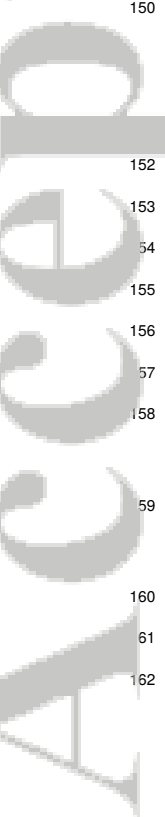

storage layer, but outlined the importance of considering the effects of vertical sorting of sediments in future research works.

The points presented above underline the limitations of the actual knowledge and also the contradictory findings that continue to spark debate over the relationship between non-uniform sediment and bar morphodynamics. The work presented here aims to better understand this relationship, by clearly distinguishing free migrating bars from hybrid bars. To this goal, a two-dimensional fully-nonlinear model is constructed to simulate a laboratory experiment carried out by Lanzoni [2000b]. Based on this model, nine scenarios are then simulated to study the effects of sediment sorting and sediment heterogeneity on bar characteristics, taking into account vertical sediment sorting. The numerical model is constructed using the Telemac-Mascaret Modelling System (TMS) ${ }^{1}$ in which the bed evolution module is based on the active layer model formulated by Hirano [1971], where the vertical substrate is decomposed in several sediment storage layers (i.e. bookkeeping layer model) [Blom, 2008].

A thorough description of the materials and methods used for the study is given in Section 2, which includes the formulation of the mathematical and numerical model, details on the laboratory experiment used for the numerical model calibration and on the setting-up of this model, a presentation of the numerical scenarios and of the methods to analyse the computed bar characteristics. In Section 3, the numerical results of interest corresponding to the flow and sediment transport, bars properties and planform and vertical sorting of sediment are fully detailed for all the scenarios simulated. Then, on the basis of these results, a discussion is held in Section 4 on the influence of sediment size heterogeneity and sediment sorting on free and hybrid bars morphodynamics. The conclusions of this work are given in Section 5.

\section{Materials and methods}

\subsection{Mathematical and numerical model}

The two-dimensional morphodynamic model used in this work presents two components: a hydrodynamic module and a morphodynamic module. The hydrodynamic module is based on the solution of the shallow-water equations (SWE) [de Saint-Venant, 1871; Weiyan, 1992; Nezu et al., 1994; Vreugdenhil, 2013]:

$$
\left\{\begin{array}{l}
\partial_{t} h+\vec{u} \cdot \nabla(h)+h \nabla \cdot(\vec{u})=0 \\
\partial_{t} u+\vec{u} \cdot \nabla(u)=-g \partial_{x} z_{f}-g S_{f, x}+h^{-1} \nabla \cdot\left(h v_{t} \nabla u\right) \\
\partial_{t} v+\vec{u} \cdot \nabla(v)=-g \partial_{y} z_{f}-g S_{f, y}+h^{-1} \nabla \cdot\left(h v_{t} \nabla v\right)
\end{array},\right.
$$

where $t[\mathrm{~s}]$ is the time, $\partial_{t}=\partial / \partial_{t}, \nabla=\left(\partial_{x}, \partial_{y}\right)$ is the gradient vector field, $g=9.81 \mathrm{~m} / \mathrm{s}^{2}$ is the acceleration due to gravity, $h[\mathrm{~m}]$ is the water depth, $z_{b}[\mathrm{~m}]$ is the elevation of the bed topography, $z_{f}=z_{b}+h[\mathrm{~m}]$ is the free surface elevation, $\vec{u}=(u, v)[\mathrm{m} / \mathrm{s}]$ is the depthaveraged flow velocity vector with $u$ and $v[\mathrm{~m} / \mathrm{s}]$ the component along the longitudinal $x$-axis and transversal $y$-axis direction respectively, with $|\vec{u}|[\mathrm{m} / \mathrm{s}]$ the module of $\vec{u}$, and $v_{t}\left[\mathrm{~m}^{2} / \mathrm{s}\right]$ is the turbulent eddy viscosity term that models the so-called Reynold stresses and the differential dispersion terms originated from the lack of vertical uniformity of the horizontal velocity field. The friction law $\overrightarrow{S_{f}}[-]$ of Chézy is given as follow:

$$
\overrightarrow{S_{f}}=\left(S_{f, x}, S_{f, y}\right)=\frac{\vec{u}|\vec{u}|}{C^{2} h},
$$

where $S_{f, x}$ and $S_{f, y}$ correspond to the components of the friction law $\vec{S}_{f}[-]$ along the longitudinal $x$-axis and transversal $y$-axis direction respectively and $C\left[\mathrm{~m}^{1 / 2} / \mathrm{s}\right]$ corresponds to the Chézy friction coefficient. The formula of Nikuradse [1950] is used to calculate the

\footnotetext{
${ }^{1}$ www.opentelemac.org
} 
equivalent friction coefficient of Chézy denoted $C_{f}=g / C^{2}[-]$ as a function of the equivalent roughness height of the bed denoted with $k_{s}[\mathrm{~m}]$ :

$$
C_{f}=2\left[\log \left(\frac{30 h}{e k_{s}}\right) / \kappa\right]^{-2},
$$

where $\kappa$ is the von Kármán coefficient ( $=0.40$ for clear waters) and $e$ is the base of the natural logarithm.

The morphodynamic module is based on the Exner equation [Exner, 1920; García, 2008]. In case of non-uniform sediment, the Exner equation is applied to every size fraction of sediment in which the mixture is subdivided. The following procedure is adopted: i) the sediment mixture is discretized into sediment fractions, and for each fraction the representative sediment diameter is given, $i$ ) the bedload transport capacity equation and the mass conservation formula are applied for each separate fraction of sediment.

The solution for sediment mass conservation is based on the mathematical concept proposed by Hirano [1971], who developed a continuity model for the vertical sorting of sediment. The method is based on the decomposition of the bed into a homogeneous top layer, called active layer, and an unchanging homogeneous substrate [Church and Haschenburger, 2017; Ashmore et al., 2018]. The active layer is a fully mixed layer, defined as the layer where all the bed fluctuations are concentrated [Blanpain, 2009; Stecca et al., 2016]. Following Hirano [1971]'s concept, the bed is discretized in the vertical direction as follows:

$$
z_{b}=\eta_{a: 1}+L_{a},
$$

where $\eta_{a: 1}[\mathrm{~m}]$ denotes the absolute elevation of the interface between the active layer and the substrate, and $L_{a}[\mathrm{~m}]$ corresponds to the active layer thickness. The sediment mass continuity equation is given as follows [e.g. Parker et al., 2007]:

$$
L_{a} \partial_{t} F_{a, i}+\left[F_{a, i}-\mathcal{F}_{a: 1, i}\right] \underbrace{\partial_{t} L_{a}}_{=0}=\frac{1}{\epsilon_{0}}\left[\mathcal{F}_{a: 1, i} \nabla \cdot \overrightarrow{q_{b}}-\nabla \cdot \vec{q}_{b, i}\right],
$$

where $\partial_{t} L_{a}=0$ because the active layer thickness is assumed to be constant during the whole simulation, $F_{a, i}$ is the volume fraction content of the $i^{t h}$ size fraction in the active layer and $\mathcal{F}_{a: 1, i}$ is the volume fraction content of the $i^{\text {th }}$ size fraction in the interface separating the active layer and the substrate, $\vec{q}_{b}=\left(q_{b, x}, q_{b, y}\right)=q_{b}(\cos \alpha, \sin \alpha)$ $\left[\mathrm{m}^{2} / \mathrm{s}\right]$ corresponds to the total volumetric bedload solid discharge per unit of width without pores, with components $q_{b, x}$ and $q_{b, y}$ along the $x$ - and $y$ - axis directions respectively, $q_{b, i}=\left(q_{b, i, x}, q_{b, i, y}\right)=q_{b, i}\left(\cos \alpha_{i}, \sin \alpha_{i}\right)\left[\mathrm{m}^{2} / \mathrm{s}\right]$ corresponds to the fractional volumetric bedload solid discharge per unit of width without pores of the $i^{\text {th }}$ size fraction, $\epsilon_{0}=\left(1-P_{0}\right)$ with $P_{0}$ the bed porosity, $\alpha$ is the angle between the bedload and the $x$-axis direction and $\alpha_{i}$ the angle between the transport rate of the $i^{\text {th }}$ size fraction and the $x$-axis direction. In the current model, the vertical sorting of sediment is made possible by discretizing the substrate into several sublayers [Blom, 2008], where the fraction volume content of $i^{t h}$ size fraction of sediment in the $k^{t h}$ sublayer is denoted $F_{k, i}$. The implementation of the above equation requires the specification of the active layer and the sublayer thicknesses, the interfacial exchange fractions and the number of sublayers [Viparelli et al., 2017]. Vertical fluxes of sediment are computed following the formulation of Hirano [1971]:

$$
\mathcal{F}_{a: 1, i}=\left\{\begin{array}{ll}
F_{a, i} & \text { if } \partial_{t} z_{b}>0 \\
F_{1, i} & \text { if } \partial_{t} z_{b}<0
\end{array},\right.
$$

where $F_{1, i}$ corresponds to the fraction volume content of $i^{\text {th }}$ size fraction of sediment in the first sublayer.

It is of key interest to accurately estimate the sediment transport in natural rivers, since bar evolution (i.e. armor formation and break-up) depends on fractional transport 
the bed slope effect on $i$ ) the magnitude [Koch and Flokstra, 1980; Soulsby, 1997] and ii) the direction of bedload transport [Koch and Flokstra, 1980; Talmon et al., 1995]. The correction of bedload magnitude is modelled with the formula proposed by Koch and Flokstra [1980], where the fractional transport rate $q_{b 0, i}$ is modified as a function of the bed slope degree with respect to the current direction:

$$
q_{b, i}=q_{b 0, i}\left(1-\beta_{1} \partial_{s} z_{b}\right)=q_{b 0, i}\left[1-\beta_{1}\left(\partial_{x} z_{b} \cos \delta+\partial_{y} z_{b} \sin \delta\right)\right],
$$

where $\beta_{1}$ is an empirical coefficient accounting for the stream-wise bed slope effect, $\delta$ is the angle between the current and the $x$-axis direction, and $s$ the coordinate along the current direction. The bedslope effect is similar to a diffusion term in the bed evolution equation [Van der Meer et al., 2011] and may smooth the bed topography and prevent from numerical instabilities [Zolezzi and Seminara, 2001; Cabrit, 2009]. The correction of bedload direction is given by the relation of Bendegom [1947]:

$$
\tan \alpha_{i}=\frac{q_{b, i, n}}{q_{b, i, s}}=\frac{\sin \delta-T_{i} \partial_{y} z_{b}}{\cos \delta-T_{i} \partial_{x} z_{b}}
$$

where $\alpha_{i}$ is the angle between the sediment transport vector of the $i^{t h}$ size fraction of sediment and $x$-axis direction which will deviate from the bed shear stress vector due to gravity effects, $q_{b, i, n}$ and $q_{b, i, s}$ correspond to the bedload magnitudes along the normal to the current direction and the stream-wise direction, respectively, and where the coefficient $T_{i}$ is calculated as follows [Talmon et al., 1995]:

$$
T_{i}=\frac{1}{\beta_{2} \sqrt{\tau_{b, i}^{*}}},
$$

where $\tau_{b, i}^{*}$ is the bed shear stress adimensionnalized by the $i^{\text {th }}$ size fraction of sediment also known as Shields parameter and scales the gravity effects as a function of the grain diameter of the $i^{\text {th }}$ size fraction, and $\beta_{2}$ is an empirical coefficient used as a calibration parameter.

The total shear stress $\tau[\mathrm{Pa}]$ is calculated from the depth averaged flow velocity field, where $\tau=0.5 \rho C_{f}\left(u^{2}+v^{2}\right)$ and $C_{f}$ is equal to the sum of skin friction and bedform drag. In this study, the bed shear stress is determined as a function of the total shear stress:

$$
\tau_{b}=\mu \tau,
$$

where $\mu=C_{f}^{\prime} / C_{f}$ is the friction factor and $C_{f}^{\prime}[-]$ is the equivalent Chézy coefficient only due to skin friction and is the only component acting on bedload [Mendoza et al., 2016]. $C_{f}^{\prime}$ is calculated assuming a flat bed by using the Nikuradse's formula (Equation 3), where the roughness height $k_{s}^{\prime}[\mathrm{m}]$ is a function of the mean sediment diameter at the bed surface with:

$$
k_{s}^{\prime}=\alpha_{k_{s}} \times d_{s, m}
$$

with $\alpha_{k_{s}}$ a calibration parameter. García [2008] summarized different values of $\alpha_{k_{s}}$ measured in the field and in the laboratory ranging from 1 to 6.6.

The numerical solution of Equations 1 is based on the finite element method $P_{1}$, where the advective terms are computed with the method of the characteristics. The numerical solution of the sediment transport continuity equation (Equation 5) is performed by a procedure that combines an implicit finite element scheme and an edge-based explicit upwind advection scheme. This procedure assures mass-conservation at machine accuracy, monotonicity of tracers, copes with dry zones and is easily applicable to domain decomposition [Hervouet et al., 2011]. 


\subsection{Numerical model setup}

The numerical model from which all scenarios are derived uses an unstructured computational mesh composed triangles with typical length of approximately $0.093 \mathrm{~m}$ with a computational time step of $\Delta t=0.04 \mathrm{~s}$ in order to keep a Courant number approximately equal to 0.2 . Mesh and time convergence analyses have been conducted in order to obtain a satisfying spatial representation of the bars and ensuring numerical stability of the model. For all simulations, the turbulent eddy viscosity is set equal to $v_{t}=10^{-6} \mathrm{~m}^{2} / \mathrm{s}$ and $\rho=1000 \mathrm{~kg} / \mathrm{m}^{3}$. The initial longitudinal bed slope is set equal to $i_{0}=0.00525$ and an initial random bed perturbation in the range $[-5 ; 5] \mathrm{mm}$ is used in order to fasten the formation of free bars. The sediment consists of two size fractions having diameter $d_{1}=0.2$ $\mathrm{mm}(67 \%)$ and $d_{2}=2 \mathrm{~mm}(33 \%)$, respectively, with $\Delta_{s}=1.65$ and $P_{0}=0.40$. In order to model the vertical sorting of sediment, the bed is discretized into nine vertical sediment storage layers where the thickness of the sublayers is equal to the active layer thickness, excepted from the deepest one.

The boundary conditions of the hydrodynamic model correspond to an upstream constant flow discharge equal to $45 \cdot 10^{-3} \mathrm{~m}^{3} / \mathrm{s}$ and a downstream constant free surface elevation. Recirculation of sediment is simulated in the numerical model, which consists of re-injecting the volume of sediment that exits the channel uniformly across the upstream boundary, so that sediment mass continuity is always ensured in the channel.

As pointed out by Defina [2003] and observed later by Qian et al. [2016] and Mendoza et al. [2016], free bars develop far from the upstream boundary. For this reason, the model flume has been extended from $x=60 \mathrm{~m}$ to $x=120 \mathrm{~m}$.

\subsection{Numerical model simulations}

Calibration of the hydrodynamic model is performed based on the available hydraulic data (i.e. mean water depth, longitudinal slope of the water surface and flow ve- 
locity), where $k_{s}=0.01 \mathrm{~m}$ yields satisfactory values of averaged water depth and velocity. Calibration of the morphodynamic model is based on the available sediment transport volume and raw data of longitudinal bed evolution profiles measured in the laboratory. Satisfactory values of bar amplitude, wavelength and celerity are obtained with $\alpha_{b}=3.2$, $\beta_{1}=1.3, \beta_{2}=1.6, \alpha_{k_{s}}=5.5$ and $L_{a}=5 \mathrm{~mm}(c f 3.1)$. Before calibrating the model, a sensitivity analysis based on the active and subsurface layers thicknesses has been conducted. This analysis showed that the sediment sorting pattern tends to be identical using layer thicknesses in the range of [5-10] $\mathrm{mm}$, even if the increasing of layers thicknesses tends to slow down the process of sediment sorting with respect to bed evolution. Using thicker layers, the computed sediment sorting pattern becomes irrelevant as the variation of fractional volume contents of sediment is too slow in comparison to bed evolution." This calibrated model is then used as a scenario of reference (run P2009-1) for the simulation runs presented thereafter.

Eight numerical scenarios (P2009-2 to -9 ) have been derived from the reference scenario (P2009-1). All scenarios have a duration of $280.000 \mathrm{~s}(\approx 83 \mathrm{~h})$ in order to reach morphodynamic equilibrium. Four of these scenarios (P2009-3, $-4,-8$ and -9 ) have a transverse obstacle obstructing $2 / 3$ of the channel width, which is inserted in the channel at $x=10 \mathrm{~m}$ on the right side wall to generate hybrid bars [e.g. Crosato et al., 2011].

The influence of sediment size heterogeneity on free and hybrid bars is analysed by comparing the results of scenarios with different sediment mixtures having the same median grain diameter, hence exhibiting different degrees of sediment size heterogeneity. Runs P2009-5 and -8 correspond to a uniform sediment of median diameter equal to $d_{50}=0.48 \mathrm{~mm}$, which is equal to the median grain diameter of the non-uniform sediment used by Lanzoni [2000b], referred to as uniform sediment (Uni-GSD); runs P2009-1 and -3 correspond to the non-uniform sediment used by Lanzoni, referred to as reference sediment (Ref GSD); runs P2009-6 and -9 correspond to a GSD with $d_{1}=0.1 \mathrm{~mm}(67 \%)$ and $d_{2}=4 \mathrm{~mm}(33 \%)$, referred to as extended sediment (Ext-GSD).

The role of planform and vertical sediment sorting on free and hybrid bars is investigated by comparing the results of two types of scenarios: scenarios for which sediment sorting is accounted (runs P2009-1, -3 and -6) and scenarios for which sediment sorting is not accounted (runs P2009-2, -4 and -7). To avoid planform and vertical grain size sorting, these scenarios are characterized by a thick active layer of $L_{a}=100 \mathrm{~m}$. Indeed, using the active layer approach of Hirano, the volume fraction content of the $i^{\text {th }}$ size fraction in the active layer $F_{a, i}(x, y, t)$ is assumed to be constant along the vertical (i.e. independent from $z$ ), but it is a function of the longitudinal, transversal coordinates $(x, y)$ and time $t$. This dependence allows to describe the time evolution of the different volume fractions in the active layer. Assuming a thick active layer is equivalent to neglect mass exchange between the active layer and the substrate, where the volume fraction of the $i^{\text {th }}$ size fraction in the substrate denoted as $F_{s u b, i}(x, y, z, t)$ is also function of the vertical axes $\mathrm{z}$ (Equation 5). All scenarios are listed in Table 1.

\subsection{Analysis methods}

In this work, $H_{b}[\mathrm{~cm}]$ denotes bar amplitude and corresponds to the elevation between a maximum and a minimum of bed topography [Nelson et al., 2015a] between the longitudinal profiles extracted at $20 \mathrm{~cm}$ from the left and the right sidewalls (i.e. at $y=$ $\pm 0.55 \mathrm{~m})$. The bar wavelength $\lambda_{b}[\mathrm{~m}]$ denotes the distance between the two nearest bar tops separated by a pool. Averaged free bar characteristics obtained numerically are computed in the last 40 meters of the channel, i.e. $80-120 \mathrm{~m}$, as here are assumed to be fully developed in this area. Similarly, the characteristics of hybrid bars are measured in the interval [35-70] $\mathrm{m}$. The bar wavelength denoted by $\lambda_{b, \max }[\mathrm{m}]$ corresponds to the longest free bar wavelength observed during a given simulation, that is representative to the most fully developed free bar during the numerical run. The bar wavelength denoted by $\lambda_{b, s}$ 
Table 1. Scenarios studied.

\begin{tabular}{|l||l|c|c|c|c|}
\hline Run & Scenario description * & $\begin{array}{c}\text { Grain Size } \\
\text { Distribution } \\
\text { (GSD) }\end{array}$ & $\begin{array}{c}\text { Obstacle } \\
\text { (Y/N) }\end{array}$ & $\begin{array}{c}\text { Sediment } \\
\text { sorting } \\
\text { (Y/N) }\end{array}$ & $\begin{array}{c}\text { Bars at } \\
\text { equilibrium } \\
\text { F=Free } \\
\text { H=Hybrid }\end{array}$ \\
\hline P2009-1 || & Reference & Ref & No & Yes & F \\
P2009-2 & Reference without sorting & Ref & No & No & F \\
P2009-3 & Reference with obstacle & Ref & Yes & Yes & F \& H \\
P2009-4 & Reference with obstacle without sorting & No & H \\
\hline P2009-5 & Reference with uniform sediment & Exi & No & No & Yes \\
P2009-6 & Reference with extended sediment & F \\
P2009-7 & Reference with extended sediment without sorting & Ext & No & No & F \\
P2009-8 & Reference with obstacle with uniform sediment & Uni & Yes & No & F \& H \\
P2009-9 & Reference with obstacle with extended sediment & Ext & Yes & Yes & F \& H \\
\hline
\end{tabular}

* The duration of the numerical simulations is equal to $280.000 \mathrm{~s}$ for all the scenarios.

[m] corresponds to the hybrid bar wavelength measured at the end of the simulation. The free bar celerity $c_{b}[\mathrm{~m} / \mathrm{h}]$ is measured as the distance of migration of a bar front during a given lapse of time, while the free bar rate $c_{r}$ [bar/h] is defined as the number of bar fronts that intersect a given section during a given lapse of time. This lapse of time corresponds to the time between when the first fully developed free bars are observed in the channel and the end of the simulation. The bed evolution $\Delta z_{b}[\mathrm{~m}]$ is computed as the difference between the channel bed elevation obtained at a given time and that from the initial time (i.e. $t=0 \mathrm{~s}$ ). The raw longitudinal bed profiles measured in the laboratory experiment are analysed and compared to consider only fully developed bar characteristics. The morphodynamic equilibrium is assumed to be reached when all morphodynamics variables are time periodic for each point of the domain.

Bar tops or crests denote the highest topographic points of bars, while pools correspond to the lowest topographic points (Figure 1). For free bar migrating in downstream direction, as in the experiments of Lanzoni, the bar fronts are located downstream of the bar top, just before the transition with the lee side. Originally defined for dunes, the lee side corresponds to the transition between the bar front and the pool and has a negative slope, while the stoss side is used for the transition between the pool and the next bar front (Figure 1). As for dunes, we compute the dimensionless ratio of bar amplitude over bar wavelength $\left(=\frac{H_{b}}{\lambda_{b}}\right)$ to determine the lee and stoss sides slopes.

Figure 1. Illustration of the terminology and nomenclature used to describe bars.

\subsection{Bar mode prediction and concept of resonance}

The physics-based predictor for the number of river bars per cross-section of Crosato and Mosselman [2009] is used in the present study. The most likely number of bars per cross section, denoted $m$, is derived from the following equation:

$$
m=\frac{\beta}{\pi} \sqrt{(b-3) f\left(\overline{\tau^{*}}\right) C_{f}},
$$

where $b$ (here $=5$ ) [-] is the degree of nonlinearity in the dependence of sediment transport on the flow velocity, $\bar{\tau}^{*}[-]$ corresponds to the reach-averaged Shields number and $f\left(\bar{\tau}^{*}\right)=\frac{0.85}{E} \sqrt{\tau^{*}}$ according to Talmon et al. [1995], where $E$ is a coefficient of calibration, commonly set equal to 0.5 . To remain consistent with the formulation for the correction of 
bedload direction used in the numerical model, $E$ is set equal to 0.53 so that $\beta_{2}=1.6$ in Equation 12.

While the bar mode is defined as an integer number, when derived using Equation (15), it results as a real number. For this reason, we indicate "mode" the real result of Equation (15). In the case of $m=1$, the system is at right resonant conditions for alternate bars. When $m<1$, the system is at sub-resonant conditions, so that hybrid bars amplitude decreases longitudinally. When $m>1$, the system is at super-resonant conditions, so that hybrid bars amplitude grows longitudinally. The resonant width-to-depth ratio for alternate bars, denoted $\beta_{r}$, is derived from Equation 15 by imposing the value $m=1$. 

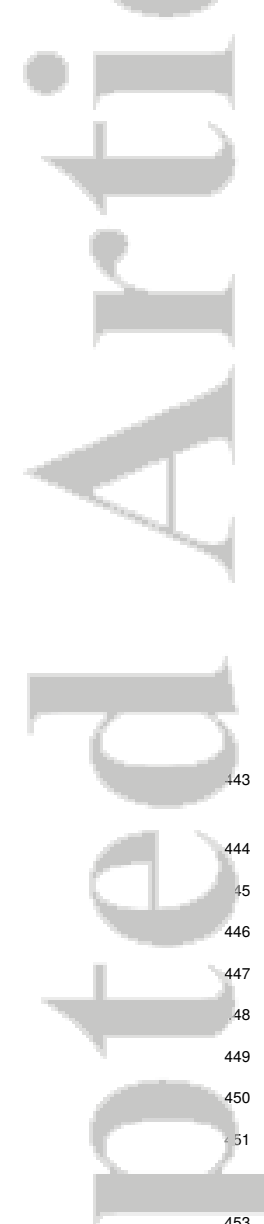

\section{Numerical results}

In this section, the influence of sediment size heterogeneity and planform and vertical sorting of sediment on bar morphodynamics are studied for the scenarios with and without the presence of an upstream obstacle obstructing $2 / 3$ of the channel width. The values of morphodynamic variables and the bar characteristics at equilibrium are summarized in Table 2 for all scenarios.

Table 2. Sediment transport and observed bar characteristics for the studied scenarios.

\begin{tabular}{|c|c|c|c|c|c|c|c|c|c|}
\hline Run & $\underset{10^{-4}\left[\mathrm{~m}^{3} / \mathrm{s}\right]}{\overline{Q_{b}}}$ & $\frac{Q_{b, 1}^{-}}{Q_{b, 2}}$ & $F_{a, 1}$ & $F_{s u b, 1}$ & $\begin{array}{c}\lambda_{b, s} \\
{[\mathrm{~m}]}\end{array}$ & $\begin{array}{r}H_{b, s} \\
{[\mathrm{~cm}]}\end{array}$ & $\underset{[\mathrm{m}]}{\lambda_{b, \max }}$ & $\begin{array}{c}H_{b} \\
{[\mathrm{~cm}]}\end{array}$ & $\begin{array}{c}c_{r} \\
{[\mathrm{~b} a r / \mathrm{h}}\end{array}$ \\
\hline P2009-1 & 1.097 & 2.6 & 0.58 & 0.65 & - & - & 14.4 & 5.2 & 0.63 \\
\hline P2009-2 & 1.091 & 4.5 & 0.67 & 0.67 & - & - & 14.7 & 5.4 & 0.61 \\
\hline P2009-3 & 1.133 & 2.3 & 0.60 & 0.66 & 28.5 & 4.6 & 20.1 & 5.8 & 0.29 \\
\hline P2009-4 & 1.150 & 4.3 & 0.67 & 0.67 & 20.6 & 8.0 & - & - & - \\
\hline P2009-5 & 1.081 & - & - & - & - & - & 13.9 & 4.7 & 0.65 \\
\hline P2009-6 & 1.229 & 2.7 & 0.53 & 0.64 & - & - & 15.0 & 6.1 & 0.70 \\
\hline P2009-7 & 1.231 & 8.2 & 0.67 & 0.67 & - & - & 15.7 & 6.2 & 0.72 \\
\hline P2009-8 & 1.108 & - & - & - & 26.4 & 5.0 & 21.8 & 5.1 & 0.31 \\
\hline P2009-9 & 1.262 & 2.6 & 0.58 & 0.65 & 30.3 & 6.1 & 22.7 & 4.1 & 0.30 \\
\hline
\end{tabular}

$\overline{Q_{b}}$ (resp. $Q_{b, 1}^{-} / Q_{b, 2}^{-}$) is the averaged solid discharge (resp. is the ratio between the averaged fractional solid discharges) crossing the downstream boundary during the 280.000 s of simulation;

$F_{a, 1}$ (resp. $F_{s u b, 1}$ ) is the spatially averaged fractional volume content of fine sediment in the active layer (resp. in the substrate excepted from the deepest layer); $H_{b}$ (resp. $H_{b, s}$ ) denotes the averaged free bar (resp. hybrid bar) amplitude measured from $t=20.000 \mathrm{~s}$ to $t=280.000 \mathrm{~s}$ (resp. at $t=280.000 \mathrm{~s}$ ); $\lambda_{b, s}$ denotes the hybrid bar wavelength measured at the end of the simulation; $c_{r}$ is the bar rate and is measured from $t=20.000 \mathrm{~s}$ to $t=280.000 \mathrm{~s}$.

\subsection{Scenarios without obstacle}

To describe the numerical results obtained in the runs without obstacle, attention is firstly given on the reference scenario (P2009-1). Bar amplitude, wavelength and celerity obtained with the reference scenario (Figure 2 and Table 3) are in good agreement with Lanzoni [2000b]'s observations. The averaged exiting volume of sediment from the beginning of the numerical experiment to $t=3 \mathrm{~h}$ is equal to $1.083 \cdot 10^{-4} \mathrm{~m}^{3} / \mathrm{s}$, which is close to $1.088 \cdot 10^{-4} \mathrm{~m}^{3} / \mathrm{s}$ measured during the laboratory experiments performed by Lanzoni [2000b]. At $t=3 \mathrm{~h}$, the computed bar wavelength range is $10.8 \pm 1.1 \mathrm{~m}$ and the bar amplitude range $3.5 \pm 0.9 \mathrm{~cm}$ (Figure 2), while Lanzoni [2000b] measured a value of $10.2 \mathrm{~m}$ and $3.4 \mathrm{~cm}$, respectively. The computed bar velocity is underestimated compared to the values measured during the experiments $(9.8 \mathrm{~m} / \mathrm{h}$ against $11.0 \mathrm{~m} / \mathrm{h}$, respectively) (Table 3 and Figure 3a). Experimentally and numerically, free bars show very steep topographic gradients at the transition between bar heads and pools, and mild stoss sides.

\begin{tabular}{|l||c|c|c|}
\hline Author & $H_{b}[\mathrm{~cm}]$ & $\lambda_{b}[\mathrm{~m}]$ & $c_{b}[\mathrm{~m} / \mathrm{h}]$ \\
\hline This work & 3.5 & 10.8 & 9.8 \\
Lanzoni [2000b] & 3.4 & 10.2 & 11.0 \\
\hline
\end{tabular}

Table 3. Free bar characteristics at $t=3 \mathrm{~h}$. 
Figure 2. Comparison of a) bed evolution along the left longitudinal profile and b) difference of bed elevation between the left and right longitudinal profiles at $t=3 \mathrm{~h}$, obtained with the calibrated numerical model (run P2009-1) and measured by Lanzoni [2000b].

./imgs/p02.pdf 
Figure 3. Bed evolution from $t=0 \mathrm{~s}$ to $t=280.000 \mathrm{~s}$ at $(x=102 \mathrm{~m} ; y=0.55 \mathrm{~m})$ for the scenarios considered in this study.

./imgs/p03.pdf 
Figure 4. Planform evolution of bed topography, shear stress and surface sediment sorting without obstacle for the (a) reference and (b) extended sediments scenarios at $t=280.000 \mathrm{~s}$.

Figure 5. Longitudinal profiles of bed evolution and vertical sediment sorting without obstacle for the (a) reference and (b) extended sediments scenarios at $t=280.000 \mathrm{~s}$. 


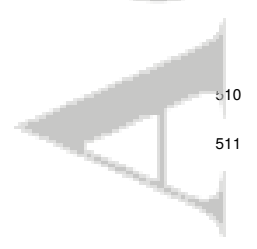

Figure 6. Bed evolution and surface sediment sorting at $t=3 \mathrm{~h}$ from $x=40 \mathrm{~m}$ to $x=80 \mathrm{~m}$ obtained with the reference scenario (run P2009-1).

Figure 7. Spatially averaged solid discharges with and without sediment sorting for (a) the reference sediment (run P2009-1) and (b) the extended sediment (run P2009-6) scenarios. $\overline{Q_{b}}$ is the averaged volume of sediment crossing the downstream boundary during the $280.000 \mathrm{~s}$ of simulation; $\overline{Q_{b}, 1}\left(\right.$ resp. $\left.Q_{\bar{b}, 2}\right)$ is the averaged volume of fine (resp. coarse) sediment crossing the downstream boundary during the $280.000 \mathrm{~s}$ of simulation.

At the early stages of the reference scenario $(t \leq 5000 \mathrm{~s})$, the transport rate of fine material is approximately 4 times higher than the coarse material rate (Figure 7a, solid lines), whereas the initial volume content of fine sediment is about twice the initial content of coarse sediment. In the upstream part of the flume, fine material is progressively removed and transported downstream as a sedimentation wave, illustrated by the wave front located at $x \approx 23 \mathrm{~m}$ in Figure 8 . This results in a decreasing of the fine material content in the upstream part of the flume and in an increasing of it in the downstream part in the active layer and it is even more pronounced in the sublayers (Table 2 and Figure 9a,b). Figure 9 shows that the fine material tends to be buried, as the upper layers gradually coarsen over time. A similar behavior has also been observed in the run with the extended sediment (Figure 7b), but is not detailed here.

$$
. / \text { imgs/p06.pdf }
$$

Figure 8. Planform surface sorting of sediment at $t=2000 \mathrm{~s}$ with the reference scenario showing the sedimentation wave front at $x \approx 23 \mathrm{~m}$ (run P2009-1). 
Figure 9. Time evolution of the spatially averaged fractional volume contents of fine sediment in each storage layer denoted $F_{k, 1}^{-}$in the (a) first $(x \in[0 ; 60] \mathrm{m})$ and $(\mathrm{b})$ second half $(x \in[60 ; 120] \mathrm{m})$ parts of the channel with the reference scenario (run P2009-1).

Figure 10. Longitudinal profiles of bed evolution and bed shear stress with the reference sediment at $t=200.000 \mathrm{~s}$ a) without obstacle with sediment sorting (run P2009-1), b) with the obstacle with sediment sorting (run P2009-3) and c) with the obstacle without sediment sorting (run P2009-4).

Figure 11. Longitudinal profiles of bed evolution and total bedload transport rate with the reference sediment at $t=200.000 \mathrm{~s} \mathrm{a)} \mathrm{without} \mathrm{obstacle} \mathrm{with} \mathrm{sediment} \mathrm{sorting} \mathrm{(run} \mathrm{P2009-1),} \mathrm{b)} \mathrm{with} \mathrm{the} \mathrm{obstacle} \mathrm{with}$ sediment sorting (run P2009-3) and c) with the obstacle without sediment sorting (run P2009-4).

In run P2009-1, even though the system remains highly dynamic and produces bars of different amplitudes, wavelengths and celerities (Figure 3a), and the averaged sediment transport rates oscillate around a constant value already after $t \approx 20.000 \mathrm{~s}$ (Figure 9), the morphodynamics equilibrium is assumed to be reached at around $t \approx 150.000 \mathrm{~s}$ when fractional transport rates of sediment and volume fractions content of sediment in the sediment storage layers are nearly constant (Figure 7a and 9 ) p Begpending on the longitudinal location in the flume, the bed displays different properties. A first zone is identified in the upstream part of the flume where bars do not form (Figure 10a). A distance is required to generate numerically a sufficient lateral bed deform/atings /eatlongde the formation of bars [Crosato et al., 2012], and is approximately equal to $x=40 \mathrm{~m}$ in run P2009-1, corresponding to approximately $3.5 \times \lambda_{b}$. A second zone can be identified immediately downstream, where bars are forming, developing and merging (Figure 10a). In the conditions of the current numerical run, this area extends from $x \approx 50 \mathrm{~m}$ to $x \approx 85 \mathrm{~m}$, corresponding to approximately from $4 \times \lambda_{b}$ to $7 \times \lambda_{b}$. The last identified area corresponds to a zone where

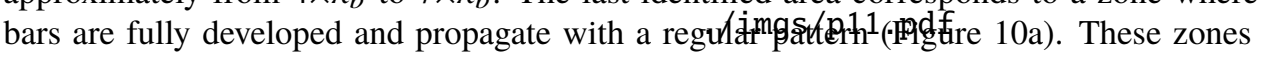
are also present when the uniform sediment (run P2009-5) and extended sediment (run P2009-6) are used, and have the same spatial extent that in the case where the reference sediment (run P2009-1) is used (e.g. Figure 4 and 5).

In such a configuration, the bed shear stress is the lowest immediately downstream of the bar fronts and progressively increases until approximately the middle of the stoss side, before decreasing progressively toward the bar front (Figure 10a). A sudden drop of bed shear stress is located downstream of the bar front, as the water depth immediately increases and the flow velocity decreases at this location. This leads to high sediment transport rates over the bar, which suddenly drops at the bar front (Figure 11a). Consequently, the free migrating bar topography, the distribution of bed shear stress and sediment transport display an asymmetrical longitudinal shape (Figure 10a, 11a and 12a,b). Small values of $\alpha$ indicate that the vector of the sediment transport slightly deviates from the flow direction (Figure 12). As a result, the gravitational forces exerted by the transverse slopes weakly contributes to the bedload transport (e.g. $9 \%$ in the case of the reference scenario, Figure 12c), where the remaining fraction of bedload follows the flow direction (Figure $12 b)$.

\subsection{Scenarios with an obstacle}

The transverse obstacle set at $x=10 \mathrm{~m}$ and obstructing $2 / 3$ of the flume width (Figure 13a,b) generates a forced bar immediately downstream in all the scenarios considered 
Figure 12. Planform distribution of the a) bed evolution, b) total volumetric bedload magnitude and c) component of the total volumetric bedload magnitude per unit of width without pores projected along $y$-axis at $t=280.000 \mathrm{~s}$ for the reference scenario (run P2009-1).

(runs P2009-3, -4, -8 and -9) [Crosato and Desta, 2009; Nelson et al., 2015b; Duró et al., 2016]. The first pool is located in front of the obstacle and is $\approx 8 \mathrm{~cm}$ deep. The forced bar located immediately downstream of the obstacle is $\approx 5 \mathrm{~m}$ long (Figure 13a,b). At $t=0$, a train of free alternate bars progressively forms in the vicinity of the obstacle and migrates downstream. In all scenarios, bars located in the vicinity of the obstacle gradually slow down and stabilize in amplitude and wavelength, leading to the development of hybrid bars in this region (from $x \approx 30 \mathrm{~m}$ to $x \approx 65 \mathrm{~m}$, Figure 13a,b).

Figure 13. Planform distribution of the bed evolution and total bedload magnitude at $t=200.000 \mathrm{~s}$ using the obstacle and the reference sediment, with a) sediment sorting (run P2009-3) and b) without sediment sorting (run P2009-4). $P$ denotes the measurement point located at $(x=102 \mathrm{~m} ; y=0.55 \mathrm{~m}$ ).

Figure 14. Bed evolution from $t=0 \mathrm{~s}$ to $t=100.000 \mathrm{~s}$ at point $P \cdot \mathrm{pdf}(x=102 \mathrm{~m} ; y=0.55 \mathrm{~m})$ with reference
sediment without (P2009-1) and with (P2009-3) the transverse obstacle.

For $t<25.000 \mathrm{~s}$, the downstream free bars obtained without (run P2009-3) and with (run P2009-4) the transverse obstacle show distinct amplitudes, wavelengths and celerities (Figure 14), while the averaged free bar amplitude, maximal wavelength and migration rate are affected by less than $10 \%$. From $t>25.000 \mathrm{~s}$, for scenarios P2009-3, $-4,-8$ and 9 , the obstacle has an influence on the downstream free bars $(x>85 \mathrm{~m})$, where their averaged characteristics differ from the ones obtained without obstacle (Table 2). The presence of hybrid bars slows down free bar migration, increasing the free bar wavelength while the amplitude can either increase when uniform or reference sediments are used (runs P2009-1 vs. -3 and P2009-5 vs. -8) or decrease when the extended sediment is used (run P2009-6

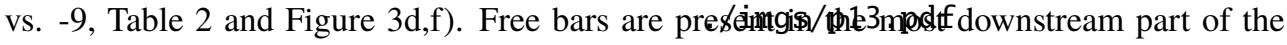
flume i.e. for $x>85 \mathrm{~m}$ only if sediment sorting is accounted for or when the uniform sediment is used (runs P2009-3, -8 and -9, Figure 3f and 13a). Otherwise, free bars are completely replaced by hybrid bars, as showed by the steady time-series of the bed topography (run P2009-4, Figure 3f and 13b).

The longitudinal distribution of bed shear stress and total bedload transport rates over free bars obtained with and without an obstacle show a similar behaviour (Figure $10 \mathrm{a}, \mathrm{b}$ and $11 \mathrm{a}, \mathrm{b})$. The variation of bed shear stress over hybrid bars (i.e. from $x \approx 30$ $\mathrm{m}$ to $x \approx 65 \mathrm{~m}$ ) is smoother than for free bars (i.e. $x>85 \mathrm{~m}$ ), as well as the longitudinal topographic variations, where the lee side and the stoss side of hybrid bars display milder slopes (Figure 10b). In the case of hybrid bars, the maximum value of bed shear stress $(\approx 3 \mathrm{~Pa})$ is located in the pools, and the minimum of bed shear stress $(\approx 0.6 \mathrm{~Pa})$ is found above bar tops and is strictly positive. Moreover, as hybrid bars are longer than free bars, the decrease of bed shear stress from the middle of the stoss side to the front of hy-

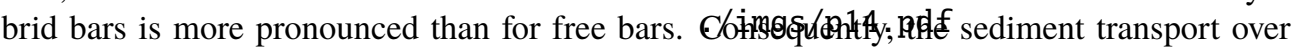
hybrid bars is distributed differently than for free bars, where the variation of sediment transport is smoother than for free bars and is weakly increased in the thalweg and weakly 
decreased over bar tops (Figure 11a,b, 12a,b and 13). As a result, the hybrid bar topography, the bed shear stress and the sediment transport rates display a more symmetrical shape with respect to the ones obtained with free migrating bars.

Figure 15. Planform evolution of bed topography, shear stress and surface sediment sorting with the obstacle for the reference sediment scenario at $t=280.000 \mathrm{~s}$.

According to Figures 15 and 16a,b, the finest sediment and the lowest shear stress are located at the downstream end of hybrid bar tops and at their fronts. Moreover, values of $d_{s, m}$ and $\tau_{b}$ tend to increase progressively until a point located between the pool and the first half of the stoss side, and then decrease progressively until the next bar top. On the opposite, the coarsest sediment tends to accumulate in the stoss side and in the thal$w e g$, where the value of the bed shear stress is higher.

Figure 16. Longitudinal profiles of bed evolution and vertical sediment sorting with the obstacle with the (a) reference and (b) extended sediments scenarios at $t=280.000 \mathrm{~s}$.

\subsection{Effects of sediment size heterogeneity}

\subsubsection{Free bars}

The spatially averaged flow velocity, water depth, bed shear stress and equilibrium

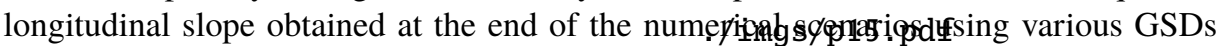
(runs P2009-1, -5 and -6) without the obstacle are summed-up in Table 4. The change of GSD does not affect the averaged flow depth and velocity, since the differences in flow velocity and water depth are less than $2 \%$. On the other hand, in comparison with uniform sediment (run P2009-5), sediment size heterogeneity leads to a general increasing of bed shear stress and Shields numbers of around $31 \%$ with the reference sediment (run P2009-1) and 81\% with the extended sediment (run P2009-6) (Table 4, Figure 4a,b). Similarly, the averaged total transport rate increases when a more heterogeneous sediment is considered, and the ratio of fine over coarse partiekejmg£ ble 2 and Figure 7a vs. 7b). These results show that increased sediment size heterogeneity induces higher bedload transport rates, where the transport of fine sediment is significantly increased, while the transport of coarse sediment is only weakly increased (Tab. 4 and Figure 7a vs. 7b). This effect is associated to the hiding-exposure phenomenon [e.g. Wilcock and Crowe, 2003]. Consequently, the increasing of sediment transport rate is followed by a small, but not negligible, increasing of longitudinal reach slope denoted as $i_{\infty}$ [-]. Indeed, at the end of the runs, the longitudinal slope obtained with uniform sediment is about $0.56 \%$,while it increases by $0.01 \%$ with the reference sediment and increases by $0.02 \%$ with the extended sediment (Table 4 ).

Figure 17. Cross-stream bed evolution of (a) free bars and (b) hybrid bars at bars front locations for the uniform, reference and extended sediments scenarios (different vertical scales are used).

Sediment size heterogeneity affects both free bar wavelength and amplitude (Figure $3 \mathrm{~b}, 5 \mathrm{a}, \mathrm{b}$ and $17 \mathrm{a}$ ). The cross-stream profiles of the bar show that in comparison with 


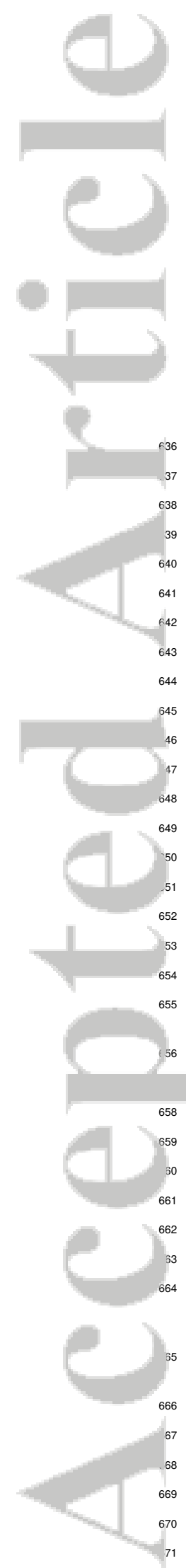

Table 4. Values of the representative hydraulic parameters obtained at $t=280.000 \mathrm{~s}$ for the numerical runs using various GSDs and sediment layer thicknesses.

\begin{tabular}{|c|c|c|c|c|c|c|c|c|c|}
\hline & Run & GSD & $\bar{u}[\mathrm{~m} / \mathrm{s}]$ & $\bar{h}[\mathrm{~m}]$ & $\bar{\tau}_{b}[\mathrm{~Pa}]$ & $\tau_{b, 1}^{*}[-]$ & $\tau_{b, 2}^{*}[-]$ & $i_{\infty}[-]$ & \multirow{5}{*}{ sorting } \\
\hline \multirow{4}{*}{ Heterogeneity } & \multicolumn{8}{|c|}{ runs without obstacle } & \\
\hline & P2009-5 & Uni & 0.54 & 0.056 & 1.6 & 28 & 9 & 0.54 & \\
\hline & P2009-1 & Ref & 0.54 & 0.056 & 2.1 & 37 & 12 & 0.55 & \\
\hline & P2009-6 & Ext & 0.54 & 0.056 & 2.9 & 51 & 16 & 0.56 & \\
\hline \multirow[t]{3}{*}{ Heterogeneity $\downarrow$} & P2009-2 & Ref & 0.54 & 0.056 & 2.0 & 35 & 11 & 0.55 & \multirow[t]{2}{*}{ \} no sorting } \\
\hline & P2009-7 & Ext & 0.54 & 0.056 & 2.5 & 44 & 14 & 0.56 & \\
\hline & & & & runs wit & obstacle & & & & \multirow{4}{*}{ sorting } \\
\hline \multirow[t]{3}{*}{ Heterogeneity } & P2009-8 & Uni & 0.53 & 0.055 & 1.6 & 28 & 9 & 0.55 & \\
\hline & P2009-3 & Ref & 0.53 & 0.056 & 2.0 & 35 & 11 & 0.56 & \\
\hline & P2009-9 & Ext & 0.53 & 0.055 & 2.6 & 46 & 14 & 0.56 & \\
\hline
\end{tabular}

Heterogeneity $\downarrow=$ increase of sediment size heterogeneity

uniform sediment, increasing sediment size heterogeneity tends to widen free bars by approximately $0.10 \mathrm{~m}(\approx 15 \%)$ with the reference sediment and $0.30 \mathrm{~m}(\approx 46 \%)$ for the extended sediment (Figure 17a). As a result, the flow is concentrated in the narrow pool, which tends to be deepen by approximately $0.8 \mathrm{~cm}(\approx 13 \%)$ with the reference sediment and $2.4 \mathrm{~cm}(\approx 40 \%)$ for the extended sediment. The change of GSD has a low impact on the elevation of the bar top (Figure 17a). Therefore, the free bar amplitude increases by approximately $11 \%$ in the case of the reference sediment with respect to the uniform sediment(Table 2 and Figure $3 \mathrm{~b}$ and $5 \mathrm{a}$ vs. $5 \mathrm{~b}$ ). In the same way, the free bar amplitude increases by approximately $12 \%$ in the case of the extended sediment with respect to the reference sediment. In comparison with the uniform sediment, the time-averaged bar rate computed at $(x=102 \mathrm{~m} ; y=0.55 \mathrm{~m})$ is weakly decreased by $3 \%$ with the reference sediment, whereas the extended sediment tends to increase moderately by $11 \%$ the bar rate (Table 2). Consequently, as bars rate and wavelength are increased with increasing sediment size heterogeneity, bars celerity turns out to be higher too. When the obstacle is set-up (runs P2009-3, -8 and -9), in comparison with uniform sediment, increased sediment size heterogeneity tends to increase the free bar amplitude by $35 \%$ with the reference sediment and to decrease by $20 \%$ with the extended sediment (Table 2 and Figure 3c). In general, if the free bar amplitude increases, the maximal wavelength tends to decrease. The mean free bar velocities tend to follow the same trend as in the runs without obstacle, where bar velocity increases with the extended sediment.

Comparison between runs with the reference sediment and with the extended sediment (runs P2009-1 vs. P2009-6, P2009-3 vs. -9) indicates that planform and vertical sediment sorting become much more pronounced when a more heterogeneous sediment is used, whereas the surface sorting pattern remains identical considering a varying sediment size heterogeneity (Figure 4a,b and 5a,b). Moreover, the fully developed bars (from $x \approx 80$ $\mathrm{m}$ to $x \approx 120 \mathrm{~m}$ ) obtained in the reference and extended sediments scenarios generally show the same vertical sediment sorting pattern, which is defined by a progressive fining from the bar top surface until the deepest sediment layer and the opposite behaviour at the pool location.

\subsubsection{Hybrid bars}

Hybrid bars arise from the presence of a transverse obstacle as described in Section 3.2. With the obstacle, sediment size heterogeneity leads to a general increasing of bed shear stress of around 25\% with the reference sediment (run P2009-3) and 62\% with the extended sediment (run P2009-9), in comparison with uniform sediment (run P20098) (Table 4). The spatially averaged bedload transport rate slighty increases by $2.5 \%$ for the runs with an obstacle in comparison with scenarios without obstacle (Table 2). The 
decreasing of the ratio between the fine over the coarse fractional bedload transport rates shows that the obstacle tends to averagely coarsen the bedload, especially for the reference sediment. The averaged volume fractions for the fine material of surface and the sublayers (excepted from the deepest layer) present higher magnitudes ( 0.60 with the Ref GSD and 0.58 with the Ext GSD) in comparison with the experiments without channel obstacle (0.58 with the Ref GSD and 0.53 with the Ext GSD, Table 2).

Figure 18. Longitudinal profiles of bed evolution at $t=200.000 \mathrm{~s}$ with the obstacle for the uniform (P2009-8), reference (P2009-3) and extended (P2009-9) sediments scenarios.

Increasing of sediment size heterogeneity tend to decrease the hybrid bar amplitude and increase the wavelength by $8 \%$ with the reference sediment, and to increase importantly the hybrid bar amplitude by $22 \%$ and the wavelength by $15 \%$ with the extended size heterogeneity (Table 2, Figure $3 \mathrm{c}$ and 18 ). The sediment sorting pattern obtained with the reference and extended sediments are similar, while the degree of sediment sorting increases if sediment size heterogeneity is increased (Figure 16a,b).

\subsection{Effects of spatial sediment sorting}

\subsubsection{Free bars}

While the spatially averaged water depth and scalar flow velocity are not significantly impacted by the sorting of sediment (Table 4) (run P2009-1 vs. P2009-2; run P2009-6 vs. P2009-7), the opposite phenomenon is observed for the bed shear stress. When the sorting of sediment is accounted for, indeed, the bed shear stress varies as a function of the local surface grain size (refer to Equation 13 and 14). In general, the averaged bed shear stress increases if sediment sorting is simulated (Table 4). Long-term simulations show that sediment sorting does not affect the longitudinal reach slope. Furthermore, for all the scenarios where sediment sorting is accounted, the surface sediment progressively coarsens whereas fine sediment tends to be buried (Figure 5a,b).

Comparison between runs in which sediment sorting is accounted (runs P2009-1 and -6) and in which sediment sorting is not accounted (runs P2009-2 and -7) show that planS/AH $\mathrm{HAff}$ vertical sediment sorting has a negligible impact on the bed evolution during the earliest stages of free bar development (i.e. for $t<80.000 \mathrm{~s}$ with the reference sediment and $t<20.000 \mathrm{~s}$ with the extended sediment, Figure 3d,e). Later on, the sorting of sediment impacts the bed evolution, where bars shift in phase by slowing down (resp. accelerating), or alternatively increasing (resp. decreasing) their wavelength (Figure 3d,e). While sediment sorting decreases weakly the maximal bar wavelength by around $5 \%$, it does not impact significantly the averaged free bar amplitude (Table 2), where bars tend to propagate at the same migration rate.

\subsubsection{Hybrid bars}

When sediment sorting is considered, at the late stage of run P2009-3, the formation of downstream free bars is controlled by a steady bar located at approximately $x=70 \mathrm{~m}$, i.e. at a distance of approximately $2.5 \times \lambda_{b, s}$ downstream from the obstacle. Free bar and hybrid bar dynamics tend to follow a cyclic and repetitive pattern: the hybrid bar gradually elongates in amplitude (Figure 19a,b), until it reaches a maximum wavelength corresponding approximately to the wavelength of the steady bars formed more upstream (Figure 19b). Then, the last hybrid bar splits into two shorter bars (Figure 19c,d). The most upstream one remains steady, whereas the second one migrates downstream as a free bar (Figure 19d,e). This phenomenon of free bar formation is not observed when sediment 
is not considered (run P2009-4), where hybrid bars develop from upstream and replace progressively all free bars (Figure 3f).

Figure 19. Planform bed evolution with an upstream transverse obstacle with the reference sediment at different times of the simulation showing the process of free bar detachment and formation (run P2009-3).

When sediment sorting is accounted for, the hybrid bar wavelength increases by $38 \%$ and the bar amplitude decreases by $74 \%$ (Table 2, Figure 13a,b and 20) with respect to the scenario without sediment sorting (run P2009-4). With sediment sorting, bars are damped in longitudinal direction [Struiksma and Crosato, 1989] and the bed shear stress is larger than zero over hybrid bar tops (Figure 10b). In the case without sediment sorting, the water depth over hybrid bars tops is close to zero, so that the bed shear stress and the sediment transport are equal to zero at bar front locations (Figure 10c 11c).

Figure 20. Longitudinal profiles of bed evolution at $t=200.000 \mathrm{~s}$ with the reference sediment with sediment sorting (run P2009-3) and without sediment sorting (run P2009-4).

\section{./imgs/p19 19 pdf 4 Discussion}

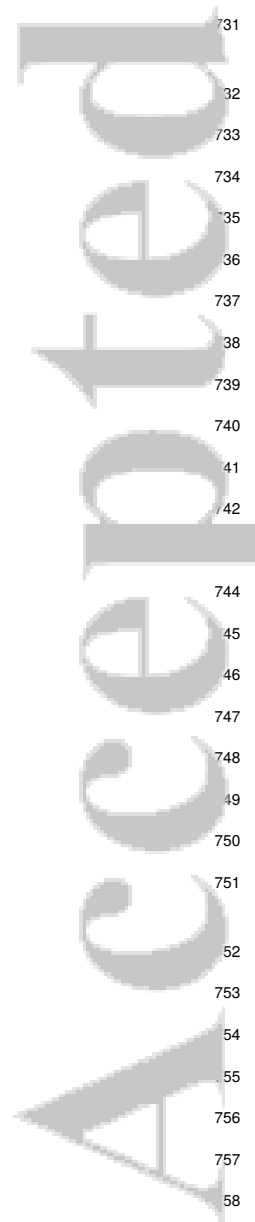

\subsection{Considerations on channel bed sediment sorting}

According to the numerical results obtained with the model reproducing Lanzoni [2000b]'s experiment P2009 (run P2009-1), the sediment sorting pattern displays the expected sediment segregation resulting in coarse material over bar tops and finer sediment on the pools. In the model, the main mechanism controlling the sorting of sediment results from the interaction between the bed topography, the bed shear stress and the GSD used for the experiment. Fine material accumulates in areas characterized by low bed shear stresses. The increase of bed shear stress along the bar induces selective entrainment, so that grain size gradually coarsens along the bar, as also observed by Nelson et al. [2015a]. The pattern of coarse material on bar tops and fine material on pools becomes more appreciable on the long-term than at the beginning of the experiments, showing that the degree of sediment sorting is amplified when bars are fully developed and that bed topography actively controls sediment sorting (Figure 4a). Numerical results also show that the sediment of surface and underneath layers coarsen progressively over time, while the sediment tends to be finer downstream than upstream (= downstream fining) and the bedload progressively coarsens during the simulation as observed experimentally by Hoey and Ferguson [1994], Seal et al. [1997] and Toro-Escobar et al. [2000] (Table 2 and Figure 7a and $9 \mathrm{a}, \mathrm{b})$. In the nature, this phenomenon should be depicted by a pattern of downstream fining, so that the fine sediment would be buried and the surface sediment would become coarser and less heterogeneous in size, and the find imesish low constraints (i.e. downstream of bar fronts).

In the area where bars are forming, developing and merging (i.e. from $x \approx 50 \mathrm{~m}$ to $x \approx 85 \mathrm{~m}$ ), free migrating bars display a sorting pattern with fine sediment in pools and coarse sediment on bar tops. The sediment at the surface of bars coarsens moderately, while the sediment of subsurface becomes finer (Figure 5a). By migrating downstream (i.e. for $x>85 \mathrm{~m}$ ), free bars display the same sediment sorting pattern but with a higher degree of sorting (Figure 5a). This highlights the fact that the sorting of sediment does not adapt immediately to the topographic changes and hydraulic conditions, as the degree 
of sediment sorting is not the same in the area of bar formation and in the area of bar stabilization. In this case, sediment sorting rather requires a certain time or length (at approximately $6.5 \times \lambda_{b}$ from the channel inlet) to find a stable condition illustrated by the fully developed bars located at $x>85 \mathrm{~m}$.

\subsection{Comparison of free and hybrid bars morphodynamics}

Free and hybrid bars show consistently a different bed topography (Table 2 and Figure $5 \mathrm{a}, \mathrm{b}$ vs $16 \mathrm{a}, \mathrm{b}, 19 \mathrm{a}-\mathrm{e}$ and 20 ). Free bars are at least two times shorter than hybrid bars, which is in agreement with previous observations [Duró et al., 2016]. Free bar amplitude is of the same order than the amplitude of hybrid bars. As a result, the slope of the lee side and of the stoss side of free bars are steeper $\left(\frac{H_{b}}{\lambda_{b}} \approx 4 \cdot 10^{-3}\right)$ than the ones of hybrid bars $\left(\frac{H_{b, s}}{\lambda_{b s}} \approx 2.5 \cdot 10^{-3}\right)$. The most striking difference is depicted at the bar front location: while free bars always show a very steep, almost vertical topographic gradient immediately downstream of their fronts, hybrid bars generally show a milder slope, which makes a smoother transition between their front and the lee side. Consequently, the distribution of bed shear stress and sediment transport along hybrid bars (Figure 10b and 11b,c) is different from the ones displayed by free bars (Figure 10a and 11a), where the longitudinal variations of bed shear stress and sediment transport are generally smoother over hybrid bars. With hybrid bars, the maximum values of bed shear stress are located in the pools and in the thalweg, while with free bars they are located closer to the middle of the stoss side. Moreover, the minimum of shear stress found immediately downstream of the bar front can be different from zero for hybrid bars, whereas it is always found to be equal to zero for free migrating bars. The averaged bed shear stress in the system is similar with and without the transverse obstacle (Table 4). However, it is relatively higher in the thalweg for hybrid bars in comparison with free bars, and to counterbalance this effect, the bed shear stress is lowered over hybrid bars tops (Figure 4a,b vs. 15). The same observation is made concerning the sediment transport rates (Figure 12a,b vs. 13a,b and 11a vs. b). The topography, the bed shear stress and the sediment transport rates measured over hybrid bars present a symmetrical shape, in contrast with free bars that show an asymmetrical shape, especially at the bar front location.

The difference observed between the distribution of bed shear stress over the hybrid and free bars explains how the hybrid bar topography enhances its stability by redistributing the bed shear stress over space, and consequently the sediment transport rates over bars. Indeed, in the case of free bars, the flow erodes the bar tops, so that the sediment is deposited in the pool found immediately downstream due to the sudden decrease of bed shear stress in this area (Figure 10a and 12a,b). This process may be at the origin of free bar migration, where bars progressively migrate by filling the pools and eroding their stoss side. In the case of hybrid bars, bar tops are characterized by low or zero bed shear stress, which prevents from bar top erosion or sedimentation because the divergence of sediment transport rates is equal to zero (Figure 10b,c and 13a,b).

Therefore, hybrid bars generate a permanent geometrical forcing which, by analogy with weak or middle amplitude meanders, deflect the flow toward the outer bend and concentrate the flow in the thalweg [Güneralp et al., 2012]. In the current numerical runs, the intensity the geometrical forcing is mainly controlled by the hybrid bar amplitude, which influences the stability of the downstream bars. When the hybrid bar amplitude is high, the geometrical forcing is high enough to sustain the development of hybrid bars everywhere in the channel (run P2009-4, Figure 10c and 13b). On the opposite, when the hybrid bar amplitude decreases, the geometrical forcing is not able to sustain the development of hybrid bars because the bed shear stress and sediment transport rates are increased over the bar tops, which in turn remobilize bars which become free (run P2009-3, Figure 10b and 13a). The origin of the difference of free bar and hybrid bar dominance in the simulations with and without sediment sorting is investigated more in detail in Section 4.3. 
From the results presented in sections Section 3.1 and Section 3.2, it is found that hybrid bars and free bars exhibit different sediment sorting patterns (Figure 4 vs. 15 and 5 vs. 16). Fully developed free migrating bars always display fine sediment in pools and coarser sediment over their tops, which is in agreement with the observations of Lisle et al. [1991], Lisle and Madej [1992], Diplas [1994], Lanzoni [2000b] and Nelson et al. [2015a]. In the current numerical runs, free bars display a progressive coarsening from the lee side until the next bar front (Figure 4a,b and 5a,b). Hybrid bars display a high concentration of fine sediment at the beginning of the lee side (Figure 15 and 16), which smoothly decreases until the middle of the stoss side, and then progressively increases until the next bar top. In this case, the coarsest sediment tends to be concentrated in the thalweg, but it is also deposited over the stoss side due to the high shear stress and sediment transport in the thalweg. Hence, this study highlights that bars of different types can show different equilibrium conditions (bed topography, distribution of shear stress and sediment sorting pattern). These differences explain why sediment size heterogeneity and sediment sorting impact differently free migrating bars and hybrid bars. Even if a number of studies already accept and use the present terminology with the existence of hybrid bars, further analyses should be carried out on a mathematical point of view.

\subsection{Influence of spatial sediment sorting on periodic bars morphodynamics}

The numerical results show that spatial sediment sorting induces higher bed shear stress, which correlates with a general coarsening of sediment at the surface and increased bed roughness (Table 2). The latter offers a larger resistance to the flow, which is taken into account by the model by computing the bed shear stress as a function of the bed roughness (Equation 3, 13 and 14). When free migrating bars are fully developed, the numerical results suggest that sediment sorting does not impact significantly the averaged free migrating bar properties.

The implementation of a lateral channel obstacle resulted in hybrid bar formation. The distribution of the bed shear stress over hybrid bars (Figure 10a) is comparable to the one obtained by Nelson et al. [2015b] over slowly migrating free bars (i.e. $c_{b} \approx 0$ ) and hybrid bars. Comparison between runs with (run P2009-3) and without (run P2009-4) sediment sorting demonstrates that the latter has a strong impact on hybrid bars as it alters their characteristics and enhance the dynamics of free bars still present at the end of the model domain, as explained above (Figure 13a). The sediment sorting results in increased hybrid bar wavelength and reduced hybrid bar amplitude, which is in agreement with the observation of Nelson et al. [2015b]. Indeed, Nelson et al. [2015b] showed numerically that the spatially varying bottom roughness due to the spatialization of sediment size had a strong influence on equilibrium bar morphology. Bars were longer and damped when a variable bottom roughness was used because the roughness effects over bar tops (where the coarse sediment is concentrated) caused the local stream-wise velocity to decrease and induced lateral flow in this region. In turn, it reduces the gradient of bed shear stress over bar tops, resulting in less deposition over the bar and explaining that longer and flatter bars are obtained when roughness is variable over space. As a result, the authors observed that the averaged bar wavelength increased by $39 \%$ whereas bar amplitude decreased by $22 \%$ if the bottom roughness was considered spatially variable. In their runs, bars tended to migrate slowly (i.e. $c_{b} \approx 0$ ) or slow down and stretch-out before reaching a quasi-equilibrium condition and became essentially fixed in place. This illustrates that the wavelength of these bars was equal to the ones of resonant free and hybrid bars [Crosato et al., 2011; Rodrigues et al., 2015; Duró et al., 2016], and explains why sediment sorting impacts in the same way the hybrid bars obtained in our model and the bars obtained by Nelson et al. [2015b].

From the theoretical perspective, the linear stability analysis (Equation 15) predicts $m=1.02\left(\beta_{r}=26.5\right)$ when sediment sorting is accounted (run P2009-3), while a higher bar "mode" equal to $m=1.06\left(\beta_{r}=25.6\right)$ is obtained when sorting is not accounted 
(run P2009-4). In both cases, the theory suggests that the system is close to resonance at super-resonant conditions as $m \approx 1$ (i.e. $\beta_{r} \approx 27$ ), suggesting that hybrid bars persist with the same characteristics from the obstacle until the channel outlet, see Siviglia et al. [2013]. While the theory is in agreement with the numerical results when sediment sorting is not accounted (run P2009-4), opposite behavior is obtained when sediment sorting is accounted (run P2009-3). In the numerical runs, hybrid bars persist only $2.5 \times \lambda_{b, s}$ downstream to the obstacle (in the same order of magnitude than Vanzo et al. [2011] who found approximately $3 \times \lambda_{b, s}$ ), and downstream to that area, the effect of the obstacle disappears and shorter free migrating bars appear. This difference may come from many reasons, such as the value chosen for $b$, or from the linear theory at the base of the formula and other simplifications, or even because the numerical solution includes truncation errors and numerical smoothing, which could explain that the theoretical bar regime is not fully represented in the simulations, where numerical smoothing is expected to increase damping in the longitudinal direction with respect to the theory. Taking these uncertainties into account, the fact that $m$ is very close to 1 (i.e. close to the resonant conditions for alternate bars) explains the tendency of the system to switch easily from dominant free bars (run P2009-3) to dominant hybrid bars (run P2009-4). Eventually, in this context, both approaches suggest that sediment sorting invariably decreases the bar "mode" $m$.

The phenomenon of free bar detachment and formation, which has already been observed in a sandy-gravel-bed river on a hybrid bar located in a secondary channel [Rodrigues et al., 2012, 2015], is observed only if sediment sorting is simulated (run P2009-3, Figure 19). This process is not observed if sediment sorting is not accounted for, because the tops of hybrid bars are high enough - and generate a sufficient geometrical forcing to prevent from erosion (Figure 10a), so that a train of hybrid bars progressively stabilizes and replaces the downstream free migrating bars. Sediment sorting is showed to impact bar characteristics, which in turn control the distribution of the hydraulics variables over space resulting in modified sediment transport. Retroactively, it enhances bar mobility in the system. Therefore, under the conditions simulated, bar mobility and bed topography seem to be the primary factor controlling the sorting of sediment, which in turn impacts bar characteristics.

\subsection{Influence of sediment size heterogeneity on periodic bars morphodynamics}

In the current numerical runs, increasing sediment size heterogeneity increased the free bar amplitude and wavelength. The major differences found between the free bars obtained with using different GSDs can be mostly explained in terms of sediment mobility. The single increase of sediment size heterogeneity leads to higher bed shear stress because the Shields numbers $\overline{\tau_{1}^{*}}$ and $\overline{\tau_{2}^{*}}$ are dependent of the chosen GSD (Table 2). This leads to higher sediment transport rates (Table 2), inducing the formation of larger bars where flows concentrate along the opposite bank in the pools and increase bed shear stress there, resulting in higher pool erosion and resulting in higher bar amplitude (Figure 4a vs. 4b, $5 \mathrm{a}$ vs. $5 \mathrm{~b}$ and $17 \mathrm{a}$ ). In addition, as a result of increased size heterogeneity, a higher degree of sediment sorting is observed. By linking this observation with the findings of $\mathrm{Nel}$ son et al. [2015b] over resonant free and hybrid bars, this implies that due to the increasing of sediment size heterogeneity, the higher concentration of coarse sediment observed over the stoss side and the bar top (Figure $4 \mathrm{a}$ vs. $4 \mathrm{~b}$ and $5 \mathrm{a}$ vs $5 \mathrm{~b}$ ) increases the local bed roughness, reducing the longitudinal flow velocity and increasing the lateral flow over bar tops, which enhances the steering of the flow exerted by the bed topography and explains that longer features grow faster than shorter ones. As a result, the free bar wavelength increases. Retroactively, as free bars are longer with increased sediment size heterogeneity, the flow shoals over the stoss side for a longer distance. For this reason, sediment transport becomes more size selective, which explains the increased degree of sediment sorting. Moreover, the increased degree of sediment sorting is also due to the fact that fine sediments are more mobile whereas coarse sediment tends to remain over bar tops when sediment size heterogeneity increases. 


\section{Conclusions}

A fully non-linear physics-based morphodynamic model has been implemented to better understand the interaction between non-uniform sediment and alternate bars, distinguishing free bars from hybrid bars based on the absence/presence of external morphodynamic forcing. The model is based on the solution of the shallow-water equations, and is coupled with a morphodynamic module which takes into consideration the gravitational effects and the hiding-exposure effects on bedload transport, the planform and vertical sediment sorting and the feedback of varying bottom roughness on sediment transport due to planform sediment sorting. Nine scenarios are simulated starting from this numerical model based on the laboratory experiment of Lanzoni [2000b] with non-uniform sediment. A comprehensive analysis is conducted on the flow and sediment transport, bar properties and planform and vertical sorting of sediment for all the simulations.

The reference scenario shows consistency with the laboratory experiment as it is able to reproduce the process of bar development and spatial sediment sorting with using layers thicknesses in the same order than the coarsest grain diameter. Moreover, the degree of complexity of the model is showed to be necessary to reproduce the phenomena of interest and to give access to processes which are difficult to observe experimentally.

The numerical simulation reproducing Lanzoni [2000b]'s laboratory experiment shows that even under the conditions of morphodynamic equilibrium, the system remains highly dynamic and produces fully developed free migrating bars of sharp different amplitude, wavelength and celerity. In the simulation, the first mechanism controlling the sort- 
ing of sediment results from the interaction between bed topography, bed shear stress and the sediment used for the experiment. The bed shear stress over these bars is relatively high on the stoss side and over the bar top, while it suddenly decreases at the bar front location due to the high topographic gradient. A similar observation is made concerning the transport of sediment. This process is at the origin of free bar migration, where bars progressively migrate by filling the pools located immediately downstream. The sediment sorting pattern is characterized by the presence of fine sediment in pools and coarse particles over bar tops, which becomes more appreciable when free migrating bars are fully developed, and seems to be primarily controlled by the bed shear stress. Vertically, these bars display a sediment sorting pattern with coarse material over bar tops and finer sediment on the deepest sediment layer, while the opposite behaviour is observed at the pool location. In this context, the implementation of a bookkeeping active layer is particularly useful to conclude that the planform and vertical sediment sorting does not adapt immediately to the fast topographic and hydraulic changes, but requires a certain time and length to find a more stable condition. Moreover, the use of a bookkeeping active layer model allowed the formation of downstream fining but also a general coarsening of the bed surface over time.

Hybrid bars are obtained by setting-up a transverse obstacle upstream. The free migrating bars and hybrid bars obtained in the simulations show consistently a different bed topography: hybrid bars are generally more than two times longer than fully developed free bars, whereas their amplitude is in the same order of magnitude than the ones of free bars. Consequently, hybrid bars are flatter than free migrating bars and display milder slopes so that the distributions of bed shear stress, sediment transport rates and sediment sorting are different for these two types of bars. In the case of hybrid bars, the bed topography, the bed shear stress and the sediment transport present a symmetrical shape while free migrating bars present an important asymmetry on their fronts. For this reason, hybrid bars display a sediment sorting pattern with the finest sediment at the beginning of the lee side which smoothly coarsens until the middle of the stoss side, and then becomes progressively finer until the next bar top. Moreover, the low (resp. zero) shear stress found above hybrid bar tops induce low (resp. zero) sediment transport in this area, so that bar tops are protected from erosion. Fixed hybrid bar tops can be seen as geometrical forcing, which have an influence on the downstream bar morphodynamics. The amplitude of hybrid bars is showed to primarily control the intensity of this geometrical forcing, which can sustain the development of hybrid bars everywhere in the reach if the forcing is high enough, or in the opposite trigger free bar detachment if the forcing becomes too low. These results are also supported by the linear analytical theory.

Planform and vertical sediment sorting are showed to only slightly modify free migrating bar morphodynamics whereas hybrid bars are greatly impacted. Under the conditions given by the experiment, hybrid bars tend to be longer and flatter if sediment sorting is accounted for. Their amplitude decreases in longitudinal direction so that they do not dominate the bed topography in the downstream end of the domain, where free migrating bars form and migrate downstream.

For free and hybrid bars, increased sediment size heterogeneity increases the degree of sediment sorting, while the sorting pattern remains the same for each type of bar. Free and hybrid bars are impacted and respond differently to changes of sediment size heterogeneity. The increasing of sediment size heterogeneity produces averagely higher, longer and faster free bars, while in the case of hybrid bars, the wavelength is increased and the amplitude is decreased only when a very heterogeneous sediment is used.

The last conclusions highlight that understanding the mechanisms involved behind non-uniform sediment and bars morphodynamics is not straightforward. Indeed, the numerical simulations show that non-uniform sediment has a different impact on bars depending on if they are free and migrating, if they are hybrid or free but do not migrate, or if different types coexist. The effects of planform and vertical sediment sorting and 
sediment size heterogeneity on free migrating bars and steady hybrid bars observed numerically could eventually explain the contradictory findings presented in the literature. The modelling of vertical sediment sorting and the clear distinction between the types of bars obtained numerically constitute a starting point for completing and improving the findings reported in the literature. This subject of debate is not closed, but the last conclusions stress the fact that a clear distinction between the types of bars has to be considered before investigating the influence of any physical parameter on bar morphodynamics. 


\section{Notation}

B Channel width [m]

$\boldsymbol{b}$ degree of nonlinearity in the dependence of sediment transport on the flow velocity [-]

C Chézy coefficient $\left[\mathrm{m}^{1 / 2} / \mathrm{s}\right]$

$\boldsymbol{C}_{\boldsymbol{f}}$ Equivalent Chézy coefficient due to form drag and skin friction [-]

$C_{f}^{\prime}$ Equivalent Chézy coefficient due to skin friction only [-]

$\boldsymbol{c}_{\boldsymbol{b}}$ Free migrating bar celerity $[\mathrm{m} / \mathrm{h}]$

$\boldsymbol{c}_{\boldsymbol{r}}$ Free migrating bar rate [bar/h]

$\boldsymbol{d}_{\boldsymbol{i}}$ Representative diameter of the $i^{\text {th }}$ size fraction [m]

$\boldsymbol{d}_{\boldsymbol{s}, \boldsymbol{m}}$ Median sediment diameter of surface [m]

$\boldsymbol{d}_{\boldsymbol{X}} X^{\text {th }}$ centile of the GSD [m]

$\boldsymbol{E}$ Coefficient of calibration for the correction of bedload direction [-]

$\mathcal{F}_{a: 1, i}$ Fraction volume content of $i^{t h}$ size fraction in the interface [-]

$\boldsymbol{F}_{\boldsymbol{k}, \boldsymbol{i}}$ Fraction volume content of $i^{t h}$ size fraction in layer $k$ [-]

$\overline{\boldsymbol{F}_{\boldsymbol{k}, \boldsymbol{i}}}$ Spatially averaged fraction volume content of $i^{t h}$ size fraction in layer $k[-]$

$\boldsymbol{F}_{\boldsymbol{s}}$ Fraction volume content of sand at the bed surface [-]

$\boldsymbol{F}_{\boldsymbol{s u b}, \boldsymbol{i}}$ Fraction volume content $i^{\text {th }}$ size fraction in the substrate [-]

$g$ Acceleration due to gravity $(=9.81)\left[\mathrm{m} / \mathrm{s}^{2}\right]$

$\boldsymbol{h}$ Water depth [m]

$\overline{\boldsymbol{h}}$ Spatially averaged water depth [m]

$\boldsymbol{H}_{\boldsymbol{b}}$ Time-averaged free bar height $[\mathrm{m}]$

$\boldsymbol{H}_{\boldsymbol{b}, \boldsymbol{s}}$ Hybrid bar height $[\mathrm{m}]$

$\boldsymbol{i}_{\mathbf{0}}$ Longitudinal bed slope at $t=0 \mathrm{~s}[-]$

$i_{\infty} \quad$ Longitudinal bed slope at the equilibrium [-]

$\boldsymbol{k}_{\boldsymbol{s}}$ Bed roughness height [m]

$\boldsymbol{L}_{\boldsymbol{a}}$ Active layer thickness [m]

$\boldsymbol{m}$ Bar "mode" (real number) [-]

$\boldsymbol{P}_{\mathbf{0}}$ Bed porosity [-]

$\boldsymbol{q}_{\boldsymbol{b}}$ Magnitude of bedload transport rate $\left[\mathrm{m}^{2} / \mathrm{s}\right]$

$\overrightarrow{\boldsymbol{q}}_{\boldsymbol{b}}=\left(\boldsymbol{q}_{\boldsymbol{b}, \boldsymbol{x}}, \boldsymbol{q}_{\boldsymbol{b}, \boldsymbol{y}}\right)$ Vector of bedload transport rate $\left[\mathrm{m}^{2} / \mathrm{s}\right]$

$\boldsymbol{q}_{\boldsymbol{b} \boldsymbol{0}}$ Magnitude of bedload transport rate without gravitational effects $\left[\mathrm{m}^{2} / \mathrm{s}\right]$

$\overrightarrow{\boldsymbol{q}_{\boldsymbol{b} 0}}$ Vector of bedload transport rate without gravitational effects $\left[\mathrm{m}^{2} / \mathrm{s}\right]$

$\boldsymbol{q}_{\boldsymbol{b}, \boldsymbol{i}}$ Magnitude of fractional transport rate of $i^{\text {th }}$ size fraction $\left[\mathrm{m}^{2} / \mathrm{s}\right]$

$\overrightarrow{\boldsymbol{q}_{\boldsymbol{b}, i}}=\left(\boldsymbol{q}_{\boldsymbol{b}, \boldsymbol{i}, \boldsymbol{x}}, \boldsymbol{q}_{\boldsymbol{b}, i, y}\right)$ Vector of fractional transport rate of $i^{t h}$ size fraction $\left[\mathrm{m}^{2} / \mathrm{s}\right]$

$\boldsymbol{q}_{\boldsymbol{b}, \boldsymbol{i}, \boldsymbol{n}}$ Magnitude of normal fractional transport rate of $i^{\text {th }}$ size fraction $\left[\mathrm{m}^{2} / \mathrm{s}\right]$

$\boldsymbol{q}_{\boldsymbol{b}, i, \boldsymbol{i}}$ Magnitude of stream-wise fractional transport rate of $i^{\text {th }}$ size fraction $\left[\mathrm{m}^{2} / \mathrm{s}\right]$

$\boldsymbol{Q}_{s, i}$ Spatially averaged discharge of $i^{t h}$ size fraction $\left[\mathrm{m}^{3} / \mathrm{s}\right]$

$s$ Coordinate in the current direction [-]

$\overrightarrow{\boldsymbol{u}}=(\boldsymbol{u}, \boldsymbol{v})$ Flow velocity vector $[\mathrm{m} / \mathrm{s}]$

$\overline{\boldsymbol{u}}$ Spatially averaged flow velocity $[\mathrm{m} / \mathrm{s}]$

$\boldsymbol{u}, \boldsymbol{v}$ Depth averaged velocity components along $x$ - and $y$-axis $[\mathrm{m} / \mathrm{s}]$

$\boldsymbol{s}$ Coordinate in the current direction [-]

$\overrightarrow{S_{f}}=\left(S_{f, x}, S_{f, y}\right)$ Friction law vector [-]

$\boldsymbol{t}$ Physical time [s]

$\boldsymbol{T}_{\boldsymbol{i}}$ Coefficient of deviation for the $i^{\text {th }}$ size fraction [-]

$W_{i}^{*}$ Dimensionless transport rate for the $i^{t h}$ size fraction of sediment [-]

$\boldsymbol{u}_{*}$ Shear velocity $[\mathrm{m} / \mathrm{s}]$

$x-, y-, z-$ Axis notation of the Coordinate Cartesian system [-]

$z_{\boldsymbol{b}}$ Bed elevation $[\mathrm{m}]$

$z_{f}$ Free surface $[\mathrm{m}]$

$\alpha_{\boldsymbol{b}}$ Coefficient used to calibrate the sediment transport capacity [-] 
$\alpha_{i}$ Angle between the vector of fractional transport and $x$-axis [-]

$\boldsymbol{\alpha}_{\boldsymbol{k}_{\boldsymbol{s}}}$ Calibration parameter [-]

$\beta$ Width-to-depth ratio [-]

$\boldsymbol{\beta}_{\boldsymbol{r}}$ Resonant width-to-depth ratio [-]

$\beta_{1}$ Koch and Flosktra's empirical factor for bed slope effects magnitude [-]

$\boldsymbol{\beta}_{2}$ Talmon's et al. empirical factor for bed slope effects deviation [-]

$\delta$ Angle between bottom shear stress and the flow direction [-]

$\boldsymbol{\Delta}_{\boldsymbol{s}}$ Relative submerged sediment density [-]

$\Delta t$ Computational time-step [s]

$\Delta z_{\boldsymbol{b}}$ Evolution of the bed topography with respect to the initial bed elevation [m]

$\boldsymbol{\epsilon}_{\mathbf{0}}$ Percentage of volumetric matter without voids [-]

$\eta_{a: 1}$ Absolute elevation of the interface [m]

$\boldsymbol{\kappa}$ Constant of von Kármán (=0.40) [-]

$\lambda_{b, \text { max }}$ Maximal free bar wavelength [m]

$\lambda_{\boldsymbol{b}, \boldsymbol{s}}$ Hybrid bar wavelength [m]

$\boldsymbol{\mu}$ Skin friction coefficient [-]

$\boldsymbol{\nabla}$ Gradient vector field $[1 / \mathrm{m}]$

$v_{\boldsymbol{t}}$ Turbulent eddy viscosity term $\left[\mathrm{m}^{2} / \mathrm{s}\right]$

$\partial_{x_{2}} \boldsymbol{x}_{1}$ Partial derivative of the quantity $x_{1}$ in $x_{2}\left[x_{2} / x_{1}\right]$

$\boldsymbol{\Phi}_{i}$ Ratio of bed shear stress over reference shear stress of $i^{t h}$ size fraction [-]

$\rho$ Water density $\left[\mathrm{kg} / \mathrm{m}^{3}\right]$

$\tau$ Total shear stress $[\mathrm{Pa}]$

$\bar{\tau}^{*}$ Spatially averaged Shields number [-]

$\tau_{\boldsymbol{b}}$ Bed shear stress $[\mathrm{Pa}]$

$\tau_{\underline{b}, i}^{*}$ Shear stress adimensionnalized by the $i^{t h}$ fraction [-]

$\tau_{b, i}^{\bar{*}}$ Spatially averaged shear stress adimensionnalized by the $i^{\text {th }}$ fraction [-]

$\tau_{r, i}$ Reference shear stress of the $i^{t h}$ size fraction [Pa]

$\tau_{r, \boldsymbol{m}}$ Reference median shear stress of bed surface $[\mathrm{Pa}]$

\section{Acknowledgments}

We would like to kindly acknowledge S. Lanzoni for sharing his experimental data (DOI: 10.1029/2000WR900161). There is no new data used in this manuscript, all data is numerical and available within the manuscript. The authors gratefully acknowledge the support of Electricité de France (EDF). The authors are very grateful to Annunziato Siviglia and the two other reviewers for their careful and meticulous reading of the paper, whose suggestions helped improve and clarify the manuscript.

\section{References}

An, C., Y. Cui, X. Fu, and G. Parker (2017), Gravel-bed River Evolution in EarthquakeProne Regions Subject to Cycled Hydrographs and Repeated Sediment Pulses, Earth Surface Processes and Landforms, 42(15), 2503-2696.

Ashmore, P., S. Peirce, and P. Leduc (2018), Expanding the Active Layer: Discussion of Church and Haschenburger (2017) What is the Active Layer? Water Resources Research 53, 510, Doi:10.1002/2016WR019675, Water Resources Research, 54(3), 1425-1427, doi:10.1002/2017WR022438.

Bendegom, L. V. (1947), Some considerations on river morphology and river improvement, De Ingenieur vol. 59-4, pp. B1-11, Dutch. English translation: Nat. Res. Council of Canada, Technical Translation, 1054, 1963. 
Blanpain, O. (2009), Dynamique sédimentaire multiclasse: de l'étude des processus à la modélisation en Manche, Ph.D. thesis, Université de Rouen.

Blom, A. (2008), Different approaches to handling vertical and streamwise sorting in modeling river morphodynamics, Water resources research, 44(3), 1 - 17.

Blondeaux, P., and G. Seminara (1985), A unified bar-bend theory of river meanders, Journal of Fluid Mechanics, 157, 449-470.

Bridge, J., and R. Demicco (2008), Earth surface processes, landforms and sediment deposits, Cambridge University Press.

Bridge, J. S. (2003), Rivers and floodplains: forms, processes, and sedimentary record, John Wiley \& Sons.

Cabrit, O. (2009), Modélisation des flux pariétaux sur les tuyères des moteurs à propergol solide, Ph.D. thesis, Montpellier 2.

Church, M., and J. K. Haschenburger (2017), What is the active layer?, Water Resources Research, 53(1), 5-10, doi:10.1002/2016WR019675.

Claude, N., S. Rodrigues, V. Bustillo, J.-G. Bréhéret, J.-J. Macaire, and P. Jugé (2012), Estimating bedload transport in a large sand-gravel bed river from direct sampling, dune tracking and empirical formulas, Geomorphology, 179, 40-57.

Claude, N., S. Rodrigues, V. Bustillo, J.-G. Bréhéret, P. Tassi, and P. Jugé (2014), Interactions between flow structure and morphodynamic of bars in a channel expansion/contraction, Loire River, France, Water Resources Research, 50(4), 2850-2873.

Colombini, M., G. Seminara, and M. Tubino (1987), Finite-amplitude alternate bars, Journal of Fluid Mechanics, 181, 213-232.

Crosato, A., and F. Desta (2009), Intrinsic steady alternate bars in alluvial channels. Part 1: experimental observations and numerical tests., in Proc. of the 6th Symp. on River Coastal and Estuarine Morphodynamics (RCEM 2009), 21-25 Sept. 2009, Santa Fe, Argentina, RCEM 2009, Vol. 2, pp. 759-765., Taylor \& Francis Group.

Crosato, A., and E. Mosselman (2009), Simple physics-based predictor for the number of river bars and the transition between meandering and braiding, Water Resources Research, 45(3), 1-12.

Crosato, A., E. Mosselman, F. Beidmariam Desta, and W. S. J. Uijttewaal (2011), Experimental and numerical evidence for intrinsic nonmigrating bars in alluvial channels, $\mathrm{Wa}$ ter Resources Research, 47(3), 1-14, doi:10.1029/2010WR009714, w03511.

Crosato, A., F. B. Desta, J. Cornelisse, F. Schuurman, and W. S. J. Uijttewaal (2012), Experimental and numerical findings on the long-term evolution of migrating alternate bars in alluvial channels, Water Resources Research, 48(6), 1-14, doi: 10.1029/2011WR011320, w06524.

de Saint-Venant, A. B. (1871), Théorie du mouvement non permanent des eaux, avec application aux crues des rivières et à l'introduction des marées dans leurs lits, Comptes Rendus des séances de l'Académie des Sciences, 73, 237-240.

Defina, A. (2003), Numerical experiments on bar growth, Water Resources Research, $39(4), 1-12$.

Diplas, P. (1994), Modelling of fine and coarse sediment interaction over alternate bars, Journal of Hydrology, 159(1), 335-351.

Duró, G., A. Crosato, and P. Tassi (2016), Numerical study on river bar response to spatial variations of channel width, Advances in Water Resources, 93(Part A), 21 - 38, doi: https://doi.org/10.1016/j.advwatres.2015.10.003.

Eekhout, J., A. Hoitink, and E. Mosselman (2013), Field experiment on alternate bar development in a straight sand-bed stream, Water Resources Research, 49(12), 8357-8369.

Engelund, F. (1970), Instability of erodible beds, Journal of Fluid Mechanics, 42(2), 225244.

Engelund, F., and O. Skovgaard (1973), On the origin of meandering and braiding in alluvial streams, Journal of Fluid Mechanics, 57(02), 289-302.

Enggrob, H., and S. Tjerry (1999), Simulation of morphological characteristics of a braided river, in Proceedings of the IAHR Symposium on River, Coastal and Estuarine 
Morphodynamics, Genova, vol. I, pp. 585-594.

Exner, F. M. (1920), Zur physik der dünen, Hölder.

Federici, B., and G. Seminara (2003), On the convective nature of bar instability, Journal of Fluid Mechanics, 487, 125-145.

Fujita, Y., and Y. Muramoto (1985), Studies on the process of development of alternate bars, Bulletin of the Disaster Prevention Research Institute, 35, 1 - 33.

García, M. H. (2008), Sedimentation engineering, Processes, Measurements, Modeling, and Practice. ASCE Manuals and Reports on Engineering Practice, 110, 1-1132.

Güneralp, I., J. D. Abad, G. Zolezzi, and J. Hooke (2012), Advances and challenges in meandering channels research, Geomorphology, 163-164(Supplement C), 1-9, doi: https://doi.org/10.1016/j.geomorph.2012.04.011, meandering Channels.

Hervouet, J., E. Razafindrakoto, and C. Villaret (2011), Dealing with dry zones in free surface flows: a new class of advection schemes, in Proceedings of the 34th World Congress of the International Association for Hydro-Environment Research and Engineering: 33rd Hydrology and Water Resources Symposium and 10th Conference on Hydraulics in Water Engineering, edited by A. Barton, pp. 4103-411, Australia.

Hirano, M. (1971), River bed degradation with armoring, Ph.D. thesis, Japanese Society of Civil Engineering.

Hoey, T. B., and R. Ferguson (1994), Numerical simulation of downstream fining by selective transport in gravel bed rivers: Model development and illustration, Water Resources Research, 30(7), 2251-2260.

Jaballah, M., B. Camenen, L. Pénard, and A. Paquier (2015), Alternate bar development in an alpine river following engineering works, Advances in Water Resources, 81, 103113, doi:http://dx.doi.org/10.1016/j.advwatres.2015.03.003, fluvial Eco-Hydraulics And Morphodynamics.

Juez, C., C. Ferrer-Boix, J. Murillo, M. Hassan, and P. García-Navarro (2016), A model based on Hirano-Exner equations for two-dimensional transient flows over heterogeneous erodible beds, Advances in Water Resources, 87, 1-18.

Koch, F., and C. Flokstra (1980), Bed Level Computations for Curved Alluvial Channels: Prepared for the 19th IAHR Congress, New Delhi, India, February 1981, Waterloopkundig Laboratorium.

Lanzoni, S. (2000a), Experiments on bar formation in a straight flume 1. Uniform sediment, Water Resources Research, 36(11), 3337-3349.

Lanzoni, S. (2000b), Experiments on bar formation in a straight flume: 2. Graded sediment, Water Resources Research, 36(11), 3351-3363.

Lanzoni, S., and M. Tubino (1999), Grain sorting and bar instability, Journal of Fluid Mechanics, 393, 149-174.

Lanzoni, S., A. Siviglia, A. Frascati, and G. Seminara (2006), Long waves in erodible channels and morphodynamic influence, Water Resources Research, 42(6), 1-15.

Le, T., A. Crosato, E. Mosselman, and W. Uijttewaal (2018a), On the stability of river bifurcations created by longitudinal training walls. Numerical investigation, Advances in Water Resources, 113, 112-125.

Le, T., A. Crosato, and W. Uijttewaal (2018b), Long-term morphological developments of river channels separated by a longitudinal training wall, Advances in Water Resources, $113,73-85$.

Lisle, T. E., and M. Madej (1992), Spatial variation in armouring in a channel with high sediment supply, Dynamics of Gravel-bed Rivers, 1, 277-296.

Lisle, T. E., H. Ikeda, and F. Iseya (1991), Formation of stationary alternate bars in a steep channel with mixed-size sediment: A flume experiment, Earth Surface Processes and Landforms, 16(5), 463-469.

Lisle, T. E., J. M. Nelson, J. Pitlick, M. A. Madej, and B. L. Barkett (2000), Variability of bed mobility in natural, gravel-bed channels and adjustments to sediment load at local and reach scales, Water Resources Research, 36, 3743-3755. 
Mendoza, A., J. D. Abad, E. J. Langendoen, D. Wang, P. Tassi, and K. E. K. Abderrezzak (2016), Effect of Sediment Transport Boundary Conditions on the Numerical Modeling of Bed Morphodynamics, Journal of Hydraulic Engineering, 143(4), .

Mosselman, E. (2012), Modelling Sediment Transport and Morphodynamics of GravelBed Rivers, Gravel-Bed Rivers: Processes, Tools, Environments, 1, 101-115.

Mosselman, E., A. Sieben, K. Sloff, and A. Wolters (1999), Effect of spatial grain size variations on two-dimensional river bed morphology, in Proceedings of River, Coastal and Estuarine Morphodynamics, Genova, vol. 1, pp. 499-507.

Nelson, P. A., R. R. McDonald, J. M. Nelson, and W. E. Dietrich (2015a), Coevolution of bed surface patchiness and channel morphology: 1 . Mechanisms of forced patch formation, Journal of Geophysical Research: Earth Surface, 120(9), 1687-1707.

Nelson, P. A., R. R. McDonald, J. M. Nelson, and W. E. Dietrich (2015b), Coevolution of bed surface patchiness and channel morphology: 2. Numerical experiments, Journal of Geophysical Research: Earth Surface, 120(9), 1708-1723.

Nezu, I., H. Nakagawa, and G. H. Jirka (1994), Turbulence in open-channel flows, Journal of Hydraulic Engineering, 120(10), 1235-1237.

Nikuradse, J. (1950), Laws of flow in rough pipes, NACA.

Orrú, C., A. Blom, and W. S. Uijttewaal (2016), Armor breakup and reformation in a degradational laboratory experiment, Earth Surface Dynamics, 4(2), 461.

Parker, G. (1990), Surface-based bedload transport relation for gravel rivers, Journal of hydraulic research, 28(4), 417-436.

Parker, G., and H. Johannesson (1989), Observations on several recent theories of resonance and overdeepening in meandering channels, River meandering, 12, 379-415.

Parker, G., M. Hassan, and P. Wilcock (2007), Adjustment of the bed surface size distribution of gravel-bed rivers in response to cycled hydrographs, Developments in Earth Surface Processes, 11, 241-285.

Powell, D. M. (1998), Patterns and processes of sediment sorting in gravel-bed rivers, Progress in Physical Geography, 22(1), 1-32.

Powell, D. M., A. Ockelford, S. P. Rice, J. K. Hillier, T. Nguyen, I. Reid, N. J. Tate, and D. Ackerley (2016), Structural properties of mobile armors formed at different flow strengths in gravel-bed rivers, Journal of Geophysical Research: Earth Surface, 121(8), 1494-1515, doi:10.1002/2015JF003794, 2015JF003794.

Proffitt, G., and A. Sutherland (1983), Transport of non-uniform sediments, Journal of Hydraulic Research, 21(1), 33-43.

Qian, H., Z. Cao, H. Liu, and G. Pender (2016), Numerical modelling of alternate bar formation, development and sediment sorting in straight channels, Earth Surface Processes and Landforms, 607, 613-622, doi:10.1002/esp.3988, eSP-15-0409.R2.

Recking, A., G. Piton, D. Vazquez-Tarrio, and G. Parker (2015), Quantifying the Morphological Print of Bedload Transport, Earth Surface Processes and Landforms, 41(6), 809-822.

Rodrigues, S., N. Claude, P. Juge, and J.-G. Breheret (2012), An opportunity to connect the morphodynamics of alternate bars with their sedimentary products, Earth Surface Processes and Landforms, 37(2), 240-248, doi:10.1002/esp.2255.

Rodrigues, S., E. Mosselman, N. Claude, C. L. Wintenberger, and P. Juge (2015), Alternate bars in a sandy gravel bed river: generation, migration and interactions with superimposed dunes, Earth Surface Processes and Landforms, 40(5), 610-628.

Scorpio, V., S. Zen, W. Bertoldi, N. Surian, M. Mastronunzio, E. Dai Prá, G. Zolezzi, and F. Comiti (2018), Channelization of a large Alpine river: what is left of its original morphodynamics?, Earth Surface Processes and Landforms, 43(5), 1044-1062, doi: 10.1002/esp.4303.

Seal, R., C. Paola, G. Parker, J. B. Southard, and P. R. Wilcock (1997), Experiments on downstream fining of gravel: I. Narrow-channel runs, Journal of Hydraulic Engineering, 123(10), 874-884. 
Seminara, G., and M. Tubino (1989), Alternate bars and meandering: free, forced and mixed interactions, River meandering, 12, 267-320.

Singh, U., A. Crosato, S. Giri, and M. Hicks (2017), Sediment heterogeneity and mobility in the morphodynamic modelling of gravel-bed braided rivers, Advances in Water Resources, 104, 127-144.

Siviglia, A., and A. Crosato (2016), Numerical modelling of river morphodynamics: latest developments and remaining challenges, Advances in Water Resources, 90, 1-9.

Siviglia, A., G. Stecca, D. Vanzo, G. Zolezzi, E. F. Toro, and M. Tubino (2013), Numerical modelling of two-dimensional morphodynamics with applications to river bars and bifurcations, Advances in Water Resources, 52, 243-260, doi: http://dx.doi.org/10.1016/j.advwatres.2012.11.010.

Soulsby, R. (1997), Dynamics of marine sands: a manual for practical applications, Thomas Telford.

Stecca, G., A. Siviglia, and A. Blom (2016), An accurate numerical solution to the SaintVenant-Hirano model for mixed-sediment morphodynamics in rivers, Advances in Water Resources, 93, 39-61.

Struiksma, N., and A. Crosato (1989), Analysis of a 2-D Bed Topography Model for Rivers, 153-180 pp., Wiley Online Library.

Takebayashi, H., and S. Egashira (2001), Dynamic state of sand bar formed on nonuniform sediment bed, Proceedings of Hydraulic Engineering, 45, 727-732.

Talmon, A., N. Struiksma, and M. Van Mierlo (1995), Laboratory measurements of the direction of sediment transport on transverse alluvial-bed slopes, Journal of Hydraulic Research, 33(4), 495-517.

Tonina, D., and J. M. Buffington (2007), Hyporheic exchange in gravel bed rivers with pool-riffle morphology: Laboratory experiments and three-dimensional modeling, Water Resources Research, 43(1), 1-16.

Toro-Escobar, C. M., C. Paola, G. Parker, P. R. Wilcock, and J. B. Southard (2000), Experiments on downstream fining of gravel. II: Wide and sandy runs, Journal of Hydraulic Engineering, 126(3), 198-208.

Tritthart, M., M. Liedermann, B. Schober, and H. Habersack (2011a), Non-uniformity and layering in sediment transport modelling 2: river application, Journal of Hydraulic Research, 49(3), 335-344.

Tritthart, M., B. Schober, and H. Habersack (2011b), Non-uniformity and layering in sediment transport modelling 1: flume simulations, Journal of Hydraulic research, 49(3), 325-334.

Tubino, M., R. Repetto, and G. Zolezzi (1999), Free bars in rivers, Journal of Hydraulic Research, 37(6), 759-775.

Van der Meer, C., E. Mosselman, C. Sloff, B. Jagers, G. Zolezzi, and M. Tubino (2011), Numerical simulations of upstream and downstream overdeepening, in RCEM 2011: Proceedings of the 7th IAHR Symposium of River, Coastal and Estuarine Morphodynamics, Beijing, China, 6-8 September 2011, Citeseer.

Vanzo, D., A. Siviglia, G. Zolezzi, G. Stecca, and M. Tubino (2011), Interaction between steady and migrating bars in straight channels, in RCEM 2011.

Viparelli, E., A. Blom, and R. R. H. Moreira (2017), Modeling Stratigraphy-Based GravelBed River Morphodynamics, chap. Modeling Stratigraphy-Based Gravel-Bed River Morphodynamics, pp. 609-637, John Wiley \& Sons, Ltd, doi:10.1002/9781118971437.ch23.

Vreugdenhil, C. B. (2013), Numerical methods for shallow-water flow, vol. 13, Springer Science \& Business Media.

Weiyan, T. (1992), Shallow Water Hydrodynamics: Mathematical Theory and Numerical Solution for a Two-dimensional System of Shallow Water Equations, no. vol. 55 in Elsevier oceanography series, Water \& Power Press.

Wilcock, P. R., and J. C. Crowe (2003), Surface-based transport model for mixed-size sediment, Journal of Hydraulic Engineering, 129(2), 120-128. 
Wintenberger, C. L., S. Rodrigues, J.-G. Bréhéret, and M. Villar (2015), Fluvial islands: First stage of development from nonmigrating (forced) bars and woody-vegetation interactions, Geomorphology, 246, 305-320.

$\mathrm{Wu}, \mathrm{W}$. (2004), Depth-averaged two-dimensional numerical modeling of unsteady flow and nonuniform sediment transport in open channels, Journal of hydraulic engineering, 130(10), 1013-1024.

Zolezzi, G., and G. Seminara (2001), Downstream and upstream influence in river meandering. Part 1. General theory and application to overdeepening, Journal of Fluid Mechanics, 438, 183-211. 
Figure 1.
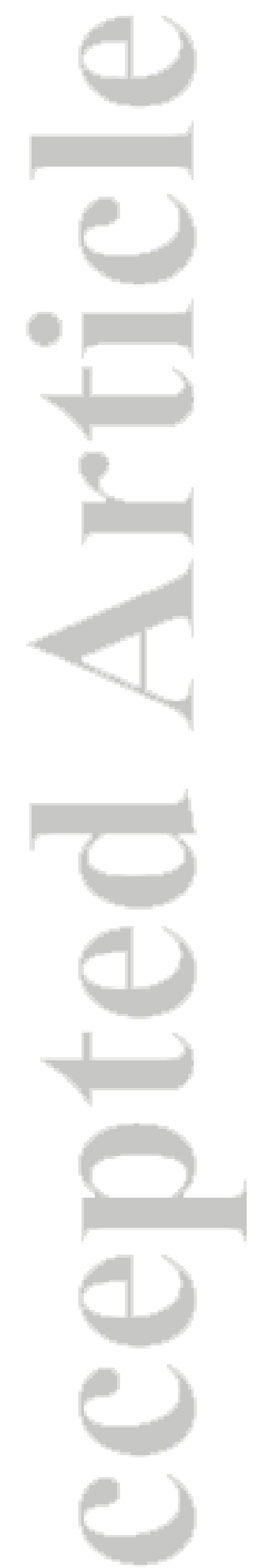

(C)2018 American Geophysical Union. All rights reserved. 


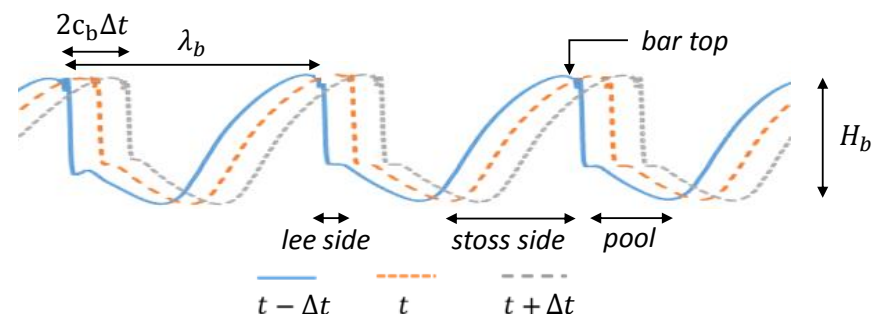


Figure 2.
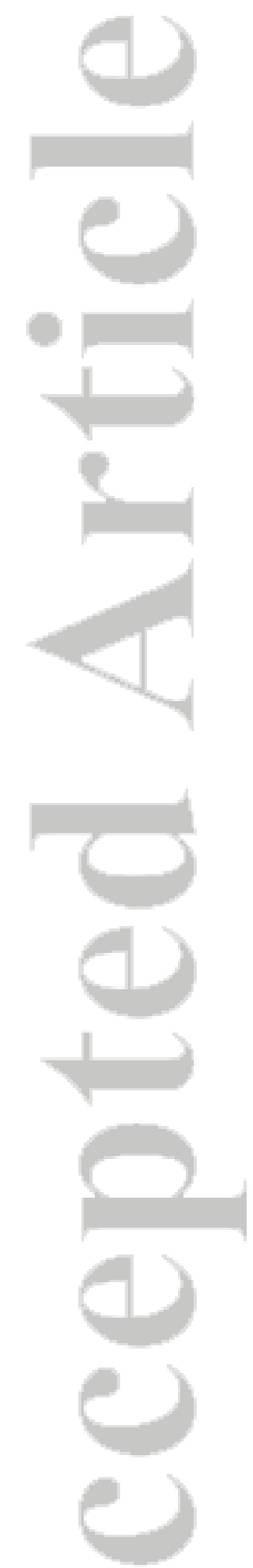

(C)2018 American Geophysical Union. All rights reserved. 
a)

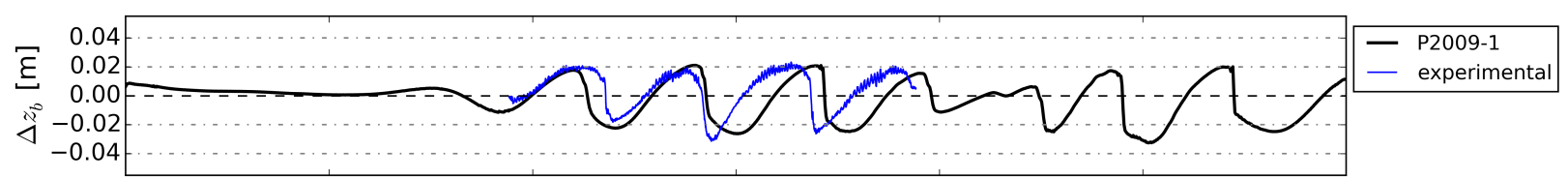

b)

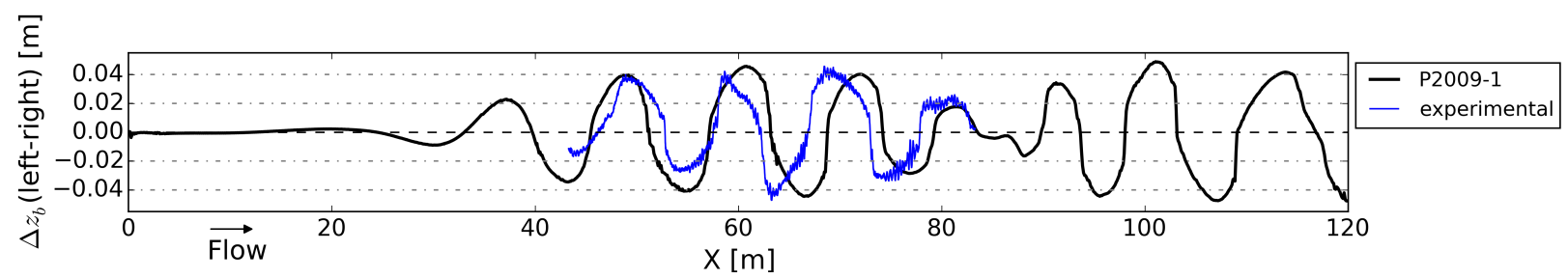


Figure 3.
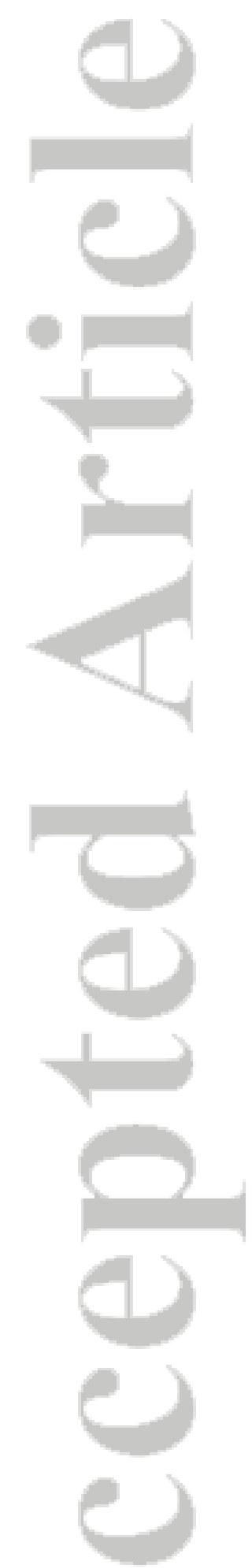

(C)2018 American Geophysical Union. All rights reserved. 
a) Reference scenario (run P2009-1)

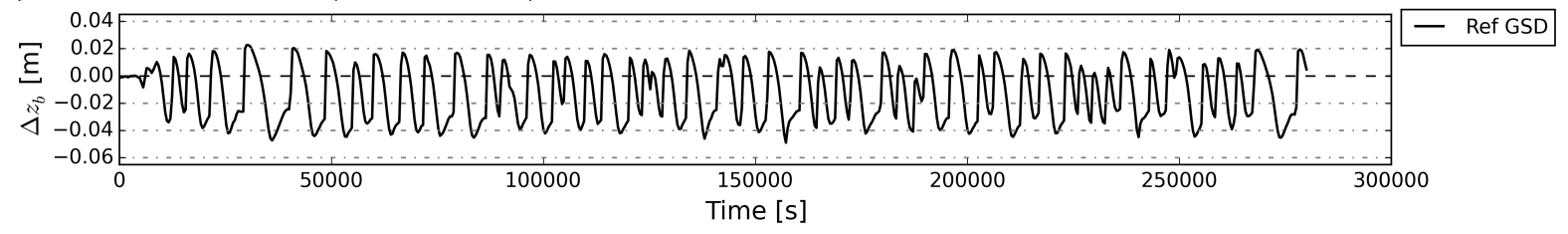

b) Influence of sediment size heterogeneity; without obstacle (runs P2009-1, -5 and -6)

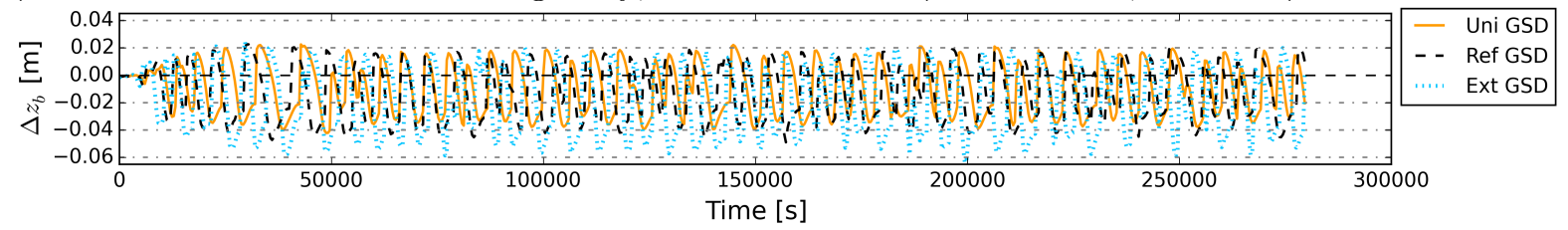

c) Influence of sediment size heterogeneity; with obstacle (runs P2009-3, -8 and -9)

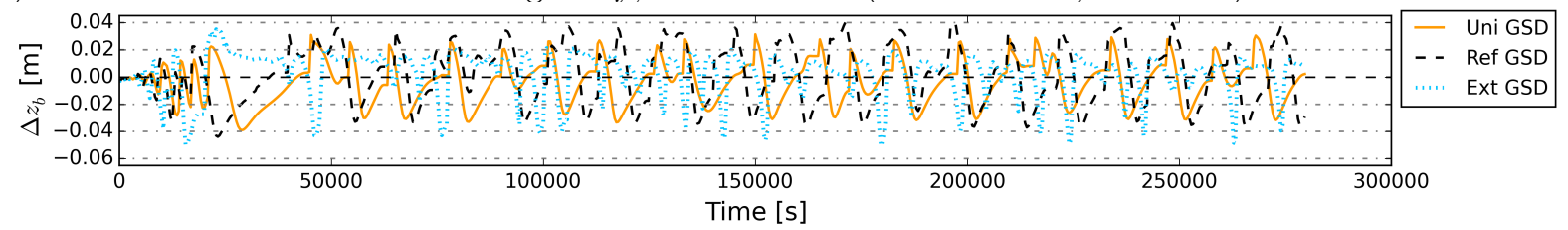

d) Influence of sediment sorting; Ref GSD; without obstacle (runs P2009-1 and -2)

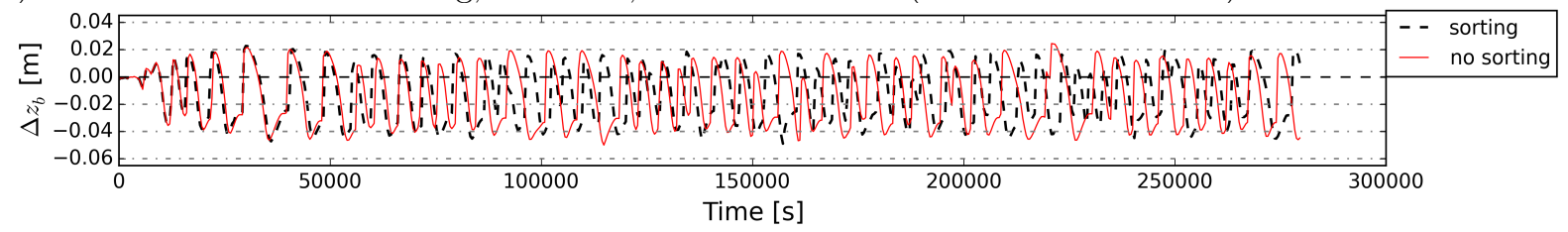

e) Influence of sediment sorting; Ext GSD; without obstacle (runs P2009-6 and -7)

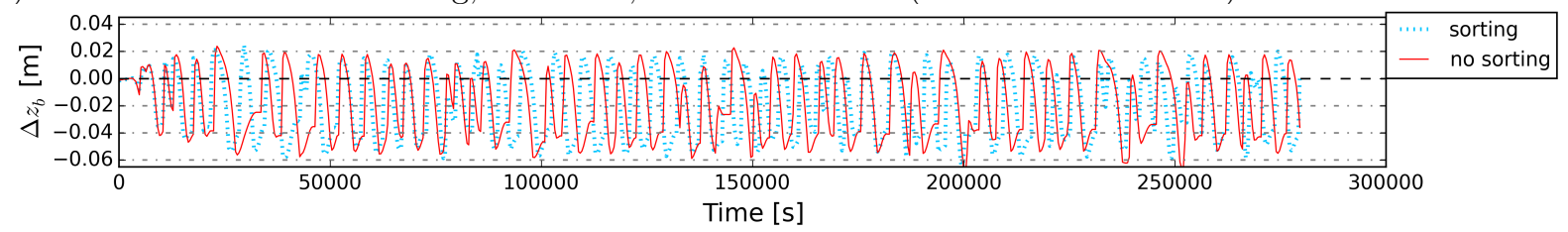

f) Influence of sediment sorting; Ref GSD; with obstacle (runs P2009-3 and -4)

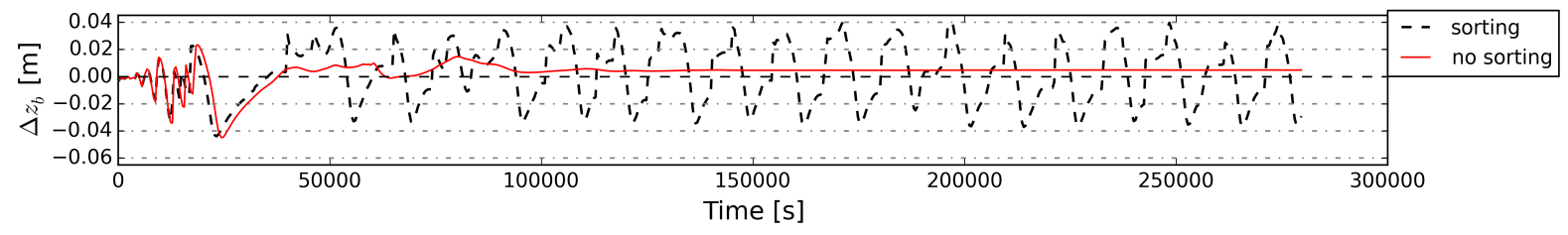


Figure 4.
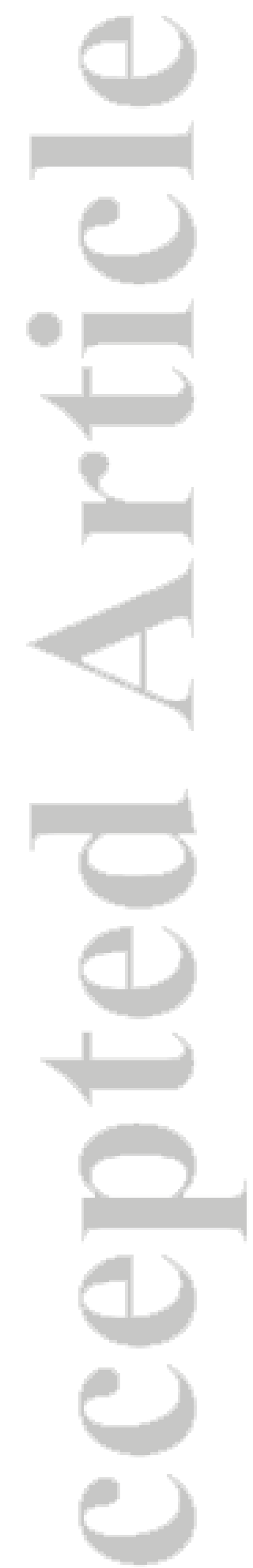

(C)2018 American Geophysical Union. All rights reserved. 


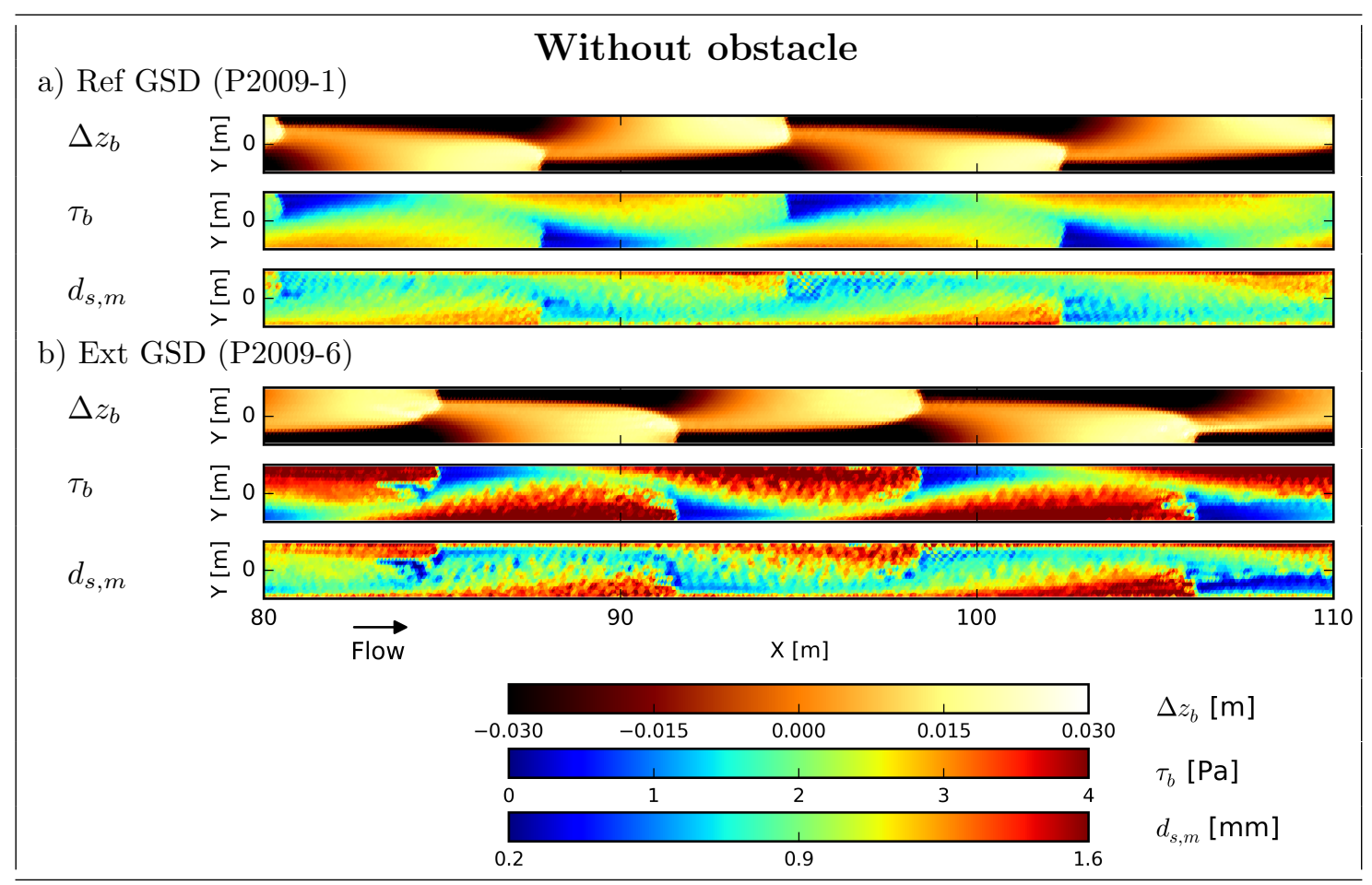




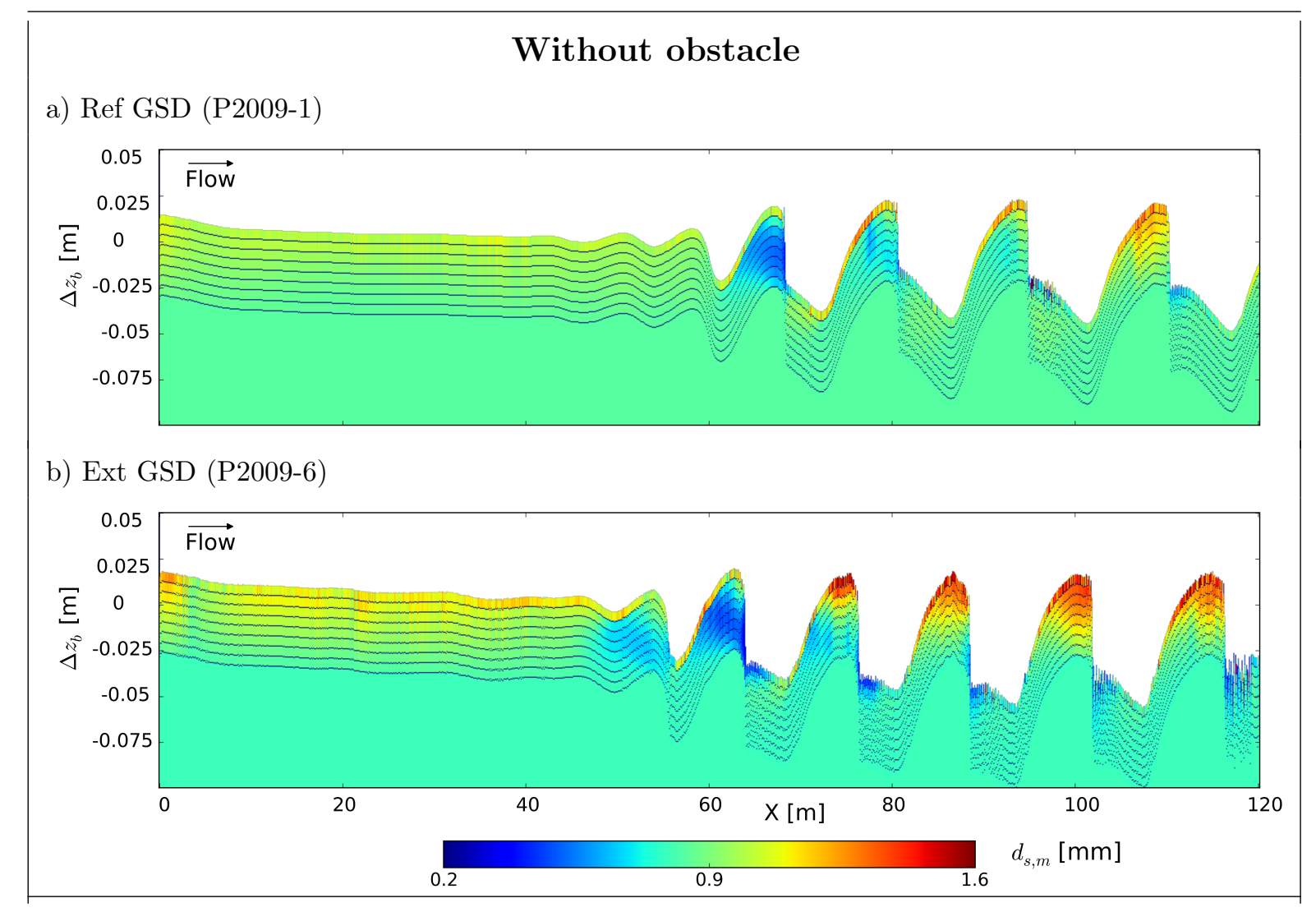


Figure 6.
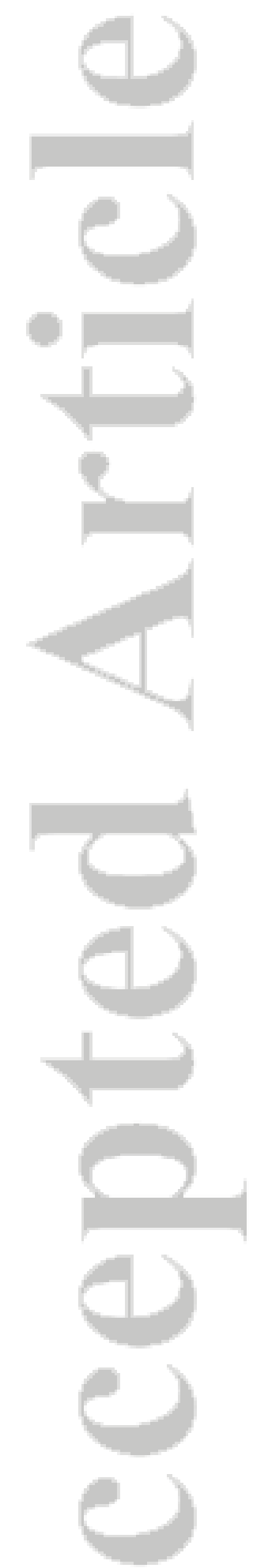

(C)2018 American Geophysical Union. All rights reserved. 


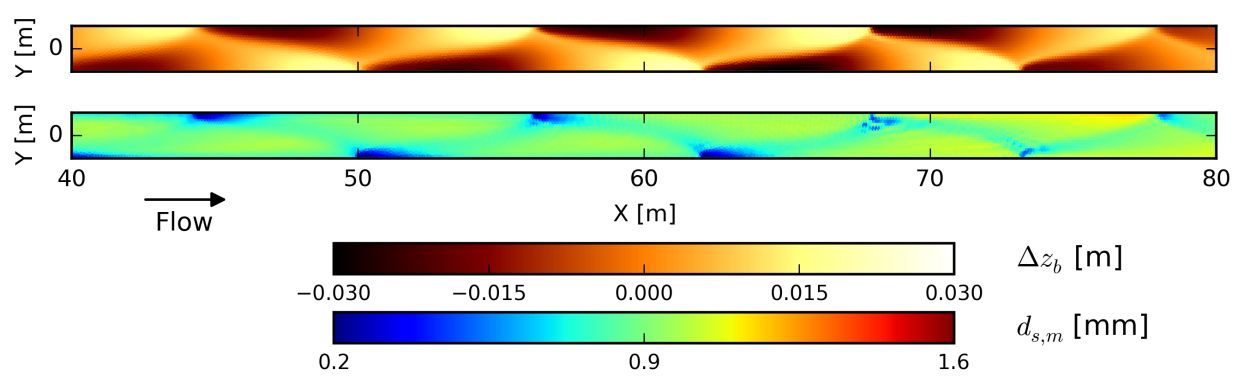

C2018 American Geophysical Union. All rights reserved. 
(a) Ref GSD

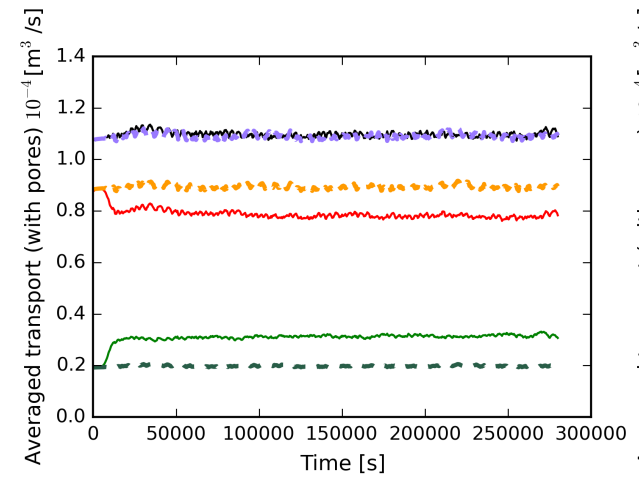

(b) Ext GSD

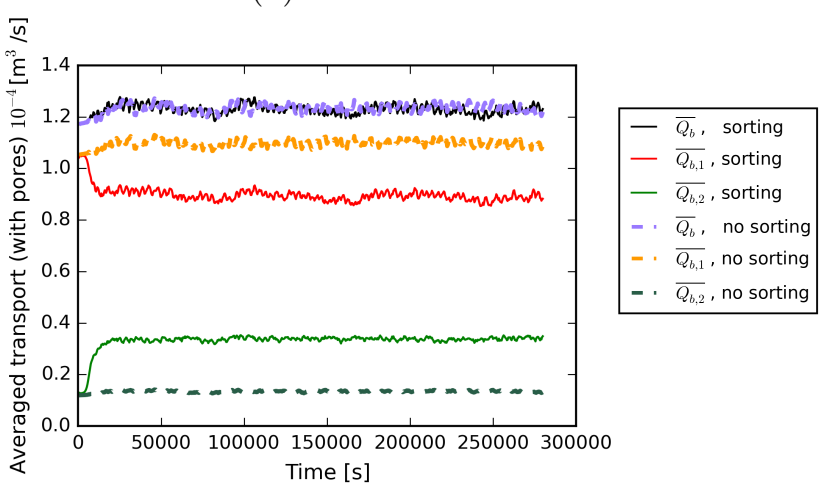


Figure 8.
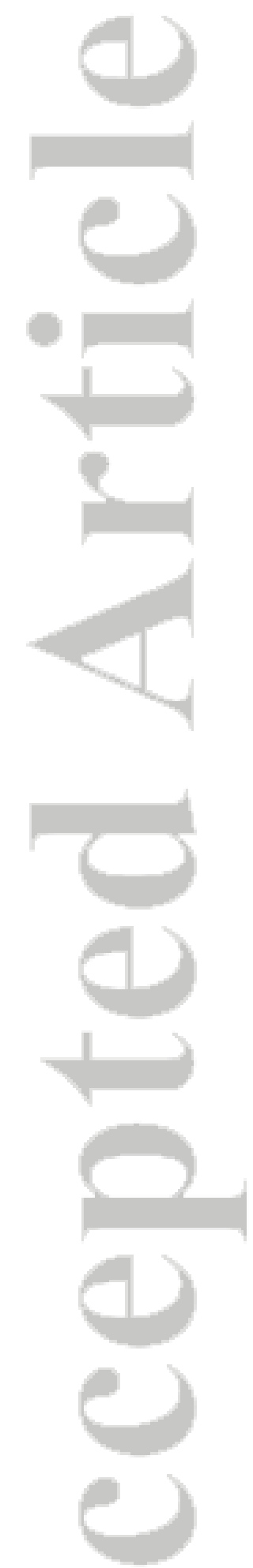

(C)2018 American Geophysical Union. All rights reserved. 


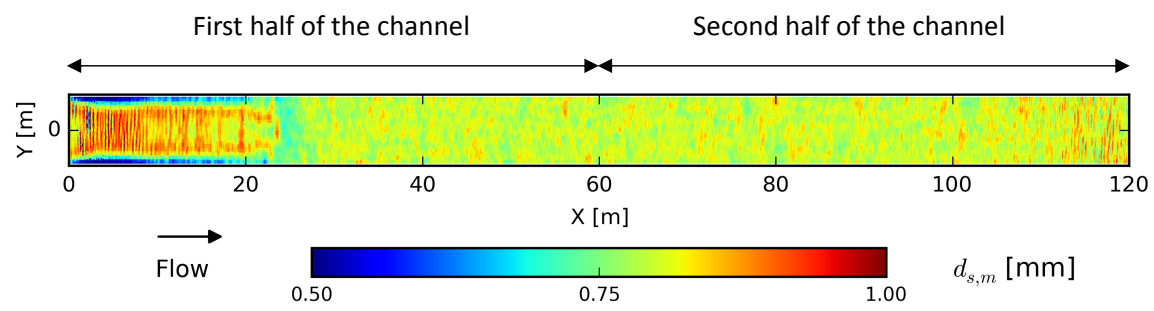

(C)2018 American Geophysical Union. All rights reserved. 
Figure 9.
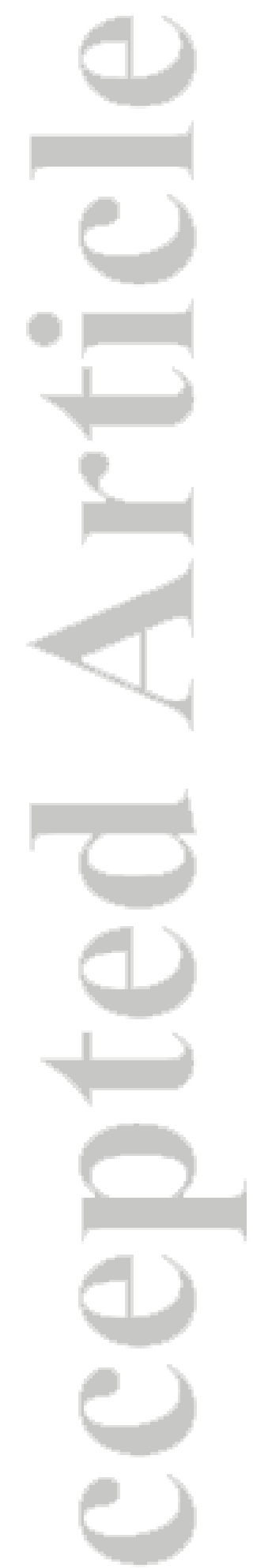

(C)2018 American Geophysical Union. All rights reserved. 
(a) first half of the channel

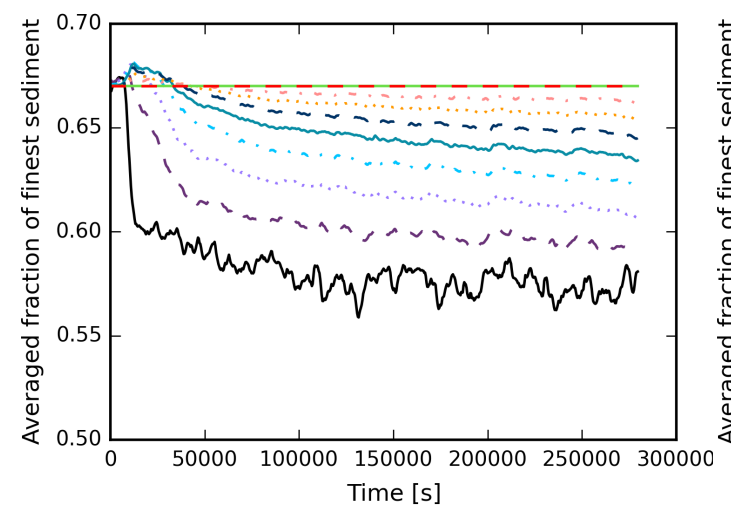

(b) second half of the channel

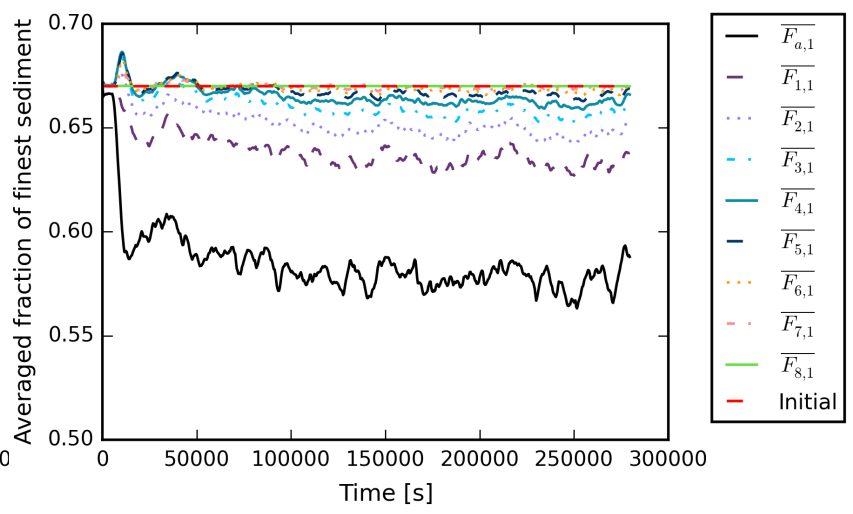


Figure 10.
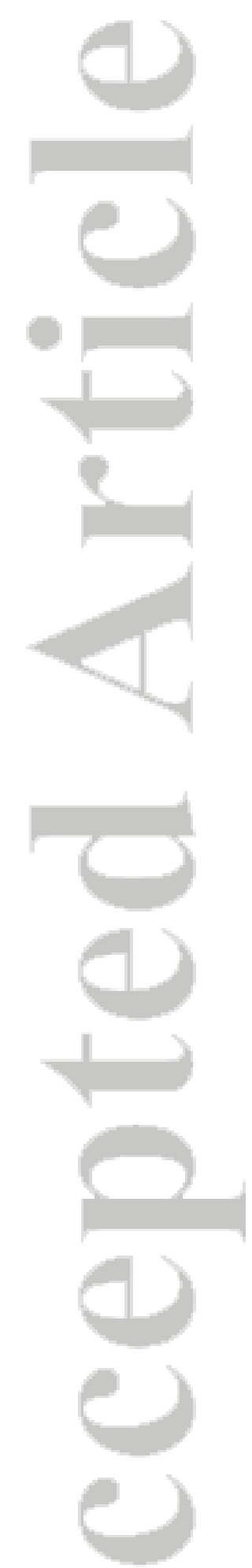

(C)2018 American Geophysical Union. All rights reserved. 
a) Without obstacle with sorting

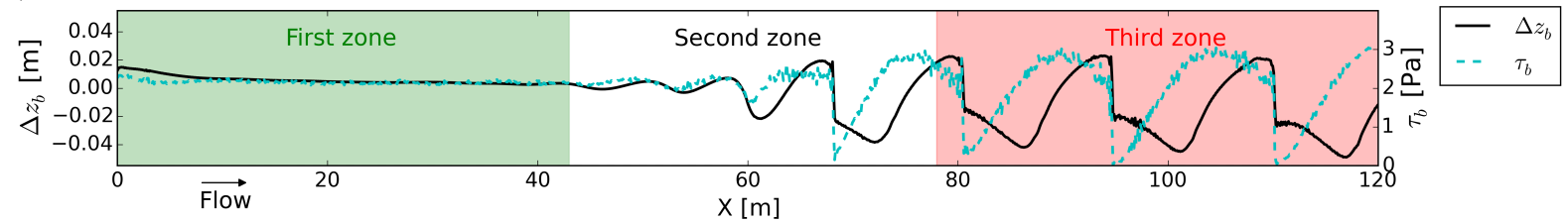

b) With obstacle with sorting

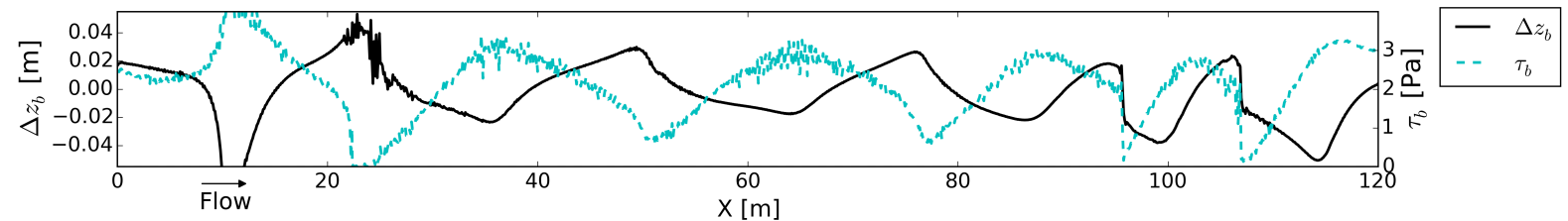

c) With obstacle without sorting

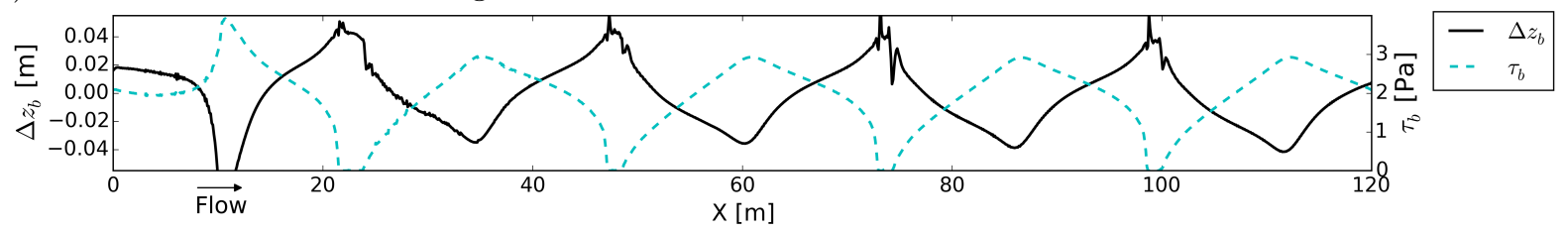


Figure 11.
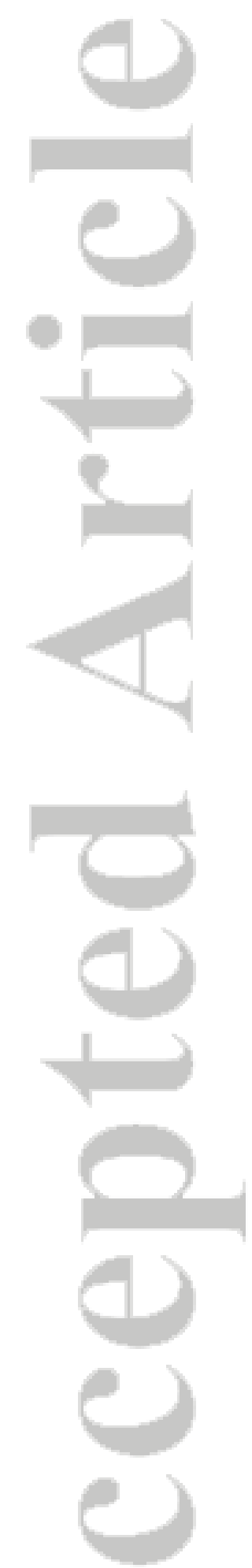

(C)2018 American Geophysical Union. All rights reserved. 
a) Without obstacle with sorting

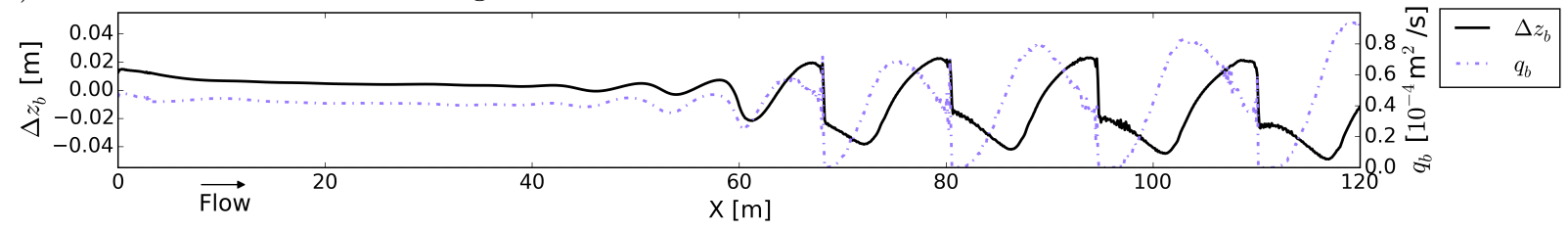

b) With obstacle with sorting

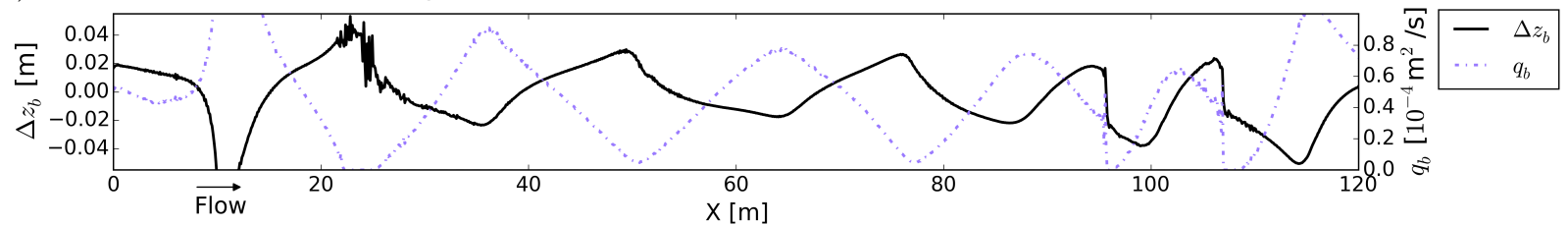

c) With obstacle without sorting

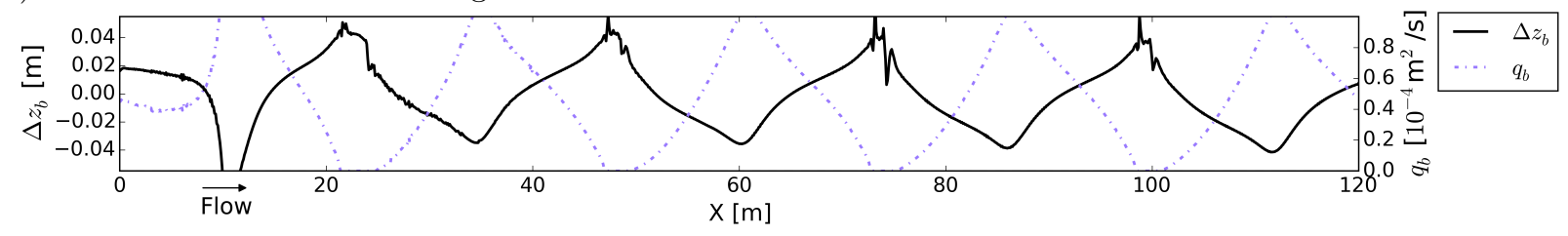


Figure 12.
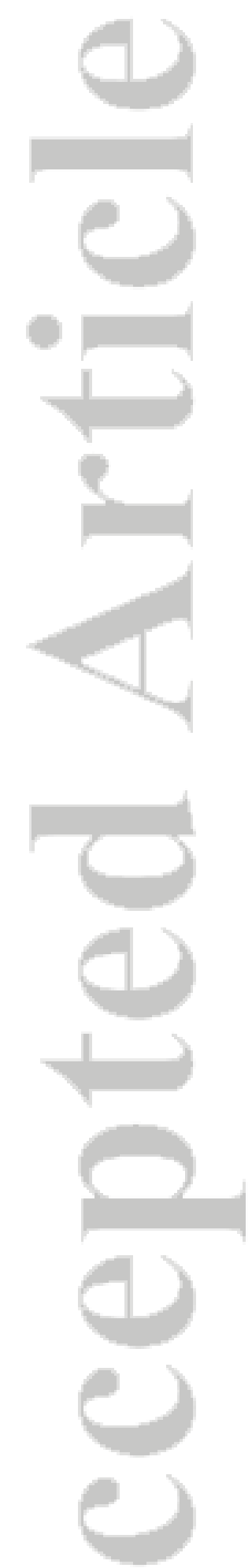

(C)2018 American Geophysical Union. All rights reserved. 


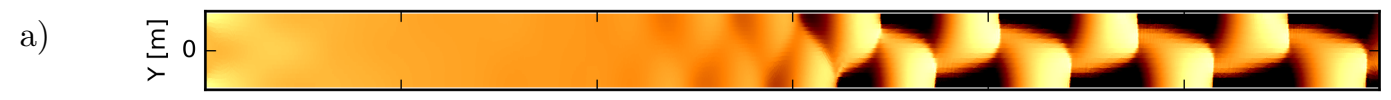

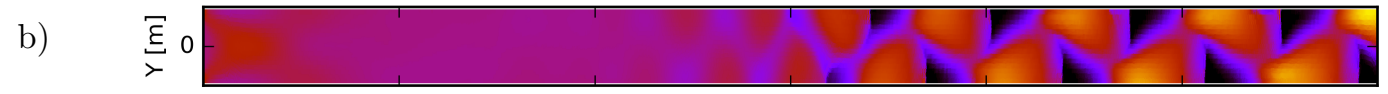

c)
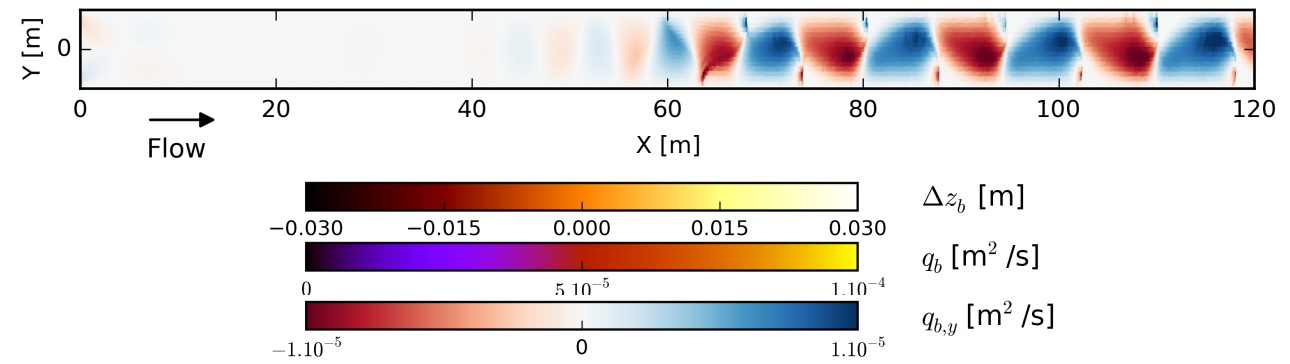
Figure 13.
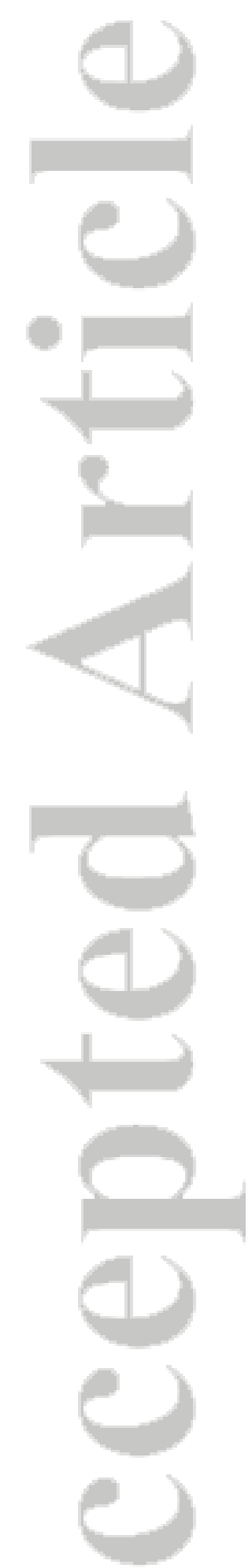

(C)2018 American Geophysical Union. All rights reserved. 
a) With sorting

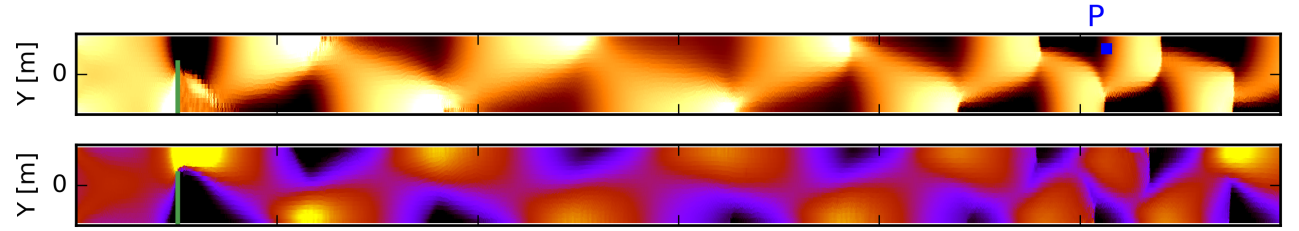

b) Without sorting
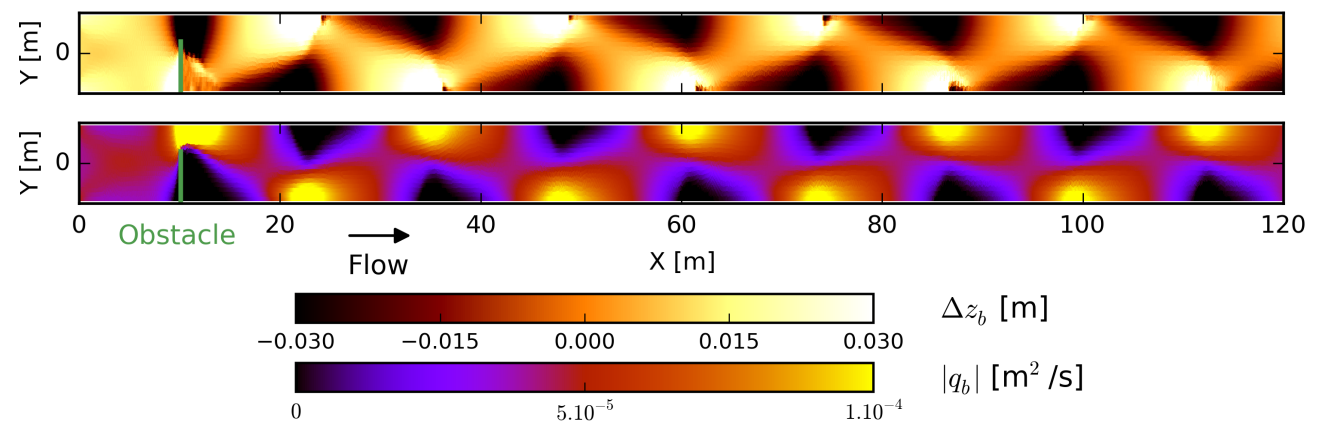
Figure 14.
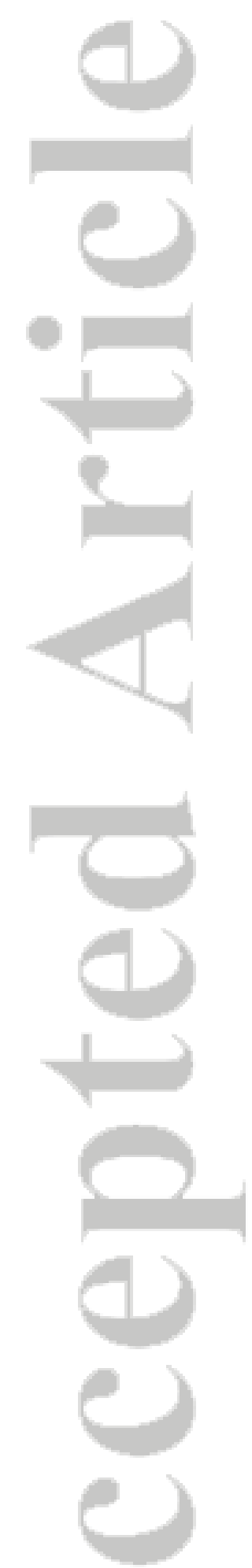

(C)2018 American Geophysical Union. All rights reserved. 


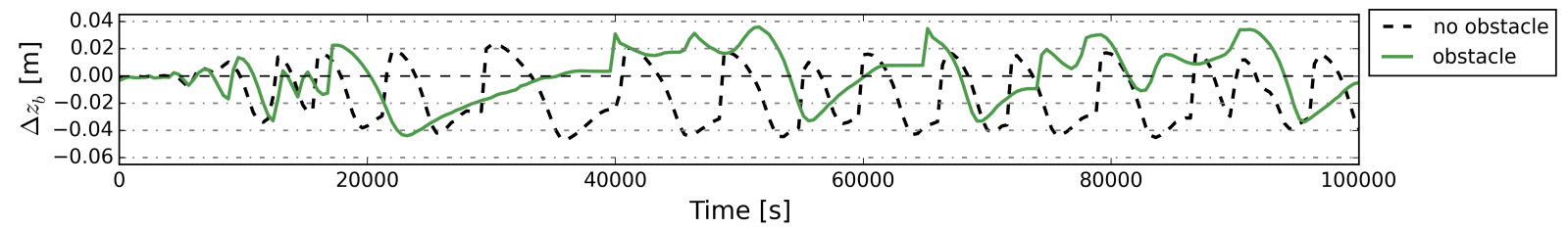


Figure 15.
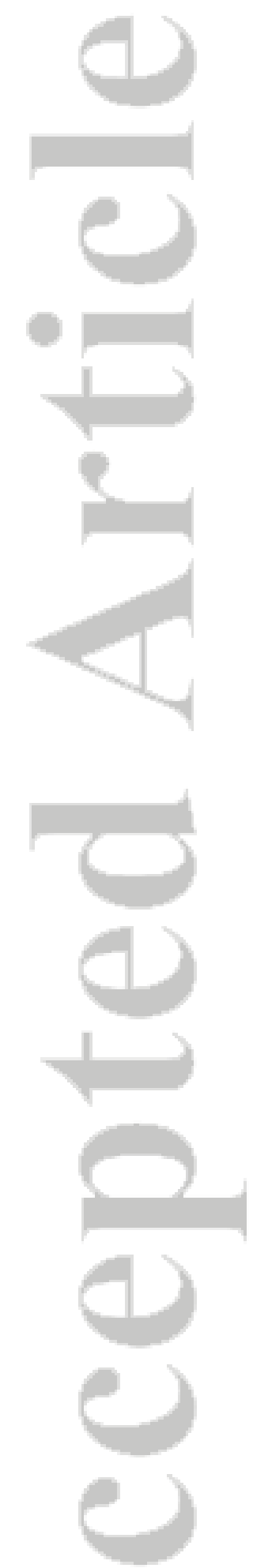

(C)2018 American Geophysical Union. All rights reserved. 


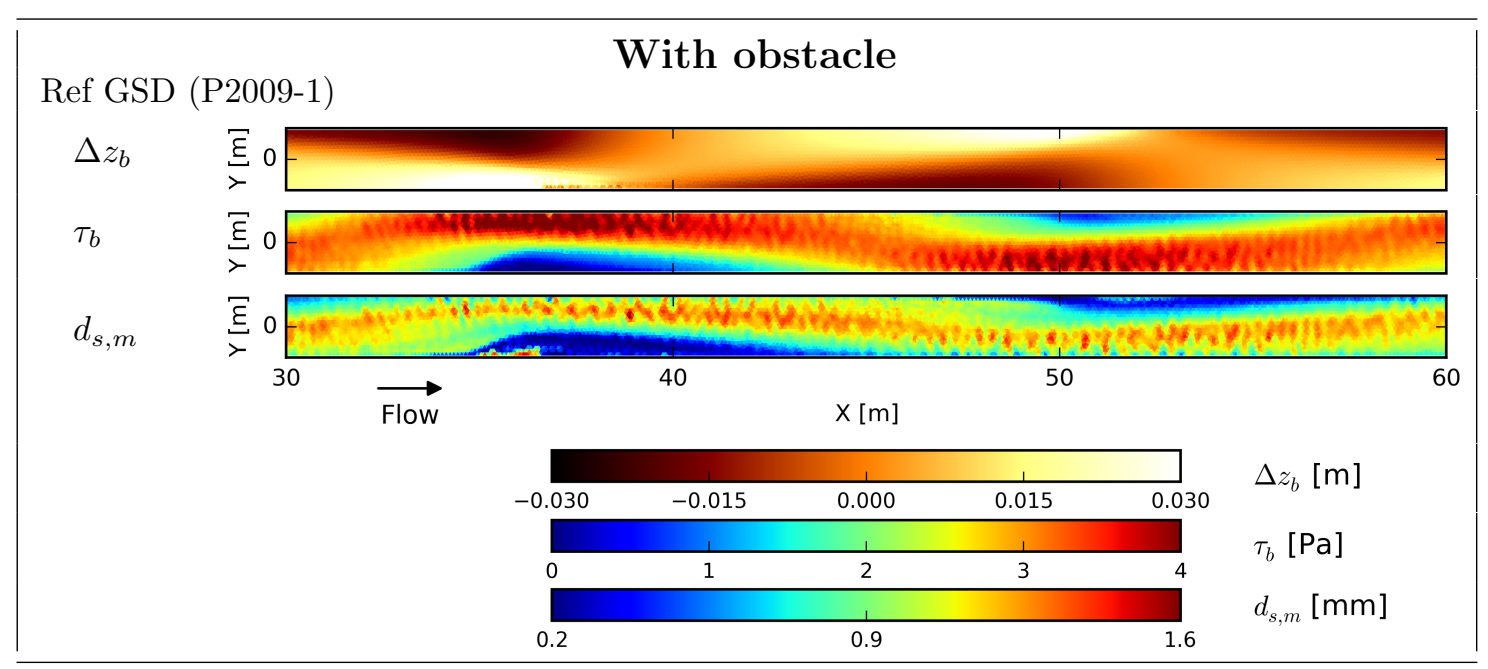


Figure 16.
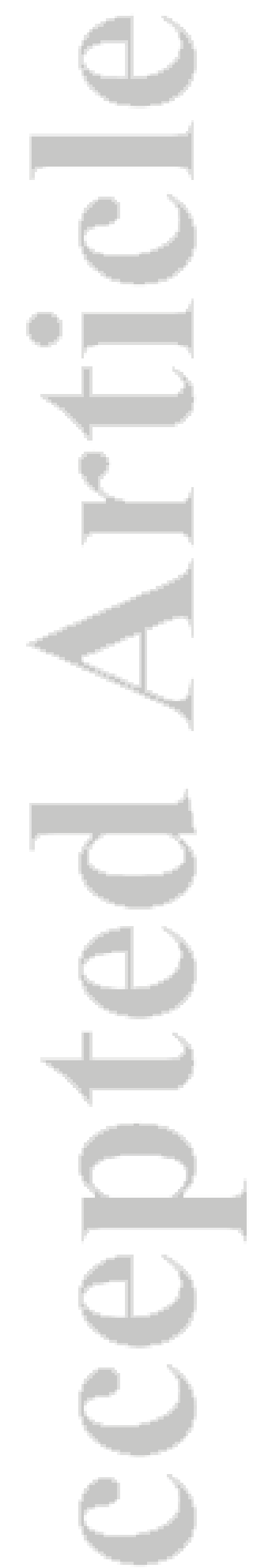

(C)2018 American Geophysical Union. All rights reserved. 


\section{With obstacle}

a) Ref GSD (P2009-3)

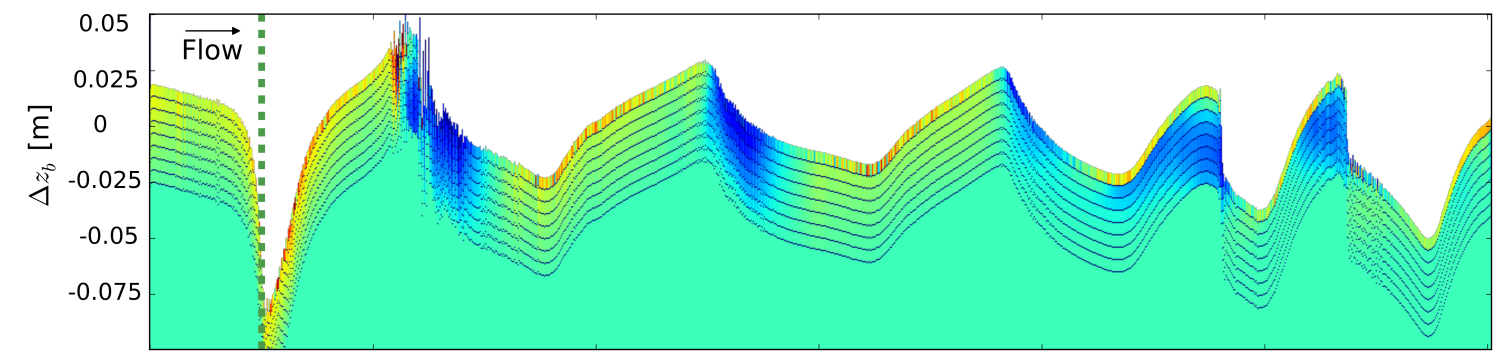

b) Ext GSD (P2009-9)

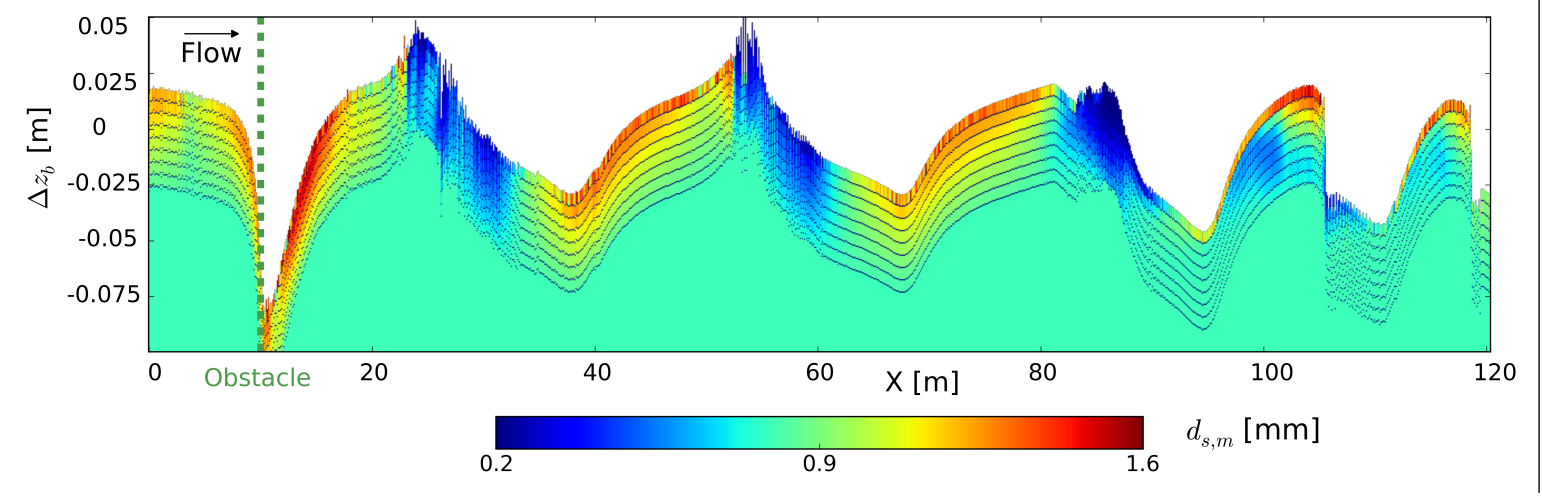


Figure 17.
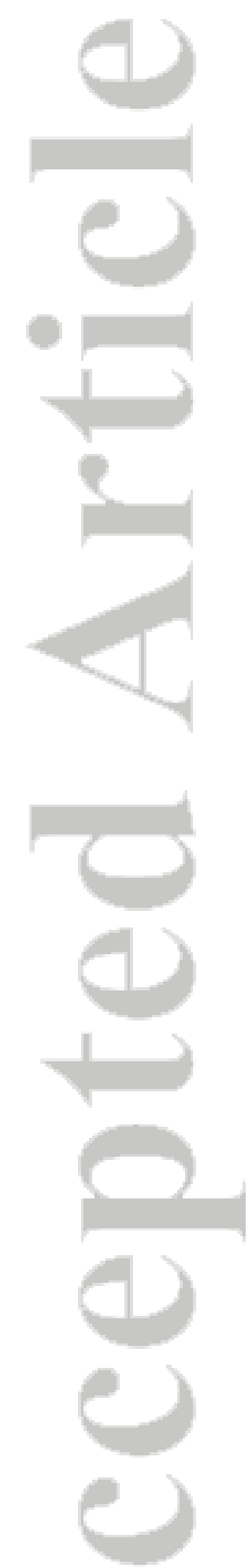

(C)2018 American Geophysical Union. All rights reserved. 
a) Free bars

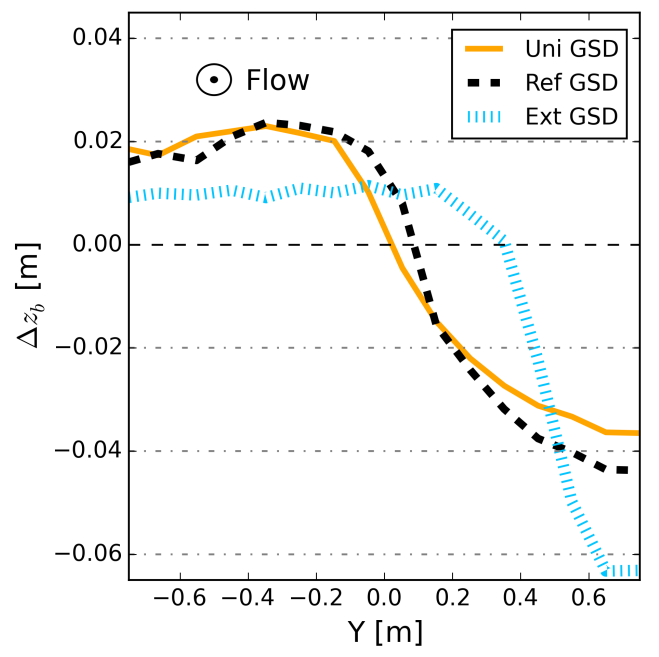

b) Hybrid bars

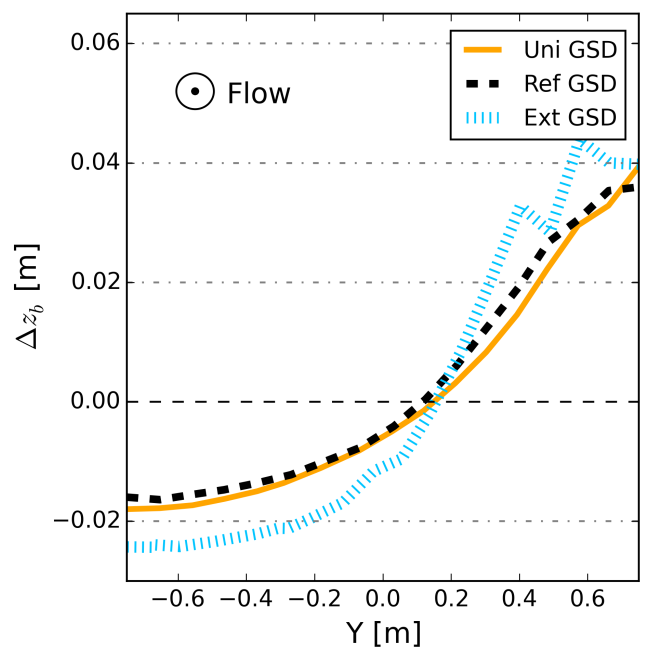


Figure 18.
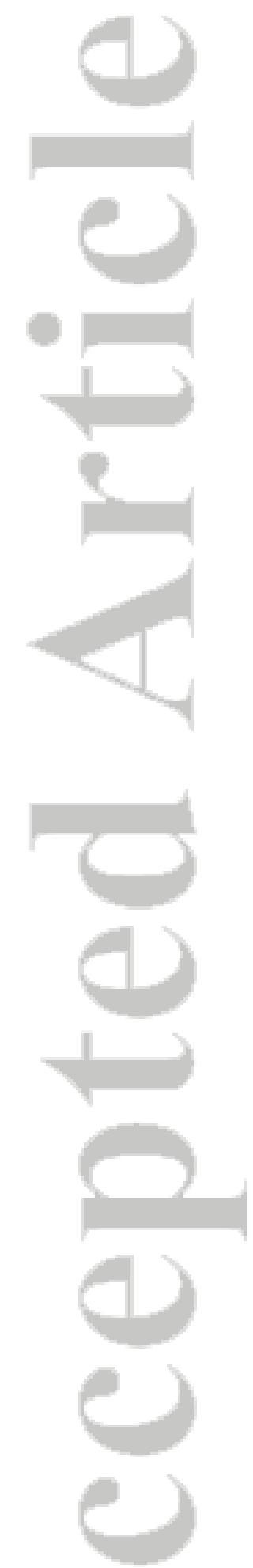

(C)2018 American Geophysical Union. All rights reserved. 


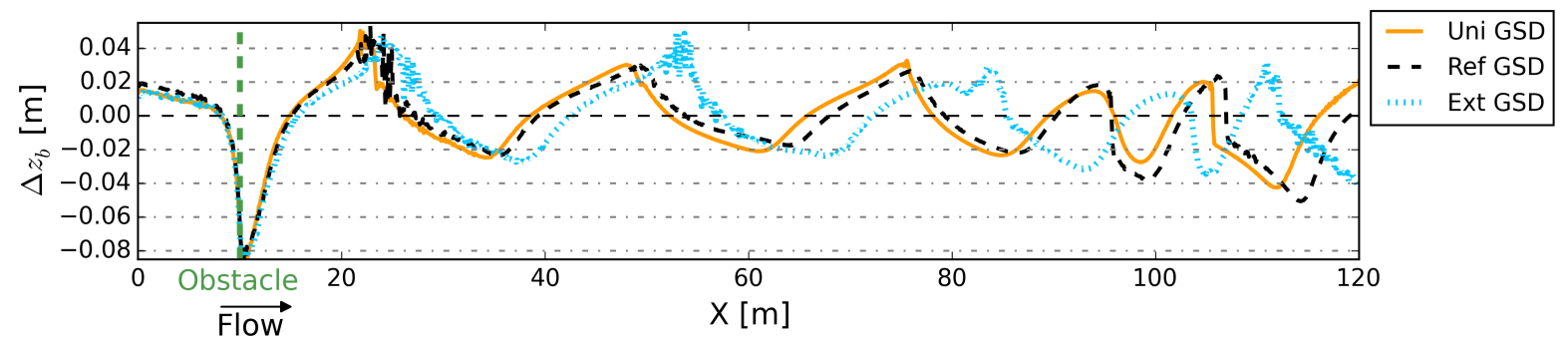


Figure 19.
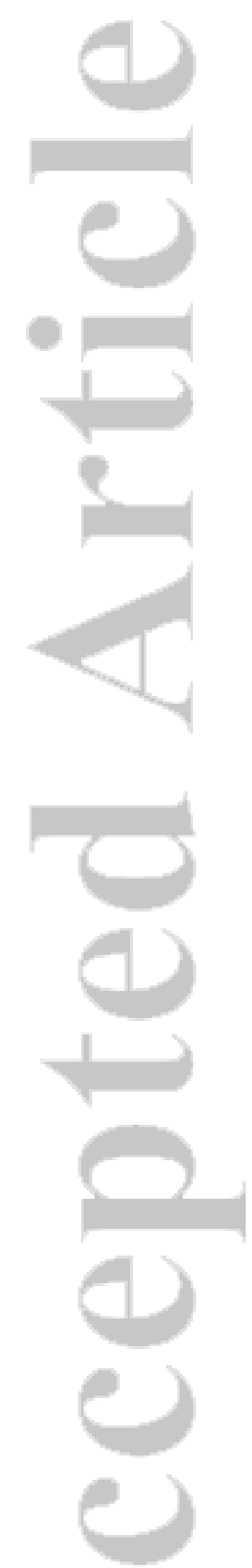

(C)2018 American Geophysical Union. All rights reserved. 


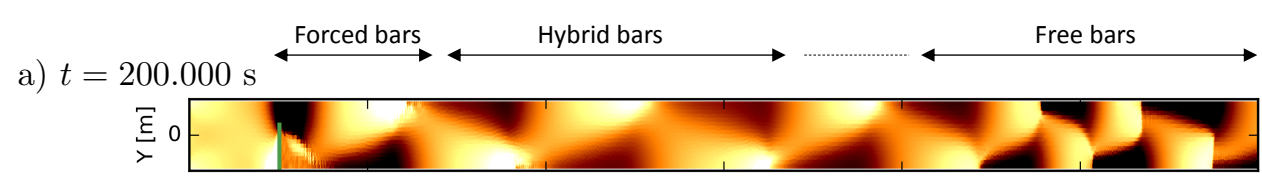

b) $t=202.800 \mathrm{~s}$

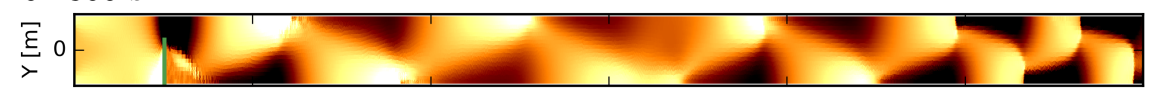

c) $t=205.600 \mathrm{~s}$

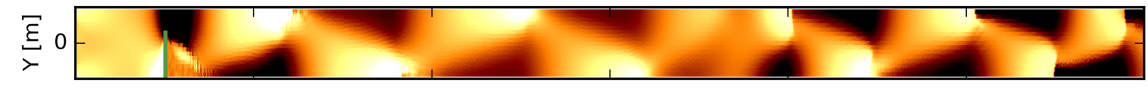

d) $t=208.000 \mathrm{~s}$

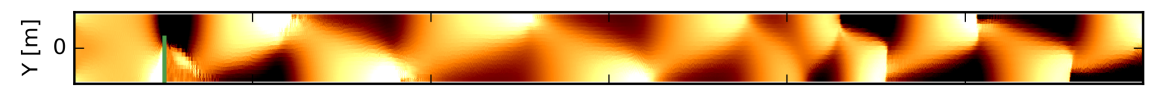

e) $t=213.200 \mathrm{~s}$

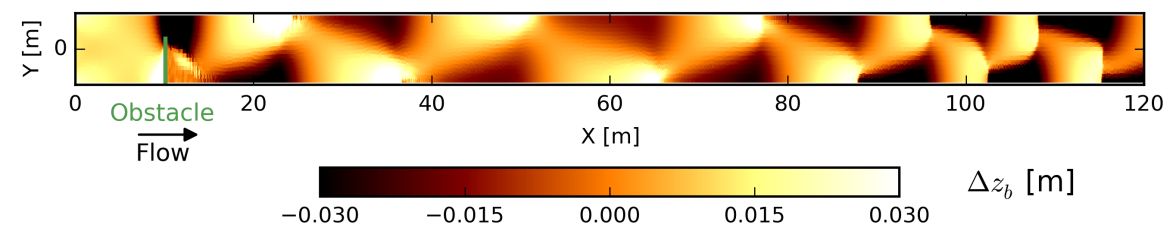


Figure 20.
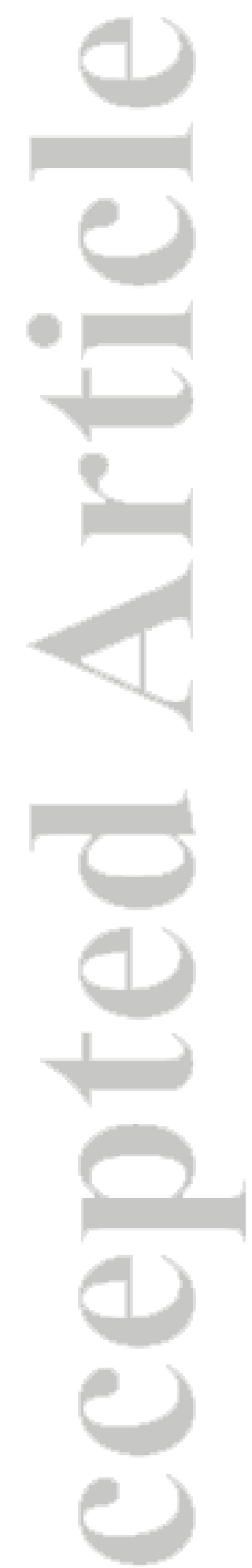

(C)2018 American Geophysical Union. All rights reserved. 


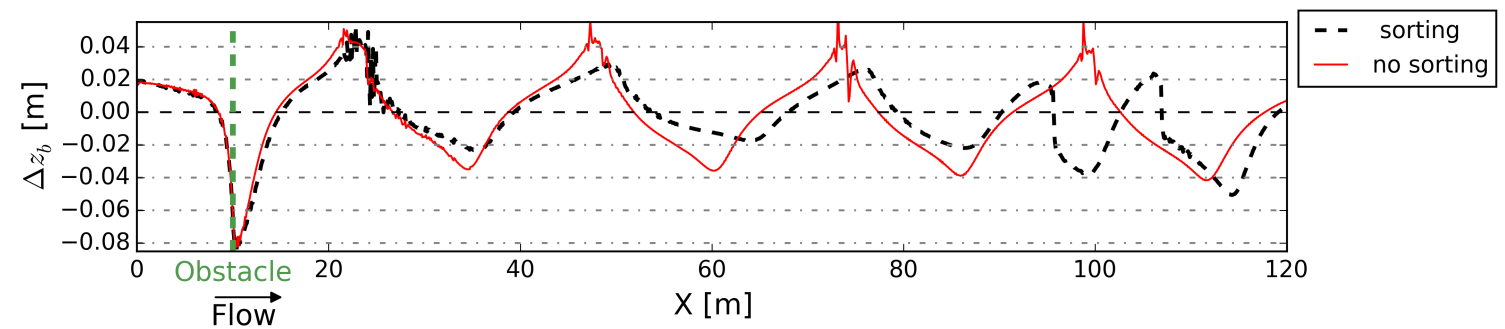




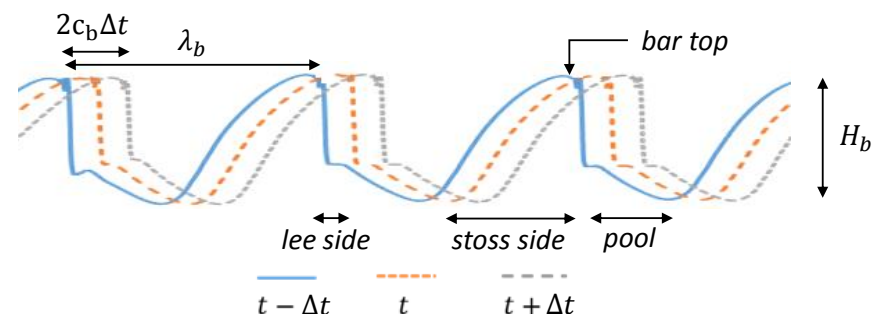


a)

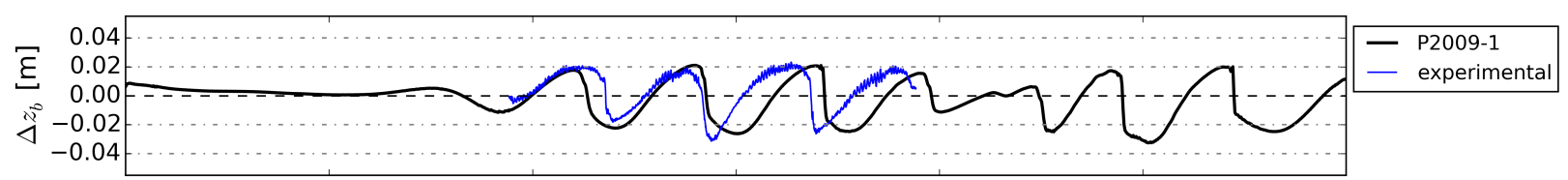

b)

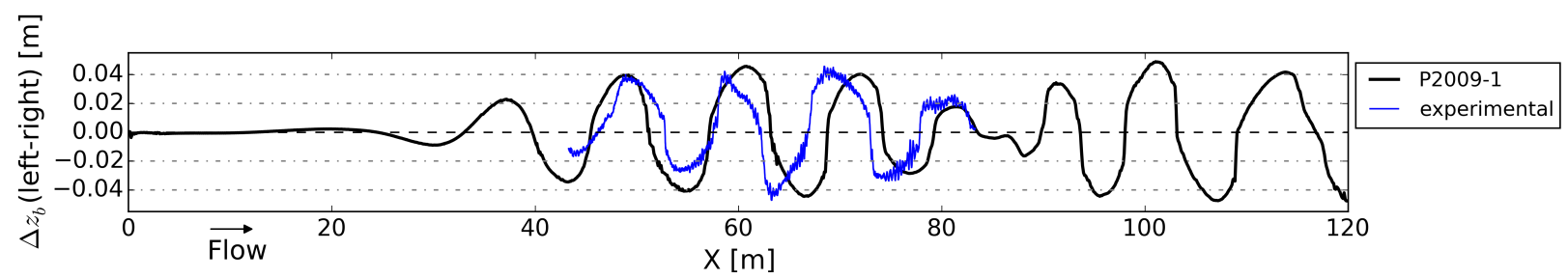


a) Reference scenario (run P2009-1)

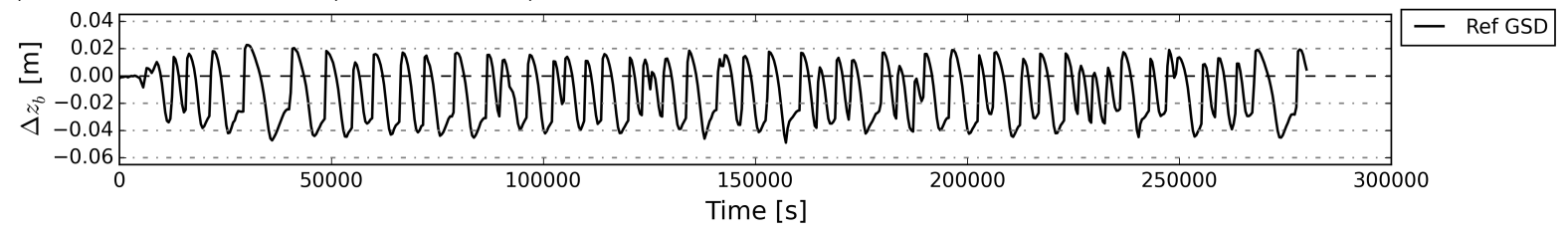

b) Influence of sediment size heterogeneity; without obstacle (runs P2009-1, -5 and -6)

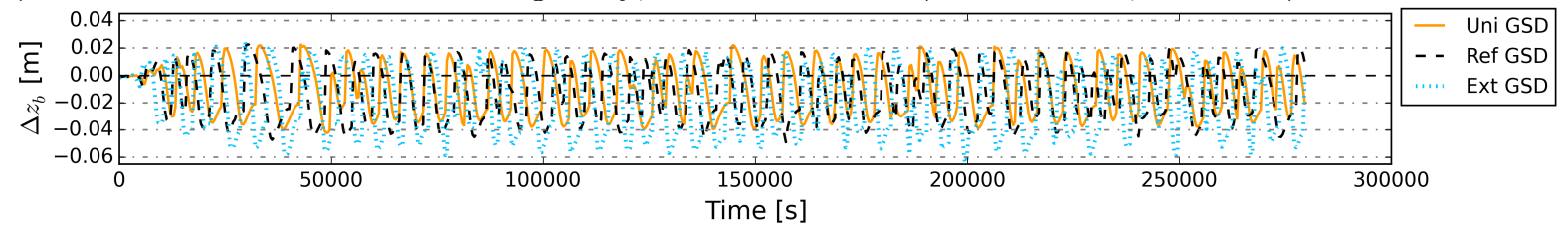

c) Influence of sediment size heterogeneity; with obstacle (runs P2009-3, -8 and -9)

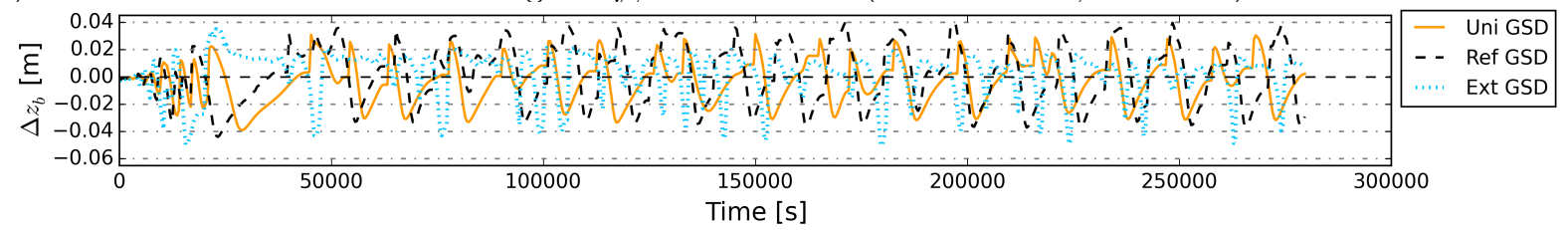

d) Influence of sediment sorting; Ref GSD; without obstacle (runs P2009-1 and -2)

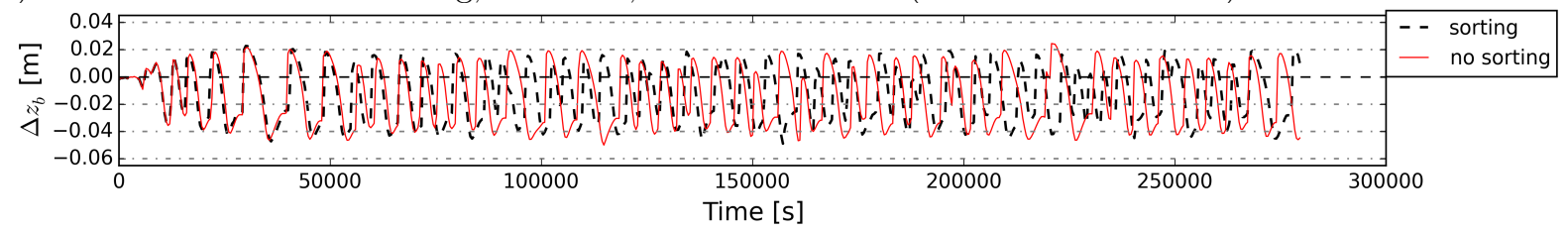

e) Influence of sediment sorting; Ext GSD; without obstacle (runs P2009-6 and -7)

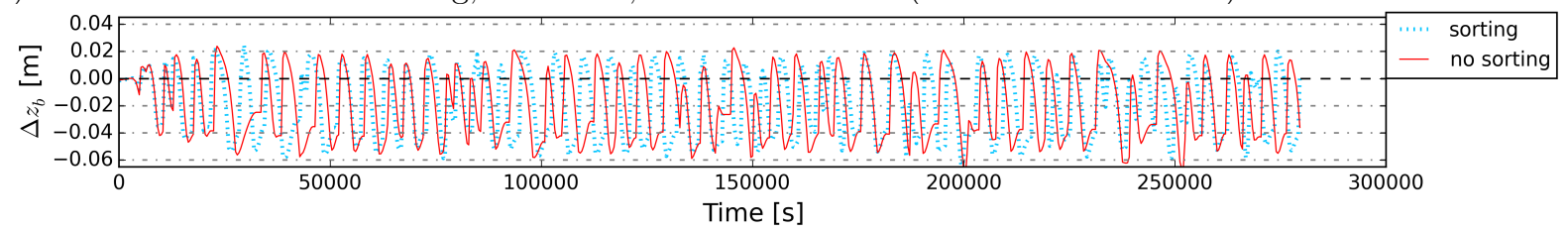

f) Influence of sediment sorting; Ref GSD; with obstacle (runs P2009-3 and -4)

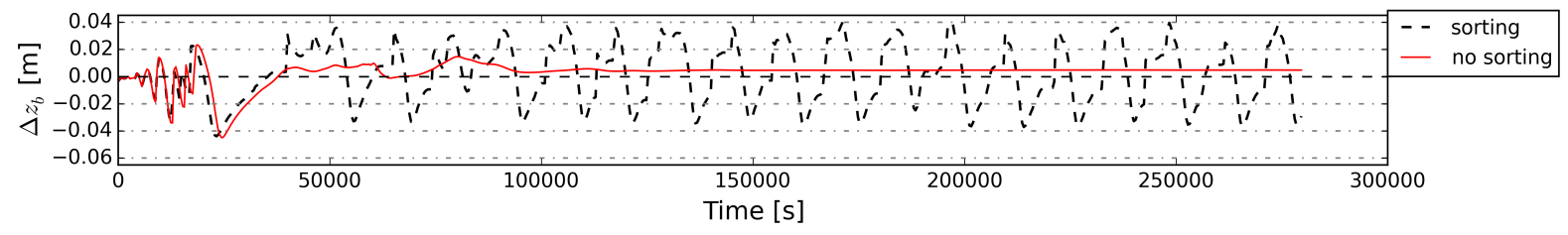




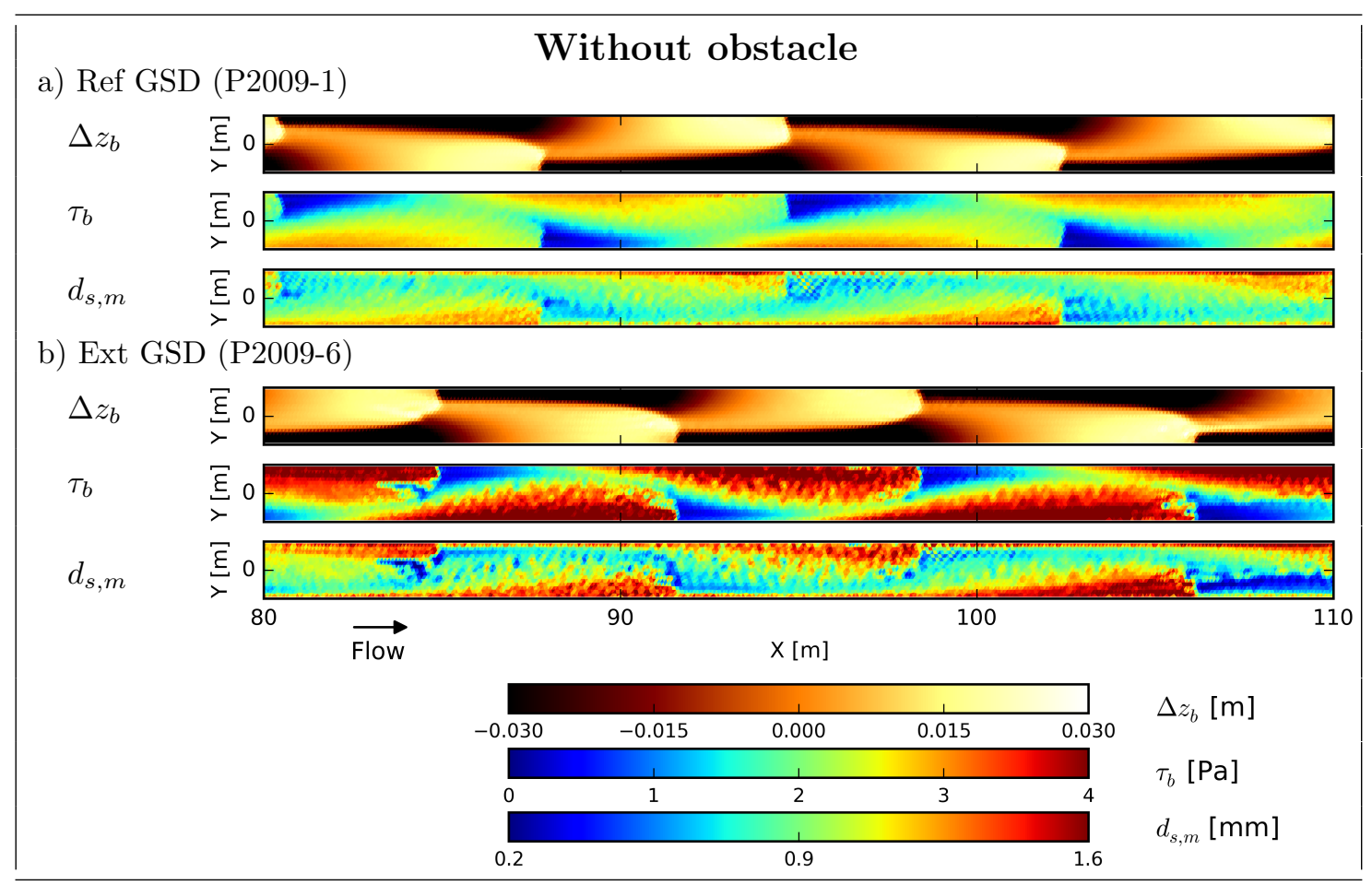




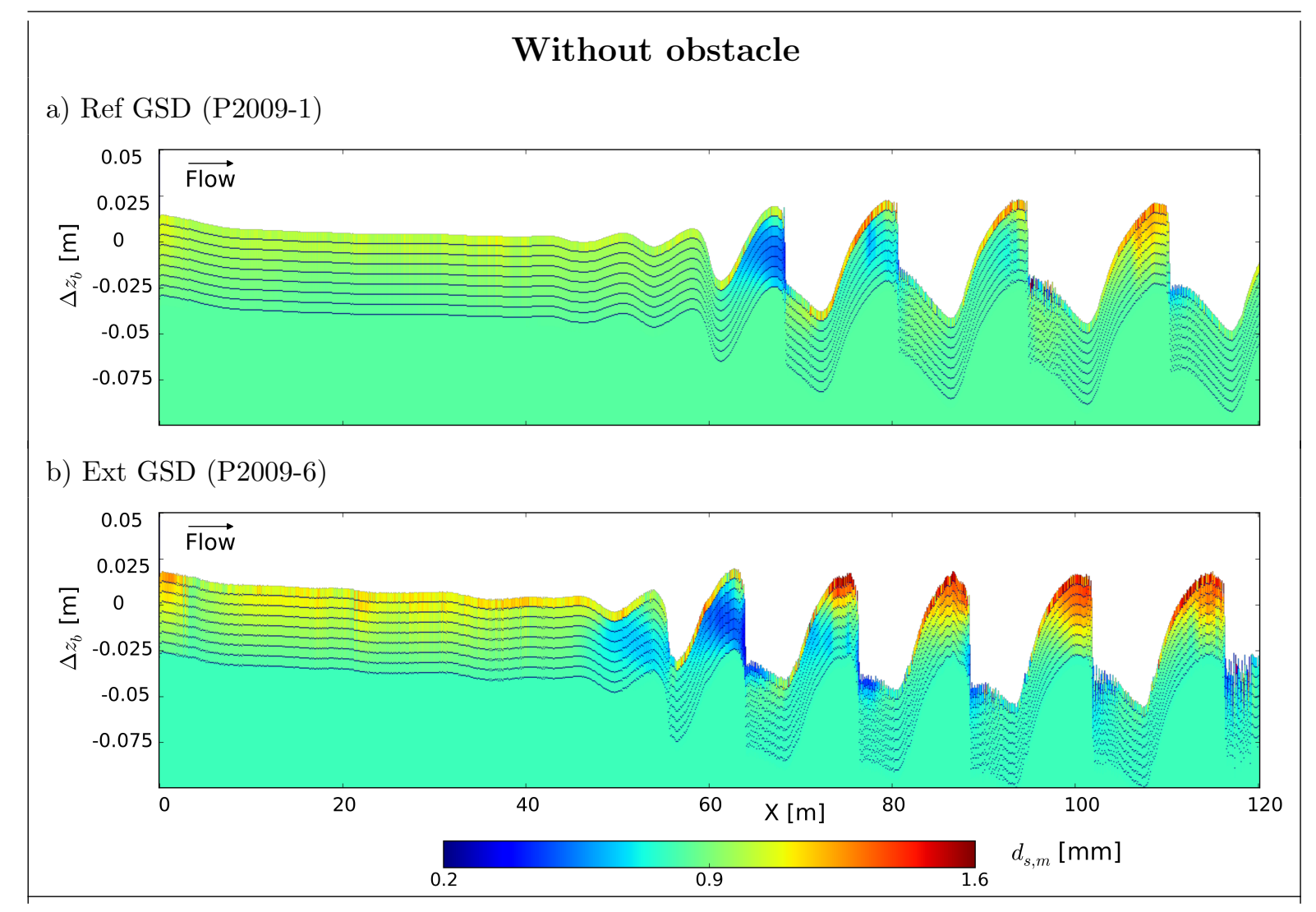




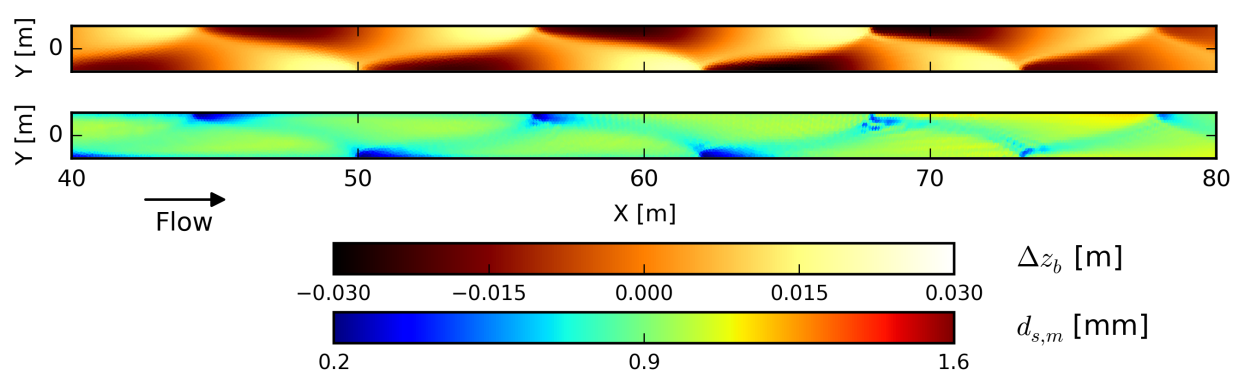

C2018 American Geophysical Union. All rights reserved. 
(a) Ref GSD

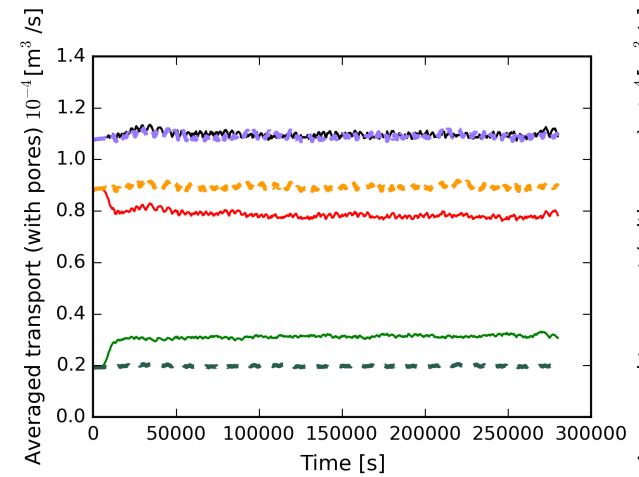

(b) Ext GSD

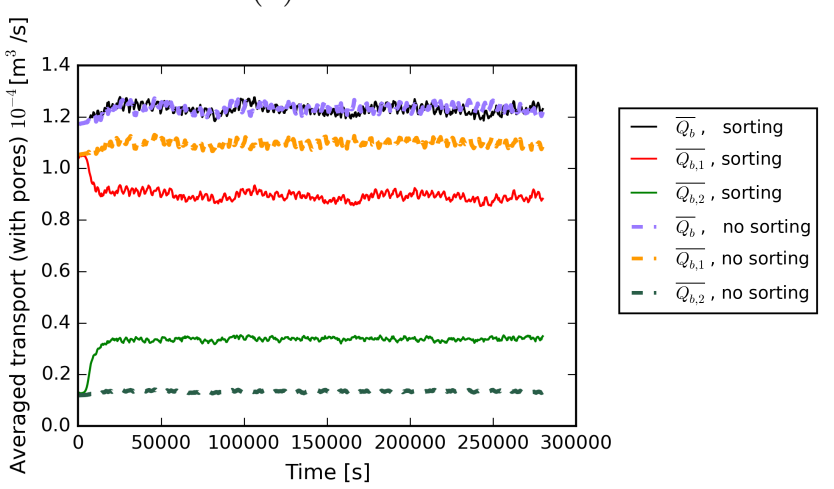




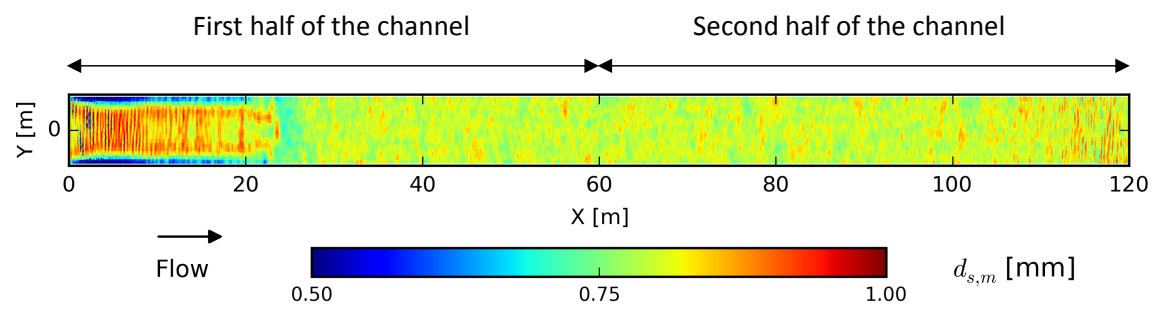

(C)2018 American Geophysical Union. All rights reserved. 
(a) first half of the channel

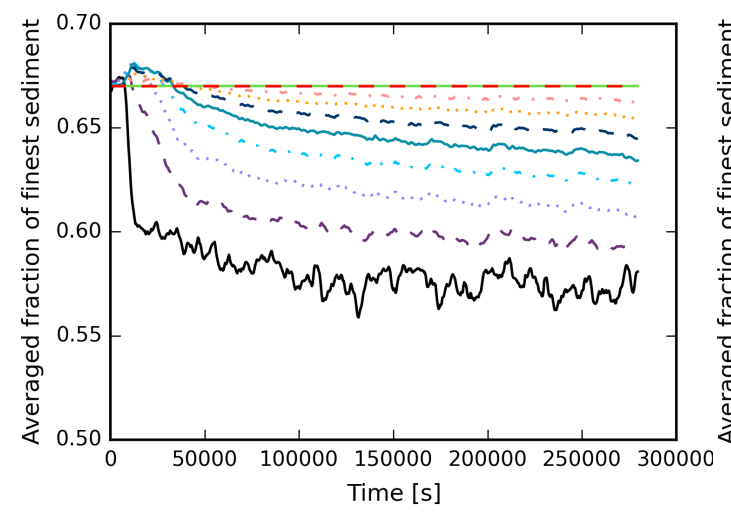

(b) second half of the channel

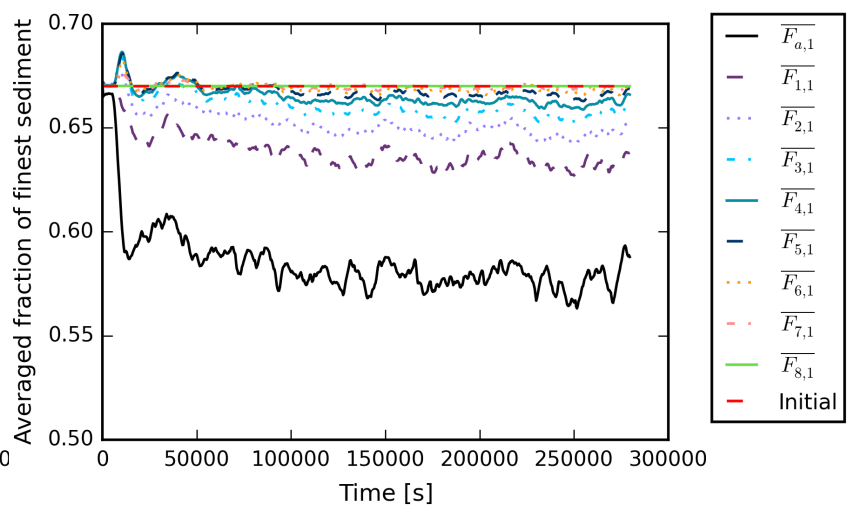


a) Without obstacle with sorting

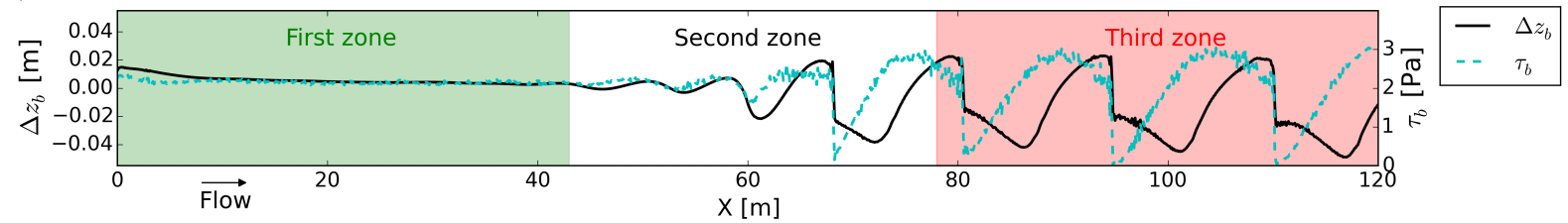

b) With obstacle with sorting

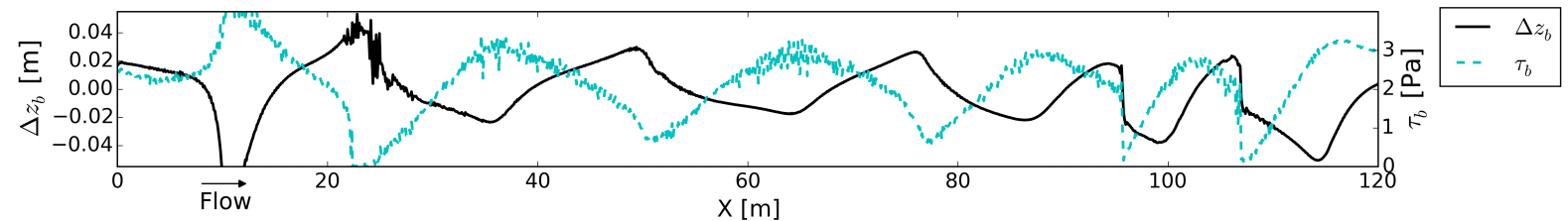

c) With obstacle without sorting

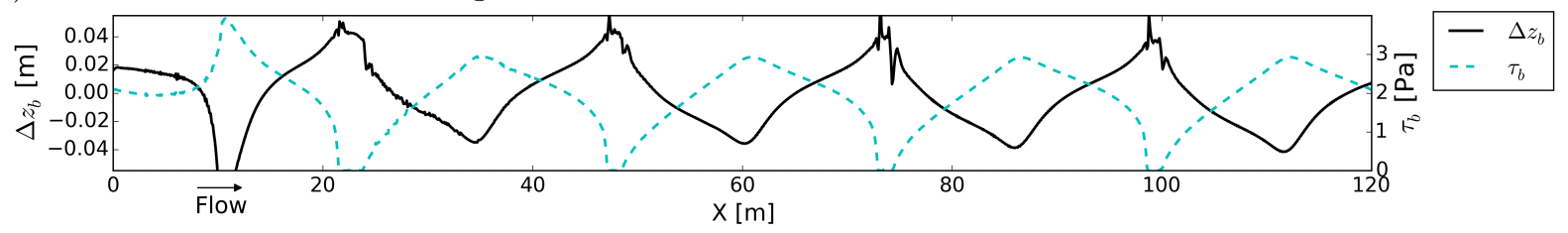


a) Without obstacle with sorting

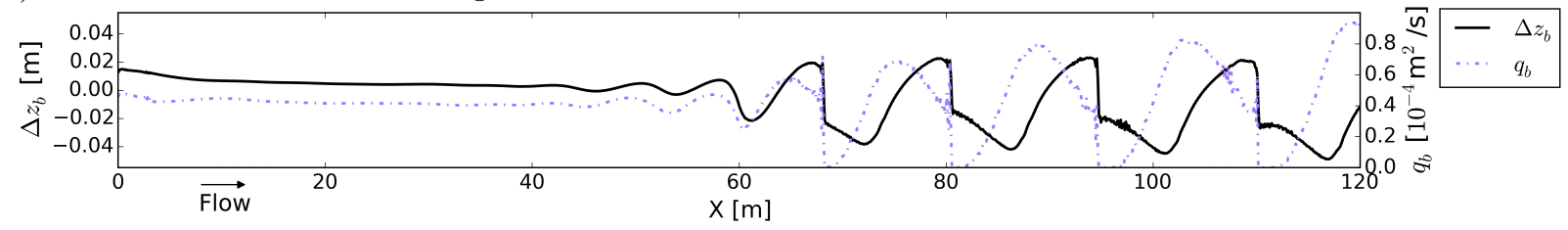

b) With obstacle with sorting

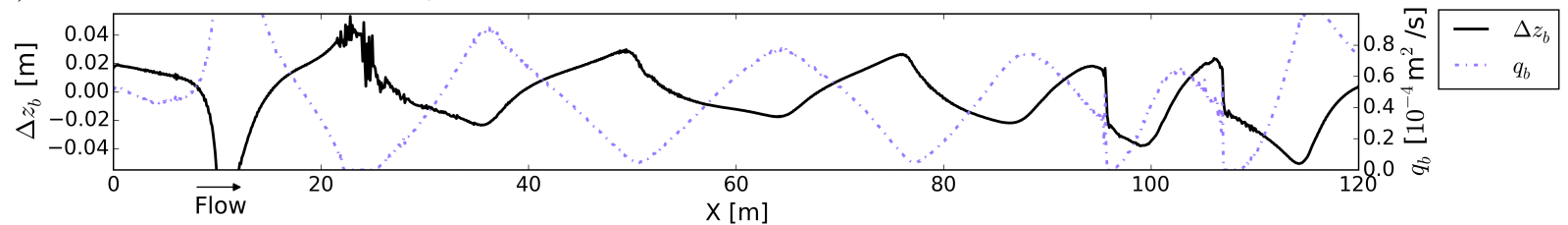

c) With obstacle without sorting

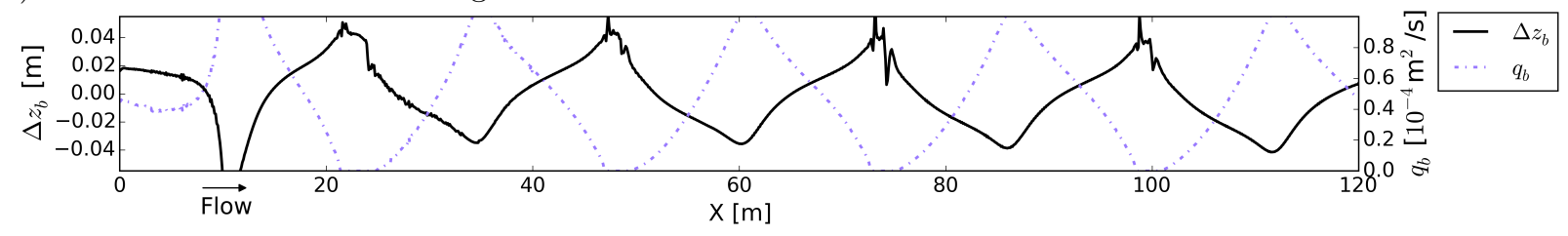




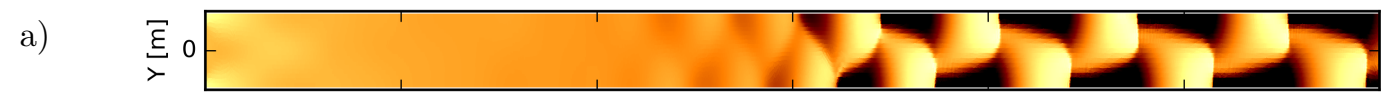

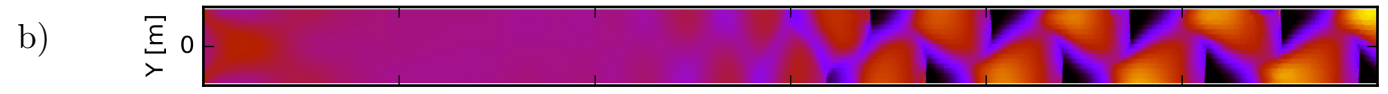

c)
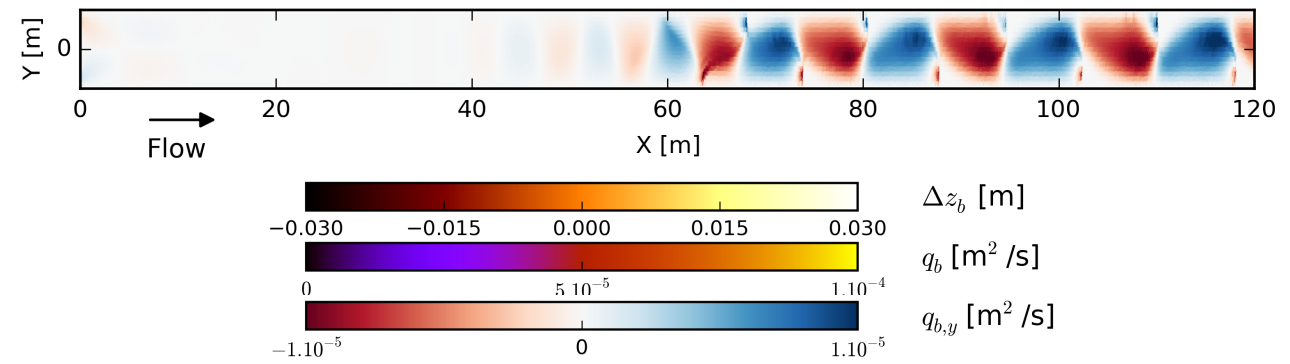
a) With sorting

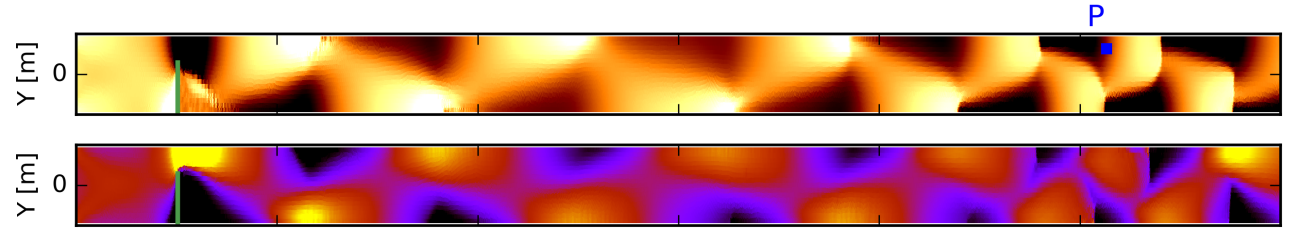

b) Without sorting
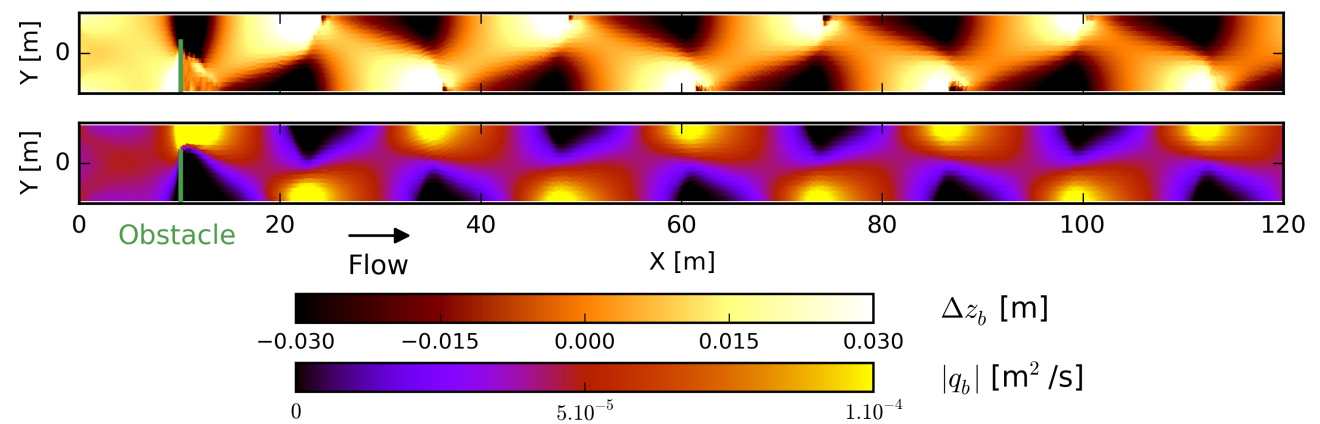


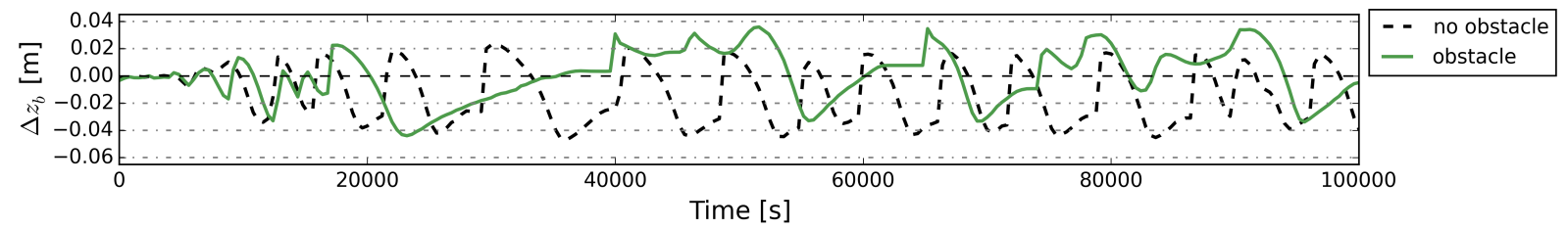




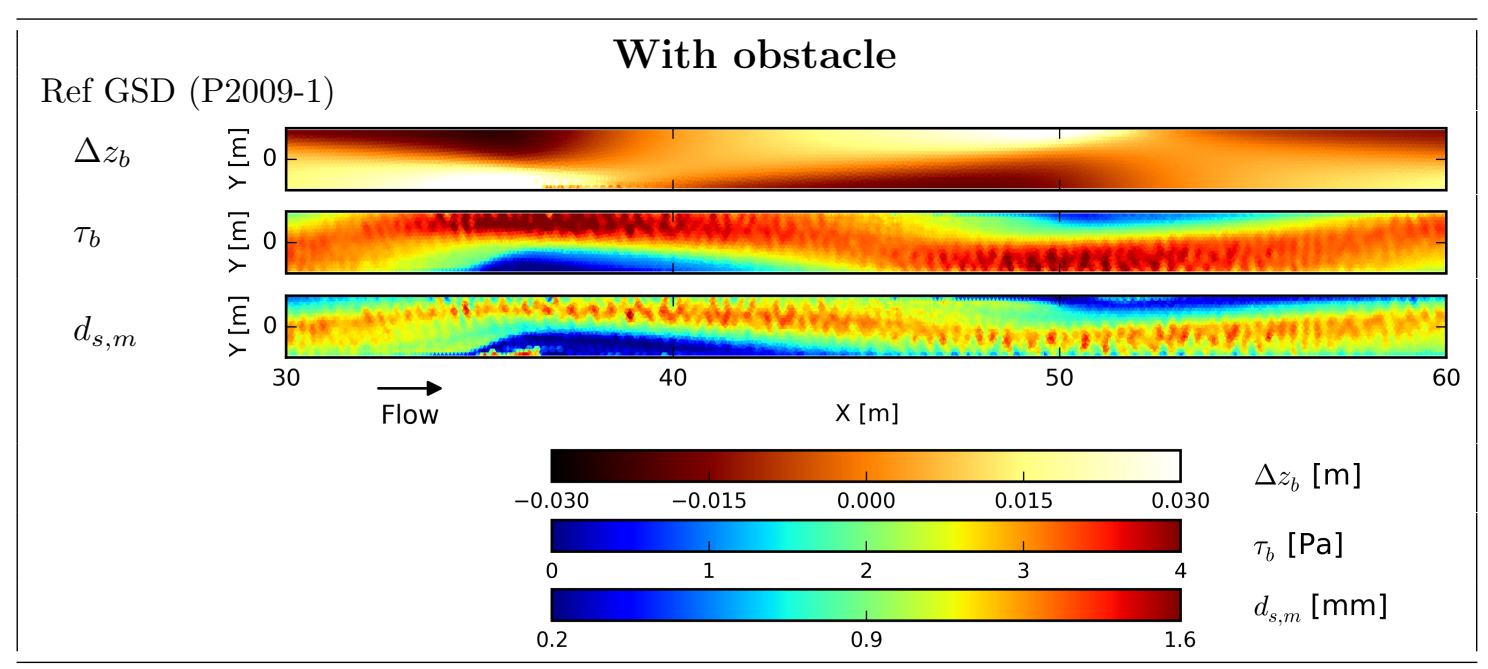




\section{With obstacle}

a) Ref GSD (P2009-3)

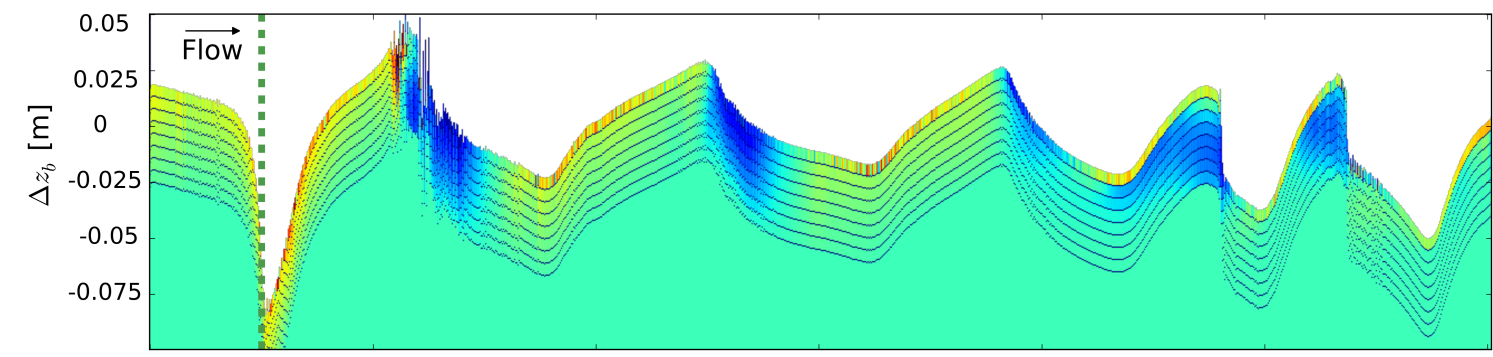

b) Ext GSD (P2009-9)

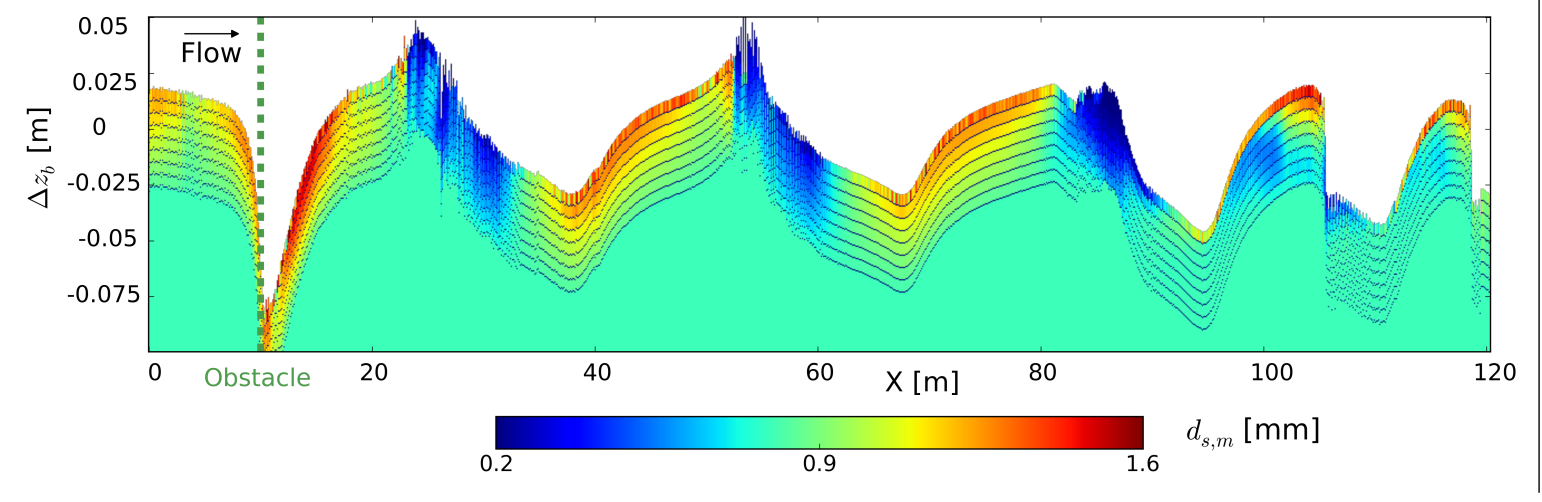


a) Free bars

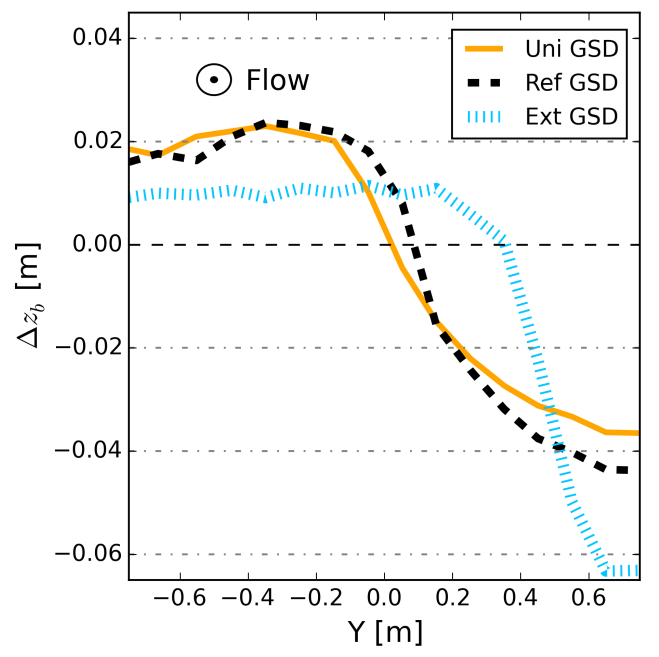

b) Hybrid bars

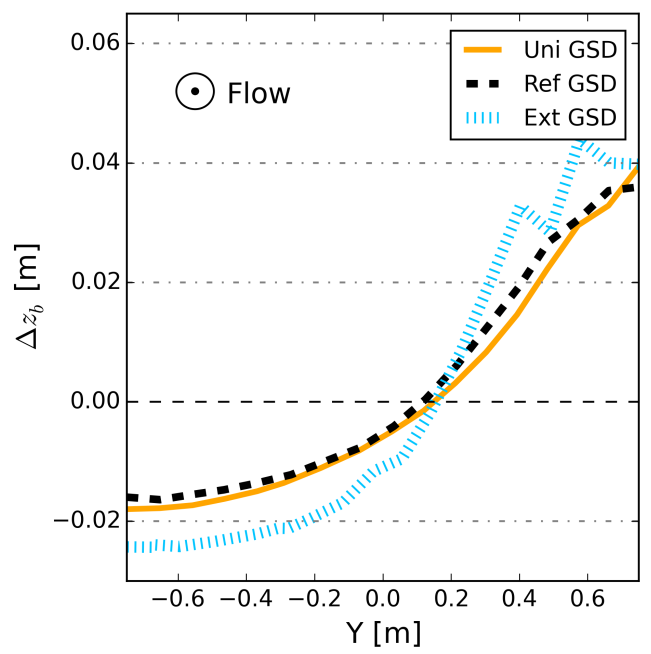




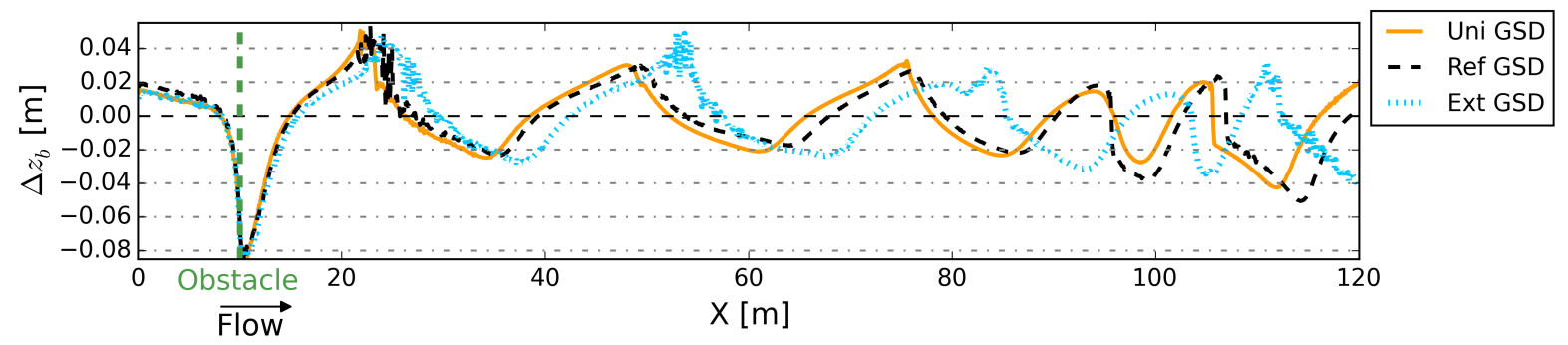




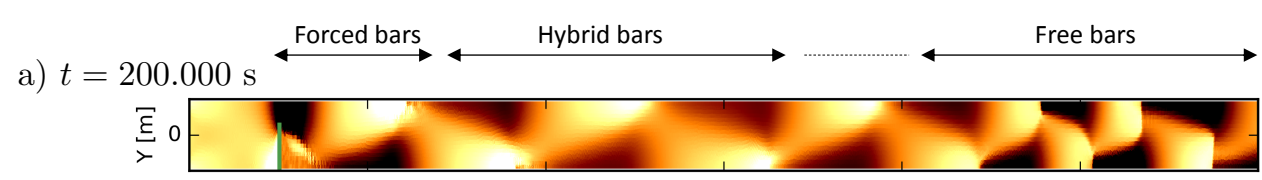

b) $t=202.800 \mathrm{~s}$

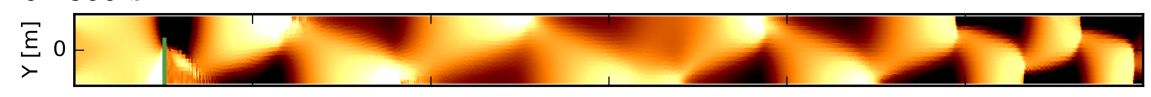

c) $t=205.600 \mathrm{~s}$

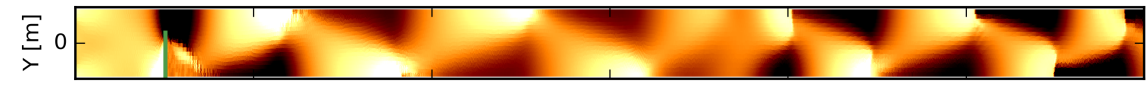

d) $t=208.000 \mathrm{~s}$

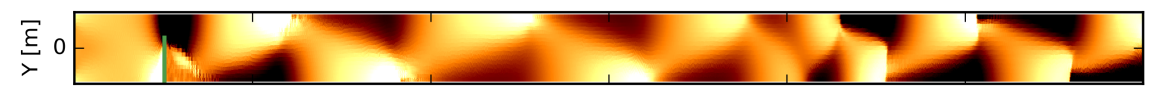

e) $t=213.200 \mathrm{~s}$

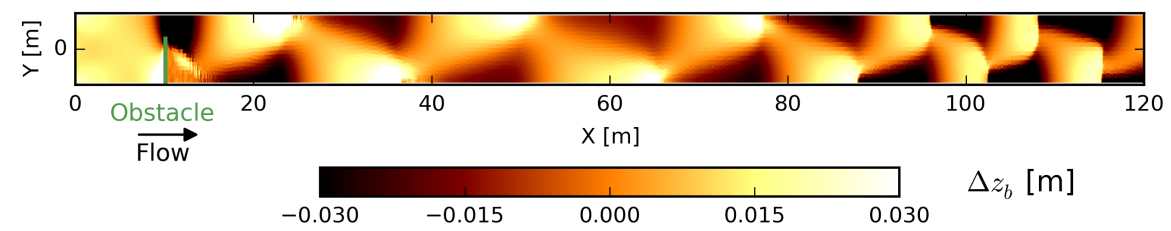




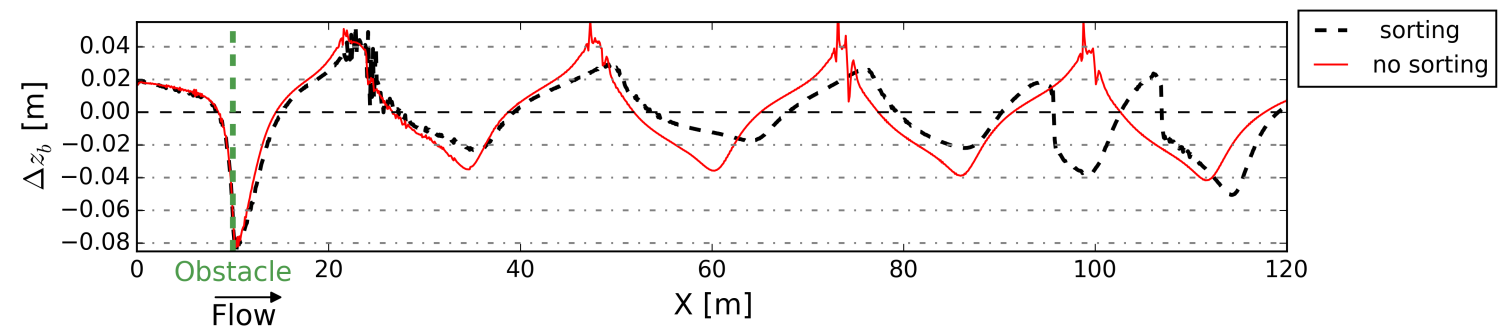

